\begin{tabular}{l|l} 
2. To: (Receiving Organization) & 3. From: (Originating Organization) \\
Distribution & SNF Characterization Project \\
\hline 5. Proj./Prog./Dept./Div.: & 6. Design Authority/ Design Agent/Cog. \\
Spent Nuclear Fuel Project & A. L.:Pjtner
\end{tabular}
8. Originator Remarks: Approval and Release.

11. Receiver Remarks:
11A. Design Baseline Document?
[] Yes $[X]$ No
4. Related EDT No.:

$N / A$

7. Purchase Order No,:

$N / A$

9. Equip./Component Mo.: N/A

10. System/Bldg./Facility: $\mathrm{N} / \mathrm{A}$

12. Major Assm. Dwg. No.: $N / A$

13. Permit/Permit Application No.: N/A

14. Required Response Date:

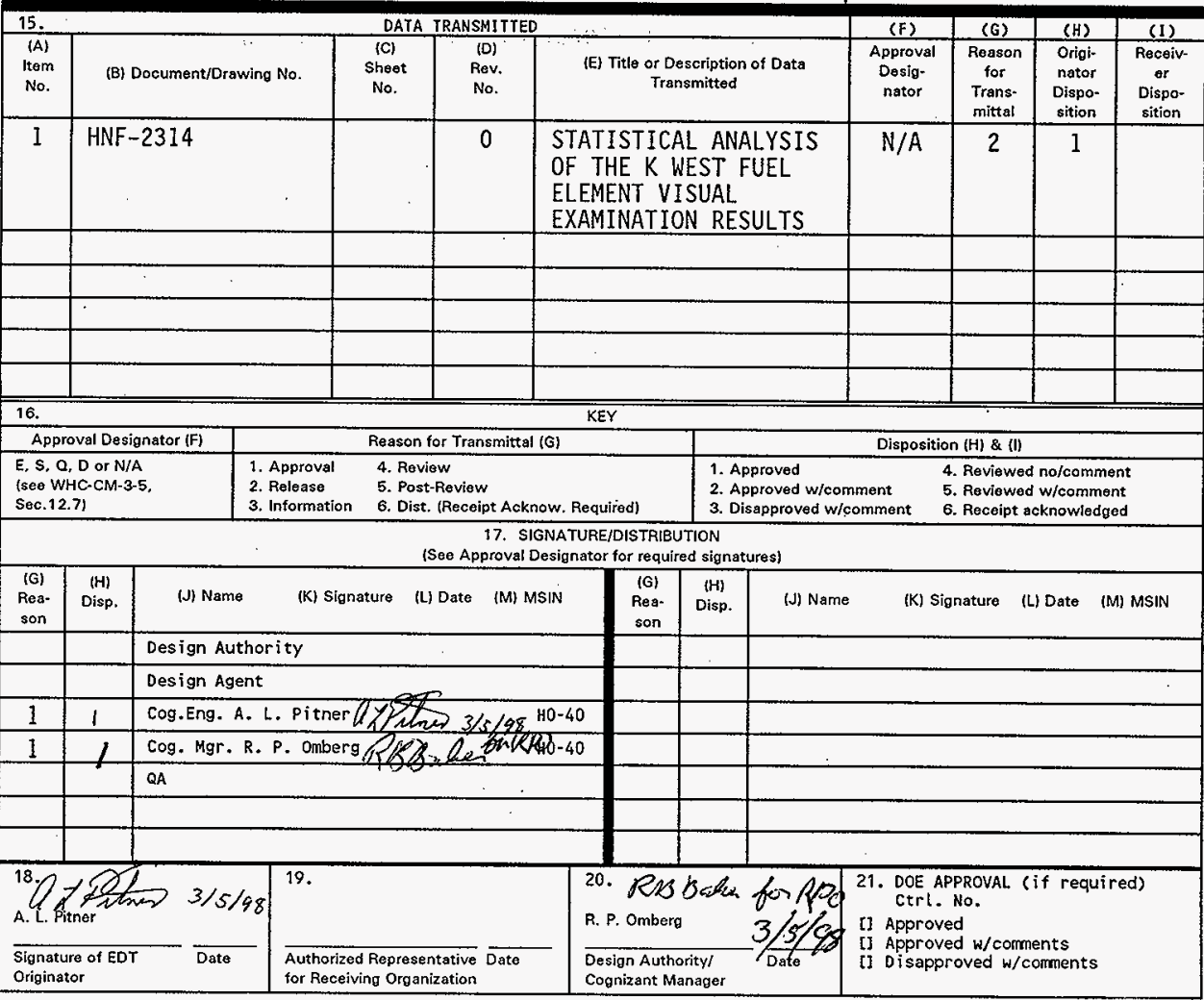




\title{
STATISTICAL ANALYSIS OF THE K WEST FUEL ELEMENT VISUAL EXAMINATION RESULTS
}

\author{
T. L. Welsh \\ B\&W Protec, Inc., Richland, WA 99352 \\ U.S Department of Energy Contract DE-AC06-96RL13200
}

A. L. Pitner

Duke Engineering and Services Hanford, Inc., Richland, WA 99352

U.S. Department of Energy Contract DE-AC06-96RL13200
EDT/ECN: 620801
Org Code: 2T960
UC: 2070
B\&R Code: EW7070000
Charge Code: LBO72
Total Pages: 90

Key Words: K West Basin Fuel, Visual Examination, Statistical Analysis

Abstract: A statistical evaluation of $K$ West fuel visual examination results was performed in an attempt to correlate observed fuel damage levels with parameters known from storage records and parameters obtained from in-basin measurements.

TRADEMARK DISCLAIMER. Reference herein to any specific comercial product, process, or service by trade name, trademark, manufacturer, or otherwise, does not necessarity constitute or imply its endorsement, recommendation, or favoring by the United States Government or any agency thereof or its contractors or subcontractors.

Printed in the United States of America. To obtain copies of this document, contact: WHC/BCS Document Control Services, P.0. Box 1970, Mailstop H6-08, Richland WA 99352, Phone (509) 372-2420; Fax (509) 376-4989.
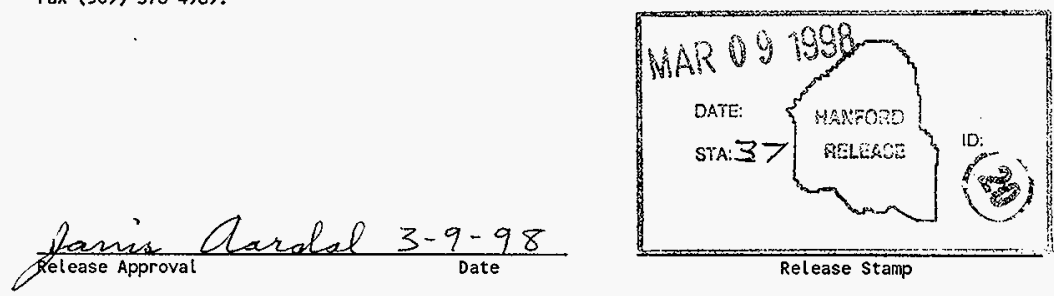
HNF-2314, Rev. 0

\section{CONTENTS}

1.0 SUMMARY ...................... 7

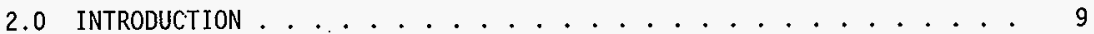

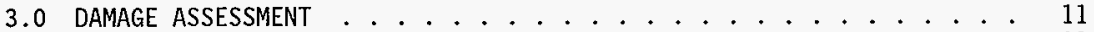

3.1 INNERS--STORAGE PARAMETERS .............. 11

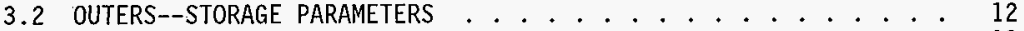

3.3 INNERS VERSUS OUTERS .................... . . . 13

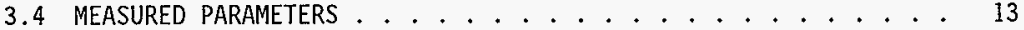

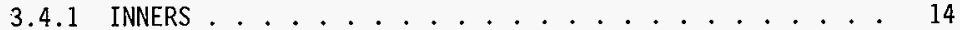

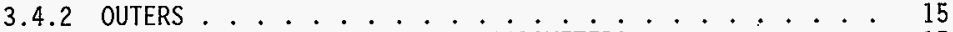

3.5 STORAGE PARAMETERS VERSUS MEASURED PARAMETERS . . . . . . 15

3.5 .1 Canister Type . . . . . . . . . . . . . . 16

3.5 .2 Fue 1 Type . . . . . . . . . . . . . . . 16

3.5 .3 Key Date .................. . . . 16

3.5 .4 Years Since Encapsulation ............ 17

3.5.5 Plutonium-240 Isotopic Values ........... 17

3.5 .6 Gas Trap Readings ............... 18

3.5.7 Cesium-137 Concentration ............ 18

3.5.8 Potassium Concentration ............ 18

3.5 .9 Coating Code .................... 18

3.5.10 Sludge Code .................... 19

4.0 REFERENCES .................... 21 


\section{LIST OF FIGURES}

1. Histogram: INNERS--Percent Intact . . . . . . . . . 39

2.. Histogram: INNERS--Percent Breached ... . . . . . . . 40

3. Histogram: INNERS--Percent Bad .............. 41

4. Histogram: OUTERS--Percent Intact . . . . . . . . . . 42

5. Histogram: OUTERS--Percent Breached . . . . . . . . . . 43

6. Histogram: OUTERS--Percent Bad ... . . . . . . . . . 44

7. Damage Versus Canister Type--INNERS . . . . . . . . . . . . 45

8. Damage Versus Fuel Type--INNERS . . . . . . . . . . . . . 46

9. Damage Versus Key Date--INNERS . . . . . . . . . . . . . . 47

10. Damage Versus Years Encapsulated-INNERS . . . . . . . . . . 48

11. Damage Versus PTutonium-240-INNERS . . . . . . . . . . 49

12. INNERS Versus Canister Type ............. 50

13. INNERS Versus Fuel Type ............... 51

14. INNERS Versus Key Date . . . . . . . . . . . . 52

15. INNERS Versus Years Encapsulated . . . . . . . . . . 53

16. INNERS versus Plutonium-240 ............ . . . 54

17. Damage Versus Canister Type--OUTERS . . . . . . . . 55

18. Damage Versus Fuel Type--OUTERS ... . . . . . . . 56

19. Damage Versus Key Date--0uTERS . . . . . . . . . . 57

20. Damage Versus Years Encapsulated--OUTERS . . . . . . . . 58

21. Damage Versus Plutonium-240--0UTERS .......... 59

22. OUTERS Versus Canister Type .............. 60

23. OUtERS Versus Fue type .............. 61

24. OUTERS Versus Key Date ................. 62

25. OUTERS Versus Years Encapsulated .............. 63 
HNF-2314, Rev. 0

\section{LIST OF FIGURES (Continued)}

26. OUTERS Versus Plutonium-240 ............. . . 64

27. INNERS-Intact Versus OUTERS-Intact . . . . . . . . 65

28. INNERS-Intact Versus OUTERS-Breached . . . . . . . . 65

29. INNERS-Intact Versus OUTERS-Bad . . . . . . . . . . 66

30. INNERS-Breached Versus OUTERS-Intact . . . . . . . . . 66

31. INNERS-Breached Versus OUTERS-Breached . . . . . . . . . . 67

32. INNERS-Breached Versus OUTERS-Bad ........... 67

33. INNERS-Bad Versus 0UTERS-Intact .............. 68

34. INNERS-Bad Versus OUTERS-Breached .............. 68

35. INNERS-Bad Versus OUTERS-Bad . . . . . . . . . . . . 69

36. SIudge Code Versus INNERS-Percent Damage . . . . . . . . 70

37. Cesium-137 versus OUTERS-Percent Damage . . . . . . . . . 71

38. S1udge Code Versus OUTERS-Percent Damage . . . . . . . . . . 72

39. Canister Type Versus Years Since Encapsulated . . . . . . . . . 73

40. Canister Type Versus Potassium . . . . . . . . . . . 74

41. Canister Type Versus Coating Code . . . . . . . . . . 75

42. Fuel Type Versus Plutonium-240 . . . . . . . . . . . 76

43. Fuel Type Versus Cesium-137 . . . . . . . . . . . . 77

44. Key Date Versus Years Since Encapsulation . . . . . . . 78

45. Key Date Versus Coating Code . . . . . . . . . . . 79

46. Key Date Versus Plutonium-240 . . . . . . . . . . 80

47. Years Since Encapsulation Versus Plutonium-240 . . . . . . . 81

48. Years Since Encapsulation Versus Coating Code ... . . . . . 82

49. Years Since Encapsulation Versus Potassium . . . . . . . . . 83

50. Plutonium-240 Versus Gas Trap ............... 84 
HNF-2314, Rev. 0

\section{LIST OF FIGURES (Continued)}

51. Plutonium-240 Versus Coating Code ........... 85

52. Plutonium-240 versus Sludge Code . . . . . . . . . . . . . 86

53. Gas Trap Versus Potassium . . . . . . . . . . 87

54. Cesium-137 versus S7udge Code ... . . . . . . . 88

55. Potassium Versus Coating Code . . . . . . . . . . . 89 
HNF-2314, Rev. 0

\section{LIST OF TABLES}

1. Canisters Selected for Visual Inspection--Storage Parameters . . . 23

2. Visualty Examined Barreis--Measured Parameters . . . . . . . 25

3. Visual Inspection Results--INNERS ............. 27

4. Visual Inspection Summary--INNERS ............. 28

5. Correlation Coefficients--INNERS Damage Versus Storage

Parameters ................ . . 29

6. Visual Inspection Results--0UTERS .............. 30

7. Visual Inspection Summary--OUTERS ............. 31

8. Correlation Coefficients--OUTERS Damage Versus Storage

Parameters .................. 32

9. Correlation Coefficients--INNERS Versus OUTERS . . . . . . 32

10. Correlation Coefficients--INNERS Damage Versus

Measured Parameters ............... 33

11. Correlation Coefficients--OUTERS Damage Versus

Measured Parameters. . . . . . . . . . . . . . 33

12. Correlation Coefficients--Known Versus Measured Parameters . . . . 34 
HNF-2314, Rev. 0

This page intentionally left blank. 
HNF-2314, Rev, 0

\section{STATISTICAL ANALYSIS OF THE K WEST FUEL ELEMENT \\ VISUAL EXAMINATION RESULTS}

\subsection{SUMMARY}

Over 250 fuel assemblies stored in 20 sealed canisters in the $K$ West Basin were removed from their canisters and visually examined for damage. Prior measurements, ${ }^{137} \mathrm{Cs}$ concentrations from $\mathrm{K}$ West canister water samples, were used to identify canisters with the potential for extensive fuel element damage and high sludge levels for laboratory evaluations. As expected, extensive fuel element damage was found in the examinations.

Attempts were made to correlate fuel damage with (1) fuel storage conditions (canister type, fuel type, key date, years since encapsulation, ${ }^{240} \mathrm{Pu}$ content) and (2) measured parameters (gas trap readings, ${ }^{137} \mathrm{Cs}$ concentration, potassium concentration, fuel coating, and qualitative sludge level). The measured parameters were obtained from in-basin measurements and observations. Such correlations, if they could be demonstrated to exist, would aid in fuel handling and treatment process handling.

Correlation coefficients were determined comparing percent damage with functions of the storage parameters (canister type, fuel type, key date, years since encapsulation, and ${ }^{240} \mathrm{Pu}$ content) for the inner and outer fuel elements separately. Several correlation coefficients were significantly different from zero, but the magnitudes (absolute values) of the correlations were smal1 (1ess than 0.5). Correlation coefficients also were determined for percent damage with functions of the measured parameters (gas trap readings, ${ }^{137} \mathrm{Cs}$ concentration, potassium concentration, fuel coating, and qualitative sludge level). Again, the comparisons considered the inner and outer fuel elements separately. Severat of the correlation coefficients were significantly different from zero, but the magnitudes of the correlations were small (usually less than 0.5 ).

Since no storage or measured parameter is strongly associated with the percent damage observed, the data were tabulated by the percent damage observed during the examination. The estimated proportion of the $K$ West population for each class of damage is presented in the following table. Since the examination was performed on fuel assemblies with the potential for high fuel element damage, the estimated proportions of the populations are biased towards the damage side. A $95 \%$ confidence interval for the estimated proportion was computed and is also presented in the following table. 
HNF-2314, Rev. 0

\begin{tabular}{||l|c|c||}
\hline \multicolumn{1}{|c|}{ Population } & $\begin{array}{c}\text { Estimated Proportion } \\
\text { of the Population }\end{array}$ & $\begin{array}{c}95 \% \text { Confidence Limits for } \\
\text { the Estimated Proportion } *\end{array}$ \\
\hline \hline INNERS - Intact & 0.8929 & $(0.8547,0.9311)$ \\
\hline INNERS - Breached & 0.0873 & $(0.0524,0.1222)$ \\
\hline INNERS - Bad & 0.0198 & $(0.0026,0.0370)$ \\
\hline OUTERS - Intact & 0.5475 & $(0.4873,0.6077)$ \\
\hline OUTERS - Breached & 0.3460 & $(0.2885,0.4035)$ \\
\hline OUTERS - Bad & 0.1065 & $(0.0692,0.1438)$ \\
\hline
\end{tabular}

*Normal approximation to the binomial.

Correlation coefficients were determined for all storage parameters (canister type, fuel type, key date, years since encapsulation, and ${ }^{240} \mathrm{Pu}$ content) and ail measured parameters (gas trap readings, ${ }^{137} \mathrm{Cs}$ concentration, potassium concentration, fuel coating, and qualitative sludge level). Several of the correlation coefficients were significantly different from zero, but the magnitudes of the correlations were small (usually less than 0.5 ). The correlation that was most obvious was the relationship between canister type and fuel coating; the heavy-white coating was observed on the fuel contained in the aluminum Mark I canisters. The higher potassium concentrations were a] so associated with this heavy-white coating. 
HNF-2314, Rev. 0

\subsection{INTRODUCTION}

A campaign was conducted in the $K$ West fuel storage basin in which selected canisters were opened and the fuel elements individually removed for visual examination (Pitner 1997). A total of 24 canisters in $K$ West were opened, with 21 of the canisters containing fuel assemblies and 3 of the canisters containing known fragmented fuel pieces ("chip can"). None of the fragmented fuel pieces from the chip cans were extracted for examination. Fue] examination was not performed in one of the canisters (both barrels) because fuel elements were wedged laterally across the inside of the $1 \mathrm{id}$. The twenty canisters from which the fuel elements were removed and examined are listed in Table 1. Table 1 also contains the canister type, fuel type, key date, years since encapsulation, and ${ }^{240} \mathrm{Pu}$ concentration. These storage parameters are known, prior to any sampling, for the fuel contained in each canister.

Prior to the visual examinations, approximately 50 canisters in the basin were subjected to gas and liquid sampling (Trimble 1997). The water samples were analyzed for fission products, total uranium, corrosion inhibitor, and $\mathrm{pH}$. The primary dissolved fission product was ${ }^{137} \mathrm{Cs}$. It is assumed that the cesium curie content in the sample is an indication of the relative level of fuel damage in each canister barrel. The ${ }^{137} \mathrm{Cs}$ content, determined from nondestructive analyses (NDA) performed by Special Analys is Support (SAS)], ranged from 0.06 to $4046 \mathrm{mCi} /$ barrel. A few samples were reported as nd (not determined/no data). A major objective of the visual examinations was to select candidate canisters containing fuel and siudge samples for detailed laboratory examination. Since damaged fuel elements and substantial sludge samples were desired for laboratory evaluations, the canisters with low cesium levels were not selected for the visual examinations. Except for one "nd" barrel, the ${ }^{137} \mathrm{Cs}$ content of the canister barrels selected for visual examination ranged from 77 to $4046 \mathrm{mCi} /$ barrel. Only seven of the 51 canisters had both barrels with a ${ }^{137} \mathrm{Cs}$ content less than $77 \mathrm{mC} /$ barrel. These seven were excluded from the selection for the visual examination. Because of the exclusion of the low cesium canisters, a high "bias" for fuel damage is possible. The potassium $(K)$ concentration was used as the indicator for the corrosion inhibitor in the water. The ${ }^{137} \mathrm{Cs}$ and $\mathrm{K}$ analytical results for those barrels selected for the visual examinations are listed in Table 2. 
HNF-2314, Rev. 0

This page intentionally left blank. 


\subsection{DAMAGE ASSESSMENT}

The procedure used to examine the $K$ West fuel elements is described in (Pitner 1997). A canister was moved to the inspection station, the 1id of one barrel was removed, ultrasonic measurements of s]udge depths performed, the individual inner and outer fuel elements temporarily removed and examined. Each element was classified as intact, breached, or bad. The 1id was then replaced. The other barrel of the canister was examined in Tike manner, and the canister was then returned to its basin storage location. A total of 252 inner elements and 263 outer elements were inspected. All steps of the examination process were recorded on videotape.

The results of the visual inspection are listed in Table 3 for the inner elements (INNERS). The results for the inner elements have been summarized in Table 4 and illustrated using histograms in Figures 1, 2, and 3. The results of the visual inspection are 1 isted in Table 6 for the outer elements

(OUTERS). The results for the outer elements have been summarized in Table 7 and illustrated using histograms in Figures 4, 5, and 6 .

\subsection{INNERS--STORAGE PARAMETERS}

A total of 252 inner elements were inspected. Each element was classified as intact, breached, or bad. The results of visual inspection for the inner elements are listed in Table 3 along with the storage parameters. To illustrate the inspection data, the percent damage (intact, breached, bad) by barrel is shown with respect to the storage parameter data in Figures 7 through 11. Bar charts were generated (Figures 12 through 16) to see if there were any obvious correlations between $K$ West fuel damage and any of the storage parameters associated with each canister that was examined. Figure 14 indicates a possible correlation between key date and percent INNERS intact (as the key date increases the percent INNERS intact decreases) and between key date and percent INNERS breached (as the key date increases the percent INNERS breached increases).

The sample correlation coefficient (assumes both variables are from a normal distribution) and the Spearman rank correlation coefficient (does not assume that either variable is from a normal distribution; nonparametric) were determined for percent damage (intact, breached, bad) and the storage parameters. Both the sample correlation coefficient and the Spearman rank correlation coefficient are measures of the closeness of a 1 inear relationship between two variables (Snedecor 1980). A positive correlation coefficient indicates a tendency for the two variables to increase together while a negative correlation coefficient indicates that large values of one variable are associated with small values of the second variable. The correlation coefficient 1 ies between -1 and 1 . The closer the correlation coefficient is to \pm 1 , the stronger the association between the two variables. The correlation coefficients for the INNERS percent damage variables and the storage parameters are listed in Table 5. 
Hypothesis testing was used to determine the significance of the observed correlation coefficient. The null hypothesis is that the correlation coefficient is zero (no relationship between the two variables). The a)ternate hypothesis is that the correlation coefficient is not zero (a relationship does exist between the two variables). Statistical significance simply indicates that there is a linear relationship with nonzero slope. The tests were performed at the 0.05 level of significance (i.e., there is a $5 \%$ chance that the null hypothesis is rejected when it really is true). If the p-vaTue (the observed significance level of the test; indicates whether the hypothesis of equality is rejected or not rejected) 1isted in Table 5 is less than or equal to 0.05 , then the null hypothesis is rejected. If the p-value listed in Table 5 is greater than 0.05 , then the null hypothes is (no relationship between the two variables) is not rejected.

- The correlation coefficient (sample or rank) for key date and INNERS-percent intact is statistically different from zero at the 0.05 level of significance (see Figure 14--as the key date increases the percent intact decreases). Note that the magnitude of the correlation (sample or rank) is less than 0.5 .

- The correlation coefficient (sample or rank) for key date and INNERS-percent breached is statistically different from zero at the 0.05 level of significance (see Figure 14--as the key date increases the percent breached increases). Note that the magnitude of the correlation (sample or rank) is less than 0.5 .

\subsection{OUTERS--STORAGE PARAMETERS}

A total of 263 outer elements were inspected. Each element was classified as intact, breached, or bad. The results of the inspection for the outer elements are listed in Table 6 along with the storage parameters. To illustrate the inspection data, the percent damage (intact, breached, and bad) by barrel is shown in Figures 17 through 21 . Bar charts were generated (Figures 22 through 26) to see if there were any obvious correlations between $K$ West fuel damage and any of the storage parameters associated with each canister that was examined. No obvious correlations are evident.

The sample correlation coefficient and the rank correlation coefficient were determined for the OUTERS percent damage variables (intact, breached, and bad) and the storage parameters. These correlation coefficients are listed in Table 8 .

Hypothesis testing was used to determine the significance of the observed correlation coefficient. The null hypothesis is that the correlation coefficient is zero (no relationship between the two variables). The alternate hypothesis is that the correlation coefficient is not zero (a relationship does exist between the two variables). The tests were performed at the 0.05 level of significance (i.e., there is a $5 \%$ chance that the null 
HNF-2314, Rev. 0

hypothesis is rejected when it really is true). If the p-value listed in Table 8 is less than or equal to 0.05 , then the null hypothes is is rejected. If the p-value listed in Table 8 is greater than 0.05 , then the nul] hypothesis (no relationship between the two variables) is not rejected.

- There were no correlation coefficients which were statistically different from zero at the 0.05 level of significance.

\subsection{INNERS VERSUS OUTERS}

The INNERS damage data (percent intact, percent breached, percent bad) were plotted (Figures 27 through 35 ) with respect to the OUTERS damage data (percent intact, percent breached, percent bad) to see if any correlations existed between the two variables. The sample correlation coefficient (assumes normal population) and the rank correlation coefficient (nonparametric; neither variable from a normal population) were determined for each combination of the two variables. The correlation coefficients are listed in Table 9.

Hypothesis testing was used to determine the significance of the observed correlation coefficient. The null hypothesis is that the correlation coefficient is zero (no relationship between the two variables). The alternate hypothesis is that the correlation coefficient is not zero (a relationship does exist between the two variables). The tests were performed at the 0.05 level of significance (i.e., there is a $5 \%$ chance that the null hypothesis is rejected when it really is true). If the p-value listed in Table 9 is less than or equal to 0.05 , then the null hypothes is is rejected. If the p-value listed in Table 9 is greater than 0.05 , then the nul 1 hypothesis (no relationship between the two variables) is not rejected.

- There were no correlation coefficients which were statistically different from zero at the 0.05 level of significance.

\subsection{MEASURED PARAMETERS}

Prior to the visual examinations, approximately 50 canisters in the basin were subjected to liquid sampling (Trimble 1997). The results of liquid sampling are listed in Table 2.

During the visual examination it was found that nearly all of the fuel elements had some kind of coating on the exterior surface. The general coating observations for each canister barrel are given in Table 2 . The level of coating (medium or heavy) is identified along with the observed coloration of the coating. Since the observed coating descriptions are qualitative, an indicator variable was established to identify the classes (coating descriptions). The indicator variable for fuel coating took on four values (1 represented the medium gray/white coating, 2 represented the medium orange coating, 3 represented the medium light green coating, and 4 represented the heavy white coating). 
HNF-2314, Rev, 0

Attempts were made to measure sludge depth levels in the canister using an ultrasonic probe. The results for $K$ West were inconclusive. Many measurements corresponded to the bottom of the canister. Significant non-zero depth measurements were actually believed to be from foreign material, such as grafoil pieces from the 1 id seal or other debris. Sludge rings (bottom level bands indicative of being buried in canister sludge) were not observed for most of the $K$ West fuel examined. However, definite visual indications of sludge presence were noted in $K$ West. Sludge clouds often were released when the lids were removed, and sludge frequently trailed the fuel elements as they were extracted from the canisters. A qualitative estimate of the sludge leve? in each canister barrel was made from these visual observations. Three categories were used to describe the sludge level: minimal, moderate, and maximum. An indicator variable was established for the sludge level. The indicator variable took on three values ( 1 represented the minimal level, 2 represented the moderate leve1, and 3 represented the maximum leve1). The sludge level indications for each canister barrel are also presented in Table 2.

The $K$ West Basin fuel elements were loaded into canisters in the 105-N Basin, lids were installed, a nitrogen gas blanket was established, and corrosion inhibitor (potassium nitrite) was added to the water. The gas blanket (gas space) was obtained by forcing nitrogen gas through a lid valve while expelling water from the barrel and leaving a $64 \mathrm{~mm}$ gas space over the fuel (Trimble 1996). This also cleared most water from the gas trap. After loading, the canisters were shipped to the 105-K West Basin for storage. As a result of transferring the canisters from one water basin to another, a portion of the gas in the gas traps was replaced with water (Conn 1992). This encapsulation occurred at least twelve years ago. Fuel damage allows the metallic uranium fuel to be corroded by the canister water. The corrosion releases fission products and generates hydrogen gas. The hydrogen gas then passes through the gas trap into the basin water. The gas trap readings were a measure of the water level in the gas trap obtained using an ultrasonic probe positioned at the bottom of the gas trap. As hydrogen is generated it displaces water from the gas trap. Thus, low gas trap readings are indications of hydrogen generation and therefore fuel corrosion. The gas trap measurements (Trimble 1997) are included in Table 2.

\subsubsection{INNERS}

The sample correlation coefficient and the Spearman rank correlation coefficient were determined for percent damage (intact, breached, and bad) and the measured parameters. The correlation coefficients are listed in Table 10.

- The sample correlation coefficient for sludge code and INNERSpercent breached is statistically different from zero at the 0.05 level of significance (see Figure 36--as the sludge code goes from minimal to maximum the percent breached increases). Note that the magnitude of the sample correlation is less than 0.5. 
HNF-2314, Rev. 0

- The sample correlation coefficient for sludge code and INNERSpercent intact is statistically different from zero at the 0.10 Tevel of significance (see Figure 36--as the sludge code goes from minimal to maximum the percent intact decreases). Note that the magnitude of the sample correlation is less than 0.5 .

\section{4 .2 OUTERS}

The sample correlation coefficient and the Spearman rank correlation coefficient were determined for percent damage (intact, breached, and bad) and the measured parameters. The correlation coefficients are listed in Table 11 .

- The sample correlation coefficient for ${ }^{137} \mathrm{Cs}$ and OUTERS-percent intact is statistically different from zero at the 0.05 level of significance (see Figure $37-$ the lowest level for ${ }^{137} \mathrm{Cs}$ is associated with the highest percentage of intact OUTERS). Note that the magnitude of the correlation (sample or rank) is less than 0.5 .

- The sample correlation coefficient for ${ }^{137} \mathrm{Cs}$ and OUTERS-percent bad is statistically different from zero at the 0.05 level of significance (see Figure $37-$ as the ${ }^{137} \mathrm{Cs}$ increases the percent bad increases).

- The sample correlation coefficient for sludge code and OUTERSpercent bad is statistically different from zero at the 0.05 level of significance (see Figure 38 -as the sludge code goes from minimal to maximum the percent bad increases).

- The sample correlation coefficient for sludge code and OUTERSpercent intact is statisticaliy different from zero at the 0.10 level of significance (see Figure 38--the minimum sludge code is associated with the maximum percent intact). Note that the magnitude of the correlation (sample or rank) is less than 0.5 .

\subsection{STORAGE PARAMETERS VERSUS MEASURED PARAMETERS}

The sample correlation coefficient and the Spearman rank correlation coefficient were determined for the storage parameters (canister type, fuel type, key date, years since encapsulation, and ${ }^{240} \mathrm{Pu}$ content) and the measured parameters (gas trap, $\left[{ }^{137} \mathrm{Cs}\right],[\mathrm{K}]$, fuel coating, and qualitative s] udge level). The correlation coefficients are listed in Table 12. Parameters within each group (storage or measured) were also evaluated against the other parameters in the same group. 
HNF-2314, Rev, 0

\subsubsection{Canister Type}

The correlation coefficients (sample and rank) were significantiy different from zero for canister type and years since encapsulation (Figure 39). The MK I aluminum canisters contained the fuel with the longest time (years since encapsulation), the MK II stainless steel canisters contained the fuel with the smallest time. Note that the magnitude of the correlation (sample and rank) is approximately 0.8 .

The correlation coefficients (sample and rank) were significantly different from zero for canister type and potassium concentration (Figure 40). The highest potassium concentration was associated with samples from the MK I aluminum canisters. The smallest potassium concentration was associated with samples from the MK II stainless steel canisters. Note that the magnitudes of the correlations (sample and rank) are approximately 0.7 and 0.5 respectively.

The correlation coefficients (sample and rank) were significantly different from zero for canister type and coating code (Figure 41). The heavy white coating was associated with the MK I aluminum canisters. Note that the magnitudes of the correlations (sample and rank) are approximately 0.7 and 0.6 respectively.

The correlation coefficients (sample and rank) were equal to one and significantly different from zero for canister type and gas trap readings. This is a result of having gas trap readings for the MK II stainless steel canisters only.

\subsubsection{Fuel Type}

The sample correlation coefficient was significantly different from zero for fuel type and ${ }^{240} \mathrm{Pu}$ content (Figure 42 ). The higher ${ }^{240} \mathrm{Pu}$ concentrations are associated with the MIV fuel. Note that the magnitude of the correlation is less than 0.5 .

The rank correlation coefficient was significantly different from zero for fuel type and ${ }^{137} \mathrm{Cs}$ concentration (Figure 43 ). The highest ${ }^{137} \mathrm{Cs}$ concentrations are associated with MIA fuel. Note that the magnitude of the correlation is less than 0.5 .

\subsubsection{Key Date}

The sample correlation coefficient was significantly different from zero for key date and years since encapsulation (Figure 44). Most of the smaller key dates (older fuel) are associated with the smallest number of years since encapsulation. Note that the magnitude of the correlation is less than 0.5 . 
HNF-2314, Rev. 0

The rank correlation coefficient was significantly different from zero for key date and coating code (Figure 45). Coating Code 2 (medium-orange) is associated with the larger key date (newer fuel). Most of the smaller key dates (older fuel) are associated with coating Code 1 (medium-gray). Note that the magnitude of the correlation is less than 0.5 .

The rank correlation coefficient was significantly different from zero for key date and ${ }^{240} \mathrm{Pu}$ content (Figure 46 ). The majority of the higher key dates are associated with the smaller ${ }^{240} \mathrm{Pu}$ isotopic values. Note that the magnitude of the correlation is Tess than 0.5 .

\subsubsection{Years Since Encapsulation}

The correlation coefficients with respect to canister type and key date are discussed in sections 3.5 .1 and 3.5 .3 respectively.

The correlation coefficients (sample and rank) were significantly different from zero for years since encapsulation and ${ }^{240} \mathrm{Pu}$ content (Figure 47). The lowest number of years since encapsulated is associated with the lowest ${ }^{240} \mathrm{Pu}$ isotopic value. This single data point is enough to indicate a possible trend. Note that the magnitude of the correlation is less than 0.5 .

The correlation coefficients (sample and rank) were significantly different from zero for years since encapsulation and coating code

(Figure 48). The lower vaiues for years since encapsulation are associated with coating code 1 (medium-gray) and coating code 4 (heavy white) is only associated with higher values for years since encapsulation. Note that the magnitude of the correlation is less than 0.5.

The correlation coefficients (sample and rank) were significantly different from zero for years since encapsulation and potassium concentration (Figure 49). The highest potassium concentrations are associated with the larger values for years since encapsulation. Note that the magnitude of the correlation is approximately 0.5 .

\subsubsection{Plutonium-240 Isotopic Values}

The correlation coefficients with respect to fuel type, key date, and years since encapsulation are discussed in Sections $3.5 .2,3.5 .3$, and 3.5.4 respectively.

The sample correlation coefficient was significantly different from zero for ${ }^{240} \mathrm{Pu}$ content and gas trap readings (Figure 50 ). The high gas trap readings are associated with the larger ${ }^{240} \mathrm{Pu}$ concentration values. Note that the magnitude of the correlation is approximately 0.5 .

The rank correlation coefficient was significantly different from zero for ${ }^{240} \mathrm{Pu}$ content and coating code. (Figure 51). Coating Code 4 has oniy lower ${ }^{240} \mathrm{Pu}$ concentration values. Note that the magnitude of the correlation is less than 0.5 . 
The correlation coefficients (sample and rank) were significantly different from zero for ${ }^{240} \mathrm{Pu}$ content and sludge code (Figure 52). A line with nonzero slope can be fit to the data. The majority of the higher ${ }^{240} \mathrm{Pu}$ concentrations are associated with.sludge Code 1 (minimal). Note that the magnitude of the correlation is less than 0.5 .

\subsubsection{Gas Trap Readings}

The correlation coefficients with respect to canister type and ${ }^{240} \mathrm{Pu}$ content are discussed in Sections 3.5 .1 and 3.5 .5 respectively.

The sample correlation coefficient was significantly different from zero for gas trap readings and the potassium concentration (Figure 53). The majority of the small gas trap readings are associated with the small potassium concentrations. The largest potassium reading is associated with a larger gas trap reading. This single data point is enough to indicate a possible trend. Note that the magnitude of the correlation is 0.7 .

\subsubsection{Cesium-137 Concentration}

The correlation coefficients with respect to fuel type are discussed in Section 3.5.2.

The correlation coefficients (sample and rank) were significantly different from zero for the ${ }^{137} \mathrm{Cs}$ concentration and sludge code (Figure 54). The largest ${ }^{137} \mathrm{Cs}$ concentrations are associated with sludge Code 3 (maximum). Note that the magnitude of the correlation is approximately 0.5 .

\subsubsection{Potassium Concentration}

The correlation coefficients with respect to canister type, years since encapsulation, and gas trap readings are discussed in Sections 3.5.1, 3.5.4, and 3.5 .6 respectively.

The correlation coefficients (sample and rank) were significantly different from zero for potassium concentration and coating code (Figure 55). The large potassium concentrations are associated with coating Code 4 (heavywhite). Note that the magnitudes of the correlations are 0.7 (sample) and 0.6 (rank).

\subsubsection{Coating Code}

The correlation coefficients with respect to canister type, key date, years since encapsulation, ${ }^{240} \mathrm{Pu}$ content, and potassium concentration are discussed in Sections 3.5.1, 3.5.3, 3.5.4, 3.5.5, and 3.5.8 respectively. 
HNF-2314, Rev. 0

\subsubsection{Sludge Code}

The correlation coefficients with respect to ${ }^{240} \mathrm{Pu}$ content and ${ }^{137} \mathrm{CS}$ concentration are discussed in sections 3.5 .5 and 3.5 .7 respectively. 
HNF-2314, Rev. 0

This page intentionaliy left blank. 


\subsection{REFERENCES}

Pitner, A. L., 1997, Visual Examinations of $K$ West Fuel Elements, HNF-SD-SNF-TI-046, Rev. 0, Duke Engineering \& Services Hanford, Inc., Richland, Washington.

Trimble, D. J., 1997, Analysis of Water from $K$ West Basin Canisters (Second Campaign, HNF-SD-SNF-TI-048, Rev. 0, Duke Engineering \& Services Hanford, Inc., Richland, Washington.

Trimble, D. J., 1996, Data Analysis of Gas and Liquid from K West Basin Fuel Canisters, WHC-SD-SNF-ANAL-008, Rev. 0, Westinghouse Hanford Company, Richland, Washington.

Conn, K. R., 1992, Calculation of Water Leve7 in Gas Traps on MK II Fue7 Storage Canisters at 105-K West, WHC-SD-NR-ANAL-009, Rev. 0, Westinghouse Hanford Company, Richland, Washington.

Snedecor, G. W., and W. G. Cochran, 1980, Statistical Methods, 7th Edition, Iowa State University Press, Ames, Iowa. 
HNF-2314, Rev. 0

This page intentionally left blank. 
HNF-2314, Rev.. 0

Table 1. Canisters Selected for Visua] Inspection--Storage Parameters.

\begin{tabular}{|c|c|c|c|c|c|}
\hline \multicolumn{6}{|c|}{$K$ West Fuel } \\
\hline Location & $\begin{array}{c}\text { Canister } \\
\text { Type }\end{array}$ & $\begin{array}{l}\text { Fuel } \\
\text { Type }\end{array}$ & Key Date ${ }^{2}$ & Years ${ }^{3}$ & Plutonium-240 \\
\hline $0091 \mathrm{M}$ & MK II SS & MIV & 13858 & 13.5 & 11.6 \\
\hline $0091 \mathrm{U}$ & MK II SS & MIV & 13858 & 13.5 & 11.6 \\
\hline $0102 \mathrm{M}$ & MK I SS & MIA & 11806 & 15.6 & 13.3 \\
\hline $0102 \mathrm{U}$ & MK I SS & MIA & 11806 & 15.6 & 13.3 \\
\hline $0161 \mathrm{M}$ & MK I Al & MIA & 10832 & 15.6 & 12.5 \\
\hline 01610 & MK I Al & MIA & 10832 & 15.6 & 12.5 \\
\hline $0315 \mathrm{M}$ & MK I A1 & MIV & 12852 & 15.5 & 12.8 \\
\hline $0315 U$ & MK I A1 & MIV & 12852 & 15.5 & 12.8 \\
\hline $1164 \mathrm{M}$ & MK I. SS & MIA & 12127 & 15.2 & 13.7 \\
\hline $1164 U$ & MK I SS & MIA & 12127 & 15.2 & 13.7 \\
\hline $1226 \mathrm{M}$ & MK I SS & MIA & 11897 & 15.3 & 13.8 \\
\hline $1226 \mathrm{U}$ & MK I SS & MIA & 11897 & 15.3 & 13.8 \\
\hline $1265 M$ & MK II SS & MIA & 12639 & 13.9 & 12.6 \\
\hline $1265 \mathrm{U}$ & MK II SS & MIA & 12639 & 13.9 & 12.6 \\
\hline $1497 M$ & MK I SS & MIA & 11979 & 15.2 & 13.7 \\
\hline $1497 \mathrm{U}$ & MK I SS & MIA & 11979 & 15.2 & 13.7 \\
\hline $1512 M$ & MK II SS & MIV & 13858 & 13.5 & 11.6 \\
\hline $1512 \mathrm{U}$ & MK II SS & MIV & 13858 & 13.5 & 11.6 \\
\hline $1560 \mathrm{M}$ & MK I AT & MIV & 12852 & 15.0 & 12.8 \\
\hline $1560 \mathrm{U}$ & MK I AT & MIV & 12852 & 15.0 & 12.8 \\
\hline $1860 \mathrm{M}$ & MK I Al & Nat & 13015 & 15.0 & 11.8 \\
\hline $1860 \mathrm{U}$ & MK I A] & Nat & 13015 & 15.0 & 11.8 \\
\hline $2660 \mathrm{M}$ & MK I SS & MIA & 13016 & 14.4 & 12.8 \\
\hline $2660 \mathrm{U}$ & MK I SS & MIA & 13016 & 14.4 & 12.8 \\
\hline $2667 M$ & MK I SS & MIA & 13371 & 14.4 & 12.5 \\
\hline $2667 \mathrm{U}$ & MK I SS & MIA & 13371 & 14.4 & 12.5 \\
\hline $5744 \mathrm{M}$ & MK II SS & MIA & 11183 & 12.2 & 12.9 \\
\hline
\end{tabular}


Table 1. Canisters Selected for Visual Inspection--Storage Parameters. (Continued)

\begin{tabular}{|l|c|c|c|c|c||}
\hline \multicolumn{7}{|c|}{ K West Fuel } \\
\hline \hline Location & $\begin{array}{c}\text { Canister } \\
\text { Type }\end{array}$ & $\begin{array}{c}\text { Fue1 } \\
\text { Type }\end{array}$ & Key Date & Years $^{3}$ & Plutonium-240 \\
\hline $5744 U$ & MK II SS & MIA & 11183 & 12.2 & 12.9 \\
\hline $6214 M$ & MK I I SS & MIV & 11540 & Unknown & 16.9 \\
\hline $6214 U$ & MK II SS & MIV & 11540 & Unknown & 16.9 \\
\hline $6513 M$ & MK II SS & MIA & 11109 & 12.2 & 13.2 \\
\hline $6513 U$ & MK II SS & MIA & 11109 & 12.2 & 13.2 \\
\hline $6603 M$ & MK I I SS & MIV & 11540 & Unknown & 17.0 \\
\hline $6603 U$ & MK II SS & MIV & 11540 & Unknown & 17.0 \\
\hline $6641 M$ & MK II SS & MIV & 12565 & Unknown & 15.4 \\
\hline $6641 U$ & MK II SS & MIV & 12565 & Unknown & 15.4 \\
\hline $6743 M$ & MK II SS & MIA & 10982 & 12.0 & 13.2 \\
\hline $6743 U$ & MK II SS & MIA & 10982 & 12.0 & 13.2 \\
\hline $7913 M$ & MK II SS & MIA & 10350 & 11.9 & 10.3 \\
\hline $7913 U$ & MK II SS & MIA & 10350 & 11.9 & 10.3 \\
\hline
\end{tabular}

${ }^{1}$ SS: Stainless stee 1 Al: Aluminum ${ }_{3}^{2}$ Lowest key date is the oldest fuel.

${ }^{3}$ Years since encapsulation (as of September 1996). 
HNF-2314, Rev. 0

Table 2. Visually Examined Barrels--Measured Parameters.

\begin{tabular}{|c|c|c|c|c|c|}
\hline Location & $\begin{array}{c}\text { Gas } \\
\text { Trap } \\
\text { Reading } \\
\end{array}$ & $\begin{array}{r}\text { Cesium-137 } \\
\mathrm{mCi} / \text { barre] } \\
\end{array}$ & $\begin{array}{l}\text { Potassium } \\
\mu \mathrm{g} / \mathrm{ml}\end{array}$ & Fuel Coating & $\begin{array}{c}\text { Quali.tative } \\
\begin{array}{c}\text { Sludge } \\
\text { Level }\end{array} \\
\end{array}$ \\
\hline $0091 M$ & 3.2 & 614 & $<25$ & Medium-Light Green & Maximum \\
\hline 00910 & 2.9 & 571 & --- & Medium-Gray/White & Maximum \\
\hline $0102 M$ & --- & 623 & 230 & Medium-Gary/White & Moderate \\
\hline 01020 & --- & 395 & --- & Medium-Gray/White & Moderate \\
\hline $0161 \mathrm{M}$ & --- & 999 & 296 & Heavy-White & Moderate \\
\hline 01610 & --- & 486 & 280 & Heavy-White & Moderate \\
\hline $0315 \mathrm{M}$ & --- & 119 & 334 & Heavy-White & Minimal \\
\hline $0315 U$ & --- & 142 & --- & Heavy-White & Moderate \\
\hline $1164 \mathrm{M}$ & --- & 1607 & $<25$ & Medium-Gray/White & Moderate \\
\hline 11640 & $-\ldots$ & 538 & $-\cdots$ & Medium-Gray/White & Moderate \\
\hline $1226 \mathrm{M}$ & --- & 927 & $<25$ & Medium-Gray/White & Moderate \\
\hline $1226 \mathrm{U}$ & --- & 152 & $<25$ & Medium-Gray/White & Moderate \\
\hline $1265 \mathrm{M}$ & --- & 402 & $<25$ & Medium-Gray/White & Minimal \\
\hline $1265 U$ & --- & 703 & $<25$ & Medium-Gray/White & Minimal \\
\hline $1497 \mathrm{M}$ & $\ldots$ & 358 & 132 & Medium-Gray/White & Minimal \\
\hline $1497 \mathrm{U}$ & -- & 4046 & 98 & --- & Maximum \\
\hline $1512 \mathrm{M}$ & 1.9 & 765 & $<25$ & Medium-Light Green & Maximum \\
\hline $1512 U$ & 2.2 & 246 & $\ldots$ & Medium-Light Green & Maximum \\
\hline $1560 \mathrm{M}$ & --- & 179 & 38 & Heavy-White & Moderate \\
\hline $1560 \mathrm{U}$ & -- & 1242 & 254 & Heavy-White & Moderate \\
\hline $1860 \mathrm{M}$ & --- & 254 & 275 & Heavy-White & Minimal \\
\hline $1860 \mathrm{U}$ & --- & 914 & 399 & Heavy-White & Maximum \\
\hline $2660 \mathrm{M}$ & --- & 2801 & $<25$ & Medium-Gray/White & Maximum \\
\hline $2660 \mathrm{U}$ & --- & 171 & $\leq 25$ & Medium-Gray/White & Maximum \\
\hline $2667 \mathrm{M}$ & -- & 3558 & $<25$ & Medium-Gray/White & Maximum \\
\hline $2667 \mathrm{U}$ & $-\infty$ & 804 & -- & Medium-Orange & Maximum \\
\hline $5744 \mathrm{M}$ & 3.4 & 725 & --- & Medium-Gray/White & Maximum \\
\hline
\end{tabular}


HNF-2314, Rev. 0

Table 2. Visually Examined Barrels--Measured Parameters. (Continued)

\begin{tabular}{||l|c|c|c|c|c||}
\hline \multicolumn{7}{|c|}{$\begin{array}{c}\text { K West Fuel Damage } \\
\text { Location }\end{array}$} & $\begin{array}{c}\text { Gas } \\
\text { Trap } \\
\text { Reading }\end{array}$ & $\begin{array}{c}\text { Cesium-137 } \\
\text { mCi/barre1 }\end{array}$ & $\begin{array}{c}\text { Potassium } \\
\mu \mathrm{g} / \mathrm{m} 7\end{array}$ & Fuel Coating & $\begin{array}{c}\text { Qualitative } \\
\text { Sludge } \\
\text { Level }\end{array}$ \\
\hline $5744 \mathrm{U}$ & 2.2 & 1051 & 72 & Medium-Gray/White & Moderate \\
\hline $6214 \mathrm{M}$ & 7.4 & 117 & $<25$ & Medium-Gray/White & Minimal \\
\hline $6214 \mathrm{U}$ & 15.8 & 120 & 84 & Medium-Gray/White & Minimal \\
\hline $6513 \mathrm{M}$ & 1.7 & 3546 & 26 & Medium-Gray/White & Maximum \\
\hline $6513 \mathrm{U}$ & 2.9 & 1444 & $<25$ & Medium-Gray/White & Maximum \\
\hline $6603 \mathrm{M}$ & 1.9 & 662 & --- & Medium-Gray/White & Maximum \\
\hline $6603 \mathrm{U}$ & 16.6 & 195 & 106 & Medium-Light Green & Minimal \\
\hline $6641 \mathrm{M}$ & 16.2 & 77 & 242 & Medium-Gray/White & Minimal \\
\hline $6641 \mathrm{U}$ & 0.8 & 86 & - & Medium-Gray/White & Minimal \\
\hline $6743 \mathrm{M}$ & 3.1 & 807 & $<25$ & Medium-Gray/White & Minimal \\
\hline $6743 \mathrm{U}$ & 16.8 & $\mathrm{nd}$ & -- & Medium-Gray/White & Maximum \\
\hline $7913 \mathrm{M}$ & 2.4 & 345 & 94 & Medium-Gray/White & Minimal \\
\hline $7913 \mathrm{U}$ & 0.9 & 989 & $<25$ & Medium-Gray/White & Maximum \\
\hline
\end{tabular}


HNF-2314, Rev. 0

Table 3. Visual Inspection Results--INNERS.

\begin{tabular}{|c|c|c|c|c|c|c|c|c|c|c|c|c|}
\hline \multicolumn{13}{|c|}{ K West Fuel Damage--InNERS } \\
\hline Location & $\begin{array}{c}\text { Canister } \\
\text { Type }\end{array}$ & $\begin{array}{l}\text { Fuel } \\
\text { Type }\end{array}$ & $\begin{array}{l}\text { Key } \\
\text { Date }\end{array}$ & Years ${ }^{1}$ & ${ }^{240} \mathrm{Pu}$ & Total & $t^{2}$ & $\mathrm{Br}^{3}$ & $B^{4}$ & $\begin{array}{c}I \\
(\%)\end{array}$ & $\begin{array}{l}\mathrm{Br} \\
(\%)\end{array}$ & $\begin{array}{c}\text { B } \\
(\%)\end{array}$ \\
\hline $0091 \mathrm{M}$ & MK II SS & MIV & 13858 & 13.5 & 11.6 & 7 & 5 & 2 & 0 & 71.4 & 28.6 & 0.0 \\
\hline 00910 & MK II SS & MIV & 13858 & 13.5 & 11.6 & 7 & 3 & 4 & 0 & 42.9 & 57.1 & 0.0 \\
\hline $0102 M$ & MK I SS & MIA & 11806 & 15.6 & 13.3 & 7 & 7 & 0 & $\overline{0}$ & 100.0 & 0.0 & 0.0 \\
\hline $0102 U$ & MK I SS & MIA & 11806 & 15.6 & 13.3 & 6 & 6 & 0 & 0 & 100.0 & 0.0 & 0.0 \\
\hline 01610 & MK I Al & MIA & 10832 & 15.6 & 12.5 & 7 & 7 & 0 & 0 & 100.0 & 0.0 & 0.0 \\
\hline $0315 M$ & MK I Al & MIV & 12852 & 15.5 & 12.8 & 7 & 6 & 1 & 0 & 85.7 & 14.3 & 0.0 \\
\hline $0315 \mathrm{U}$ & MK I Al & MIV & 12852 & 15.5 & 12.8 & 7 & 6 & 1 & 0 & 85.7 & 14.3 & 0.0 \\
\hline $1164 \mathrm{M}$ & MK I SS & MIA & 12127 & 15.2 & 13.7 & 5 & 4 & 1 & 0 & 80.0 & 20.0 & 0.0 \\
\hline 11640 & MK I SS & MIA & 12127 & 15.2 & 13.7 & 7 & 7 & 0 & 0 & 100.0 & 0.0 & 0.0 \\
\hline $1265 \mathrm{U}$ & MK II SS & MIA & 12639 & 13.9 & 12.6 & 7 & 6 & 0 & 1 & 85.7 & 0.0 & 14.3 \\
\hline $1497 \mathrm{M}$ & MK I SS & MIA & 11979 & 15.2 & 13.7 & 4 & 4 & 0 & 0 & 100.0 & 0.0 & 0.0 \\
\hline 14970 & MK I SS & MIA & 11979 & 15.2 & 13.7 & 0 & 0 & 0 & 0 & $\ldots$ & $\cdots$ & --- \\
\hline $1512 M$ & MK 11 SS & MIV & 13858 & 13.5 & 11.6 & 7 & 4 & 3 & 0 & 57.1 & 42.9 & 0.0 \\
\hline $1512 U$ & MK II SS & MIV & 13858 & 13.5 & 11.6 & 7 & 7 & 0 & 0 & 100.0 & 0.0 & 0.0 \\
\hline $1560 M$ & MK I Al & MIV & 12852 & 15.0 & 12.8 & 6 & 4 & 1 & 1 & 66.7 & 16.7 & 16.7 \\
\hline 15600 & MK I Al & MIV & 12852 & 15.0 & 12.8 & 7 & 7 & 0 & 0 & 100.0 & 0.0 & 0.0 \\
\hline $1860 \mathrm{M}$ & MK I Al & Nat & 13015 & 15.0 & 11.8 & 7 & 6 & 1 & 0 & 85.7 & 14.3 & 0.0 \\
\hline 18600 & MK I Al & Nat & 13015 & 15.0 & 11.8 & 6 & 3 & 2 & 1 & 50.0 & 33.3 & 16.7. \\
\hline $6214 \mathrm{M}$ & MK II SS & MIV & 11540 & Unknown & 16.9 & 7 & 7 & 0 & 0 & 100.0 & 0.0 & 0.0 \\
\hline $6214 \mathrm{U}$ & MK II ss & MIV & 11540 & Unknown & 16.9 & 7 & 6 & 0 & 1 & 85.7 & 0.0 & 14.3 \\
\hline $6513 \mathrm{M}$ & MK II SS & MIA & 11109 & 12.2 & 13.2 & 7 & 6 & 1 & 0 & 85.7 & 14.3 & 0.0 \\
\hline $6513 U$ & MK II sS & MIA & 11109 & 12.2 & 13.2 & 5 & 5 & 0 & 0 & 100.0 & 0.0 & 0.0 \\
\hline $6603 \mathrm{M}$ & NK II SS & MIV & 11540 & Unknown & 17.0 & 7 & 6 & 1 & 0 & 85.7 & 14.3 & 0.0 \\
\hline 66030 & MK II SS & MIV & 11540 & Unknown & 17.0 & 7 & 7 & 0 & 0 & 100.0 & 0.0 & 0.0 \\
\hline $6641 M$ & MK II SS & MIV & 12565 & Unknown & 15.4 & 7 & 6 & 1 & 0 & 85.7 & 14.3 & 0.0 \\
\hline $6641 \mathrm{u}$ & MK II SS & MIV & 12565 & Unknown & 15.4 & 7 & 7 & 0 & 0 & 100.0 & 0.0 & 0.0 \\
\hline $6743 \mathrm{M}$ & MK II SS & MIA & 10982 & 12.0 & 13.2 & 6 & 6 & 0 & 0 & 100.0 & 0.0 & 0.0 \\
\hline 67430 & MK II SS & MIA & 10982 & 12.0 & 13.2 & 6 & 6 & 0 & 0 & 100.0 & 0.0 & 0.0 \\
\hline $7913 M$ & MK II SS & MIA & 10350 & 11.9 & 10.3 & 7 & 7 & 0 & 0 & 100.0 & 0.0 & 0.0 \\
\hline $7913 \mathrm{U}$ & MK II SS & MIA & 10350 & 11.9 & 10.3 & 7 & 7 & 0 & 0 & 100.0 & 0.0 & 0.0 \\
\hline
\end{tabular}

${ }^{1}$ Years since encapsulation (as of September 1996).

2 Intact.

${ }^{3}$ Breached.

${ }^{4}$ Bad. 
HNF-2314, Rev. 0

Table 4. Visual Inspection Summary--INNERS.

\begin{tabular}{|c|c|c|c|c|c|c|c|c|}
\hline \multicolumn{3}{|c|}{ INNERS - \%Intact by Barrel } & \multicolumn{3}{|c|}{ IMNERS - \%Breached by Barrel } & \multicolumn{3}{|c|}{ IMNERS - \%Bad by Barrel } \\
\hline class & $\begin{array}{l}\text { Midpoint } \\
\text { of Class }\end{array}$ & Frequency & Class & $\begin{array}{l}\text { Midpoint } \\
\text { of Class }\end{array}$ & Frequency & Class & $\begin{array}{l}\text { Midpoint } \\
\text { of Class }\end{array}$ & Frequency \\
\hline $40<x \leq 45$ & 42.5 & 1 & $0<x \leq 5$ & 2.5 & 0 & $0<x \leq 5$ & 2.5 & 0 \\
\hline $45<x \leq 50$ & 47.5 & 1 & $5<x \leq 10$ & 7.5 & 0 & $5<x \leq 10$ & 7.5 & 0 \\
\hline $60<x \leq 65$ & 62.5 & 0 & $20<x \leq 25$ & 22.5 & $\mathbf{0}$ & & Total & 39 \\
\hline $65<x \leq 70$ & 67.5 & 1 & $25<x \leq 30$ & 27.5 & 1 & & & \\
\hline $70<x \leq 75$ & 72.5 & 2 & $30<x \leq 35$ & 32.5 & 1 & & & \\
\hline $75<x \leq 80$ & 77.5 & 2 & $35<x \leq 40$ & 37.5 & 0 & & & \\
\hline \multirow[t]{2}{*}{$95<x \leq 100$} & 97.5 & 22 & $55<x \leq 60$ & 57.5 & 1 & & & \\
\hline & Total & 39 & & Total & 39 & & & \\
\hline
\end{tabular}

${ }^{1} X=$ Percent damage. 
Table 5. Correlation Coefficients--INNERS Damage Versus Storage Parameters.

\begin{tabular}{|c|c|c|c|c|c|c|c|}
\hline \multirow{2}{*}{ Variable 1} & \multirow{2}{*}{ Variable 2} & \multicolumn{3}{|c|}{ Sample Correlation } & \multicolumn{3}{|c|}{ Rank Correlation } \\
\hline & & N & Coefficient & $p$-value & N & Coefficient & $p$-value \\
\hline INNERS-\%Intact & Canister Type & 39 & 0.0198 & 0.905 & 40 & -0.0150 & 0.927 \\
\hline INNERS-\%Intact & Fuel Type & 39 & 0.1321 & 0.423 & 40 & 0.2027 & 0.212 \\
\hline INNERS-\%Intact & Key Date & 39 & -0.4168 & r & 40 & -0.3211 & $x$ \\
\hline INNERS-\%Intact & Years Encapsulated & 33 & 0.0263 & 0.885 & 34 & 0.0586 & 0.741 \\
\hline INNERS-\%Intact & ${ }^{240} \mathrm{Pu}$ concentration & 39 & 0.1956 & 0.233 & 40 & 0.1300 & 0.423 \\
\hline INNERS -\%Breached & Canister Type & 39 & 0.0116 & 0.944 & 40 & -0.0581 & 0.720 \\
\hline INNERS -\%Breached & Fuel Type & 39 & -0.1800 & 0.273 & 40 & -0.1877 & 0.247 \\
\hline INNERS-\%Breached & Key Date & 39 & 0.4509 & 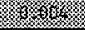 & 40 & 0.3448 & \% \\
\hline I NNERS-\%Breached & Years Encapsulated & 33 & -0.0286 & 0.874 & 34 & -0.0196 & 0.912 \\
\hline INNERS-\%B reached & ${ }^{240} \mathrm{Pu}$ Concentration & 39 & -0.2308 & 0.157 & 40 & -0.1551 & 0.339 \\
\hline INMERS -\%Bad & Canister Type & 39 & -0.0887 & 0.591 & 40 & -0.0472 & 0.771 \\
\hline INNERS-\%Bad & Fuel Type & 39 & 0.0818 & 0.621 & 40 & 0.0470 & 0.772 \\
\hline INNERS-\%Bad & Key Date & 39 & 0.0442 & 0.789 & 40 & 0.0448 & 0.782 \\
\hline INNERS-\%B ad & Years Encapsulated & 33 & -0.0024 & 0.989 & 34 & -0.0560 & 0.751 \\
\hline I NNERS-\%Bad & ${ }^{240} \mathrm{Pu}$ Concentration & 39 & 0.0291 & 0.861 & 40 & -0.0358 & 0.825 \\
\hline
\end{tabular}


HNF-2314, Rev. 0

Table 6. Visual Inspection Results--OUTERS.

\begin{tabular}{|c|c|c|c|c|c|c|c|c|c|c|c|c|}
\hline \multicolumn{13}{|c|}{ K West Fuel Damage } \\
\hline Location & $\begin{array}{c}\text { Canister } \\
\text { Type }\end{array}$ & $\begin{array}{l}\text { Fuel } \\
\text { Type }\end{array}$ & $\begin{array}{l}\text { Key } \\
\text { Date }\end{array}$ & Years ${ }^{1}$ & ${ }^{240} \mathrm{Pu}$ & Total & $I^{2}$ & $\mathrm{Br}^{3}$ & $B^{4}$ & $(\%)$ & $\begin{array}{l}\mathrm{Br} \\
(\%)\end{array}$ & $\begin{array}{c}B \\
(\%)\end{array}$ \\
\hline $0091 M$ & MK II SS & MIV & 13858 & 13.5 & 11.6 & 7 & 2 & 5 & 0 & 28.6 & 71.4 & 0.0 \\
\hline 00910 & MK II SS & MIV & 13858 & 13.5 & 11.6 & 7 & 4 & 3 & 0 & 57.1 & 42.9 & 0.0 \\
\hline $0102 M$ & MK I SS & MIA & 11806 & 15.6 & 13.3 & 7 & 3 & 4 & 0 & 42.9 & 57.1 & 0.0 \\
\hline $0102 \mathrm{U}$ & MK I SS & MIA & 11806 & 15.6 & 13.3 & 6 & 3 & 3 & 0 & 50.0 & 50.0 & 0.0 \\
\hline $0161 \mathrm{M}$ & MK I Al & MIA & 10832 & 15.6 & 12.5 & 7 & 1 & 4 & 2 & 14.3 & 57.1 & 28.6 \\
\hline 01610 & MK I Al & MIA & 10832 & 15.6 & 12.5 & 7 & 4 & 2 & 1 & 57.1 & 28.6 & 14.3 \\
\hline 0315M & $M K \backslash A !$ & MIV & 12852 & 15.5 & 12.8 & 7 & 5 & 2 & 0 & 71.4 & 28.6 & 0.0 \\
\hline $0315 \mathrm{U}$ & MK I AL & MIV & 12852 & 15.5 & 12.8 & 7 & 5 & 2 & 0 & 71.4 & 28.6 & 0.0 \\
\hline $1164 \mathrm{M}$ & MK I SS & MIA & 12127 & 15.2 & 13.7 & 6 & 0 & 4 & 2 & 0.0 & 66.7 & 33.3 \\
\hline $1164 U$ & MK I SS & MIA & 12127 & 15.2 & 13.7 & 7 & 6 & 0 & 1 & 85.7 & 0.0 & 14.3 \\
\hline $1226 \mathrm{M}$ & MK I SS & MIA & 11897 & 15.3 & 13.8 & 7 & 5 & 2 & 0 & 71.4 & 28.6 & 0.0 \\
\hline 12264 & MK I SS & MIA & 11897 & 15.3 & 13.8 & 7 & 5 & 2 & 0 & 71.4 & 28.6 & 0.0 \\
\hline $1265 \mathrm{M}$ & MK II SS & MIA & 12639 & 13.9 & 12.6 & 7 & 4 & 3 & 0 & 57.1 & 42.9 & 0.0 \\
\hline $1265 \mathrm{u}$ & MK II SS & MIA & 12639 & 13.9 & 12.6 & 7 & 3 & 4 & 0 & 42.9 & 57.1 & 0.0 \\
\hline $1497 \mathrm{M}$ & MK I SS & MIA & 11979 & 15.2 & 13.7 & 7 & 5 & 2 & 0 & 71.4 & 28.6 & 0.0 \\
\hline $1497 \mathrm{U}$ & MK I SS & MIA & 11979 & 15.2 & 13.7 & 2 & 0 & 0 & 2 & 0.0 & 0.0 & 100.0 \\
\hline $1512 M$ & MK II SS & MIV & 13858 & 13.5 & 11.6 & 7 & 4 & 2 & 1 & 57.1 & 28.6 & 14.3 \\
\hline $1512 \mathrm{U}$ & MK II SS & MIV & 13858 & 13.5 & 11.6 & 7 & 3 & 3 & 1 & 42.9 & 42.9 & 14.3 \\
\hline $1560 \mathrm{M}$ & MK I AL & MIV & 12852 & 15.0 & 12.8 & 6 & 2 & 3 & 1 & 33.3 & 50.0 & 16.7 \\
\hline 15600 & MK I AL & MIV & 12852 & 15.0 & 12.8 & 7 & 4 & 2 & 1 & 57.1 & 28.6 & 14.3 \\
\hline $1860 \mathrm{M}$ & MK I Al & Nat & 13015 & 15.0 & 11.8 & 7 & 6 & 0 & 1 & 85.7 & 0.0 & 14.3 \\
\hline 18600 & MK I Al & Nat & 13015 & 15.0 & 11.8 & 4 & 3 & 1 & 0 & 75.0 & 25.0 & 0.0 \\
\hline $2660 M$ & MK I SS & MIA & 13016 & 14.4 & 12.8 & 7 & 5 & 1 & 1 & 71.4 & 14.3 & 14.3 \\
\hline 26600 & MK I SS & MIA & 13016 & 14.4 & 12.8 & 7 & 6 & 1 & 0 & 85.7 & 14.3 & 0.0 \\
\hline $2667 \mathrm{M}$ & MK I SS & MIA & 13371 & 14.4 & 12.5 & 3 & 0 & 1 & 2 & 0.0 & 33.3 & 66.7 \\
\hline $2667 \mathrm{U}$ & MK I SS & MIA & 13371 & 14.4 & 12.5 & 7 & 6 & 1 & 0 & 85.7 & 14.3 & 0.0 \\
\hline $5744 M$ & MK II SS & MIA & 11183 & 12.2 & 12.9 & 6 & 1 & 4. & 1 & 16.7 & 66.7 & 16.7 \\
\hline $5744 \mathrm{U}$ & MK II SS & MIA & 11183 & 12.2 & 12.9 & 7 & 1 & 5 & 1 & 14.3 & 71.4 & 14.3 \\
\hline $6214 M$ & MK II SS & MIV & 11540 & Unknown & 16.9 & 7 & 3 & 4 & 0 & 42.9 & 57.1 & 0.0 \\
\hline $6214 \mathrm{U}$ & MK II $\$$ & MIV & 11540 & Unknown & 16.9 & 7 & 4 & 2 & 1 & 57.1 & 28.6 & 14.3 \\
\hline $6513 M$ & MK II SS & MIA & 11109 & 12.2 & 13.2 & 7 & 4 & 2 & 1 & 57.1 & 28.6 & 14.3 \\
\hline $6513 \mathrm{U}$ & MK II SS & MIA & 11109 & 12.2 & 13.2 & 7 & 4 & 2 & 1 & 57.1 & 28.6 & 14.3 \\
\hline $6603 M$ & MK II $\$ S$ & MIV & 11540 & Unknown & 17.0 & 7 & 2 & 3 & 2 & 28.6 & 42.9 & 28.6 \\
\hline $6603 \mathrm{U}$ & MK II SS & MIV & 11540 & Unknown & 17.0 & 7 & 4 & 3 & 0 & 57.1 & 42.9 & 0.0 \\
\hline $6641 \mathrm{M}$ & $M K \ \$ S S$ & MIV & 12565 & Unknown & 15.4 & 7 & 6 & 1 & 0 & 85.7 & 14.3 & 0.0 \\
\hline 66410 & MK II SS & MIV & 12565 & Unknown & 15.4 & 7 & 6 & 1 & 0 & 85.7 & 14.3 & 0.0 \\
\hline $6743 \mathrm{M}$ & MK II SS & MIA & 10982 & 12.0 & 13.2 & 6 & 3 & 3 & 0 & 50.0 & 50.0 & 0.0 \\
\hline $6743 \mathrm{U}$ & MK II SS & MIA & 10982 & 12.0 & 13.2 & 7 & 4 & 2 & 1 & 57.1 & 28.6 & 14.3 \\
\hline $7913 M$ & MK II SS & MIA & 10350 & 11.9 & 10.3 & 7 & 5 & 1 & 1 & 71.4 & 14.3 & 14.3 \\
\hline $7913 \mathrm{U}$ & MK II SS & MIA & 10350 & 11.9 & 10.3 & 7 & 3 & 1 & 3 & 42.9 & 14.3 & 42.9 \\
\hline
\end{tabular}

${ }^{1}$ Years since encapsulation (as of September 1996).

2 Intact.

${ }^{3}$ Breached.

${ }^{4} \mathrm{Bad}$. 
HŃF-2314, Rev. 0

TabTe 7. Visual Inspection Summary--OUTERS.

\begin{tabular}{|c|c|c|c|c|c|c|c|c|}
\hline \multicolumn{3}{|c|}{ OUTERS - \%Intact by Barrel } & \multicolumn{3}{|c|}{ OUTERS - \%Breached by Barrel } & \multicolumn{3}{|c|}{ OUTERS - \%Bad by Barrel } \\
\hline Class & $\begin{array}{l}\text { Midpoint } \\
\text { of Class }\end{array}$ & Frequency & Class & $\begin{array}{l}\text { Midpoint } \\
\text { of Class }\end{array}$ & Frequency & Class & $\begin{array}{l}\text { Midpoint } \\
\text { of Class }\end{array}$ & Frequency \\
\hline$x^{1}=0$ & $-\cdots$ & 3 & $x=0$ & $\cdots$ & 3 & $x=0$ & $\cdots$ & 19 \\
\hline $0<x \leq 5$ & 2.5 & 0 & $0<x \leq 5$ & 2.5 & 0 & $0<x \leq 5$ & 2.5 & 0 \\
\hline $5<x \leq 10$ & 7.5 & 0 & $5<x \leq 10$ & 7.5 & 0 & $5<x \leq 10$ & 7.5 & 0 \\
\hline $20<x \leq 25$ & 22.5 & 0 & $20<x \leq 25$ & 22.5 & 1 & $20<x \leq 25$ & 22.5 & 0 \\
\hline $25<x \leq 30$ & 27.5 & 2 & $25<x \leq 30$ & 27.5 & 12 & $25<x \leq 30$ & 27.5 & 2 \\
\hline $30<x \leq 35$ & 32.5 & 1 & $30<x \leq 35$ & 32.5 & 1 & $30<x \leq 35$ & 32.5 & 1 \\
\hline $35<x \leq 40$ & 37.5 & 0 & $35<x \leq 40$ & 37.5 & 0 & $35<x \leq 40$ & 37.5 & 0 \\
\hline $55<x \leq 60$ & 57.5 & 10 & $55<x \leq 60$ & 57.5 & 4 & $55<x \leq 60$ & 57.5 & 0 \\
\hline $60<x \leq 65$ & 62.5 & 0 & $60<x \leq 65$ & 62.5 & 0 & $60<x \leq 65$ & 62.5 & 0 \\
\hline $65<x \leq 70$ & 67.5 & 0 & $65<x \leq 70$ & 67.5 & 2 & $65<x \leq 70$ & 67.5 & 1 \\
\hline $70<x \leq 75$ & 72.5 & 8 & $70<x \leq 75$ & 72.5 & 2 & $70<x \leq 75$ & 72.5 & 0 \\
\hline $75<x \leq 80$ & 77.5 & 0 & $75<x \leq 80$ & 77.5 & 0 & $75<x \leq 80$ & 77.5 & 0 \\
\hline $80<x \leq 85$ & 82.5 & 0 & $80<x \leq 85$ & 82.5 & 0 & $80<x \leq 85$ & 82.5 & 0 \\
\hline $85<x \leq 90$ & 87.5 & 6 & $85<x \leq 90$ & 87.5 & 0 & $85<x \leq 90$ & 87.5 & 0 \\
\hline $90<x \leq 95$ & 92.5 & 0 & $90<x \leq 95$ & 92.5 & 0 & $90<x \leq 95$ & 92.5 & 0 \\
\hline $95<x \leq 100$ & 97.5 & 0 & $95<x \leq 100$ & 97.5 & 0 & $95<x \leq 100$ & 97.5 & 1 \\
\hline
\end{tabular}

${ }^{1}$ Percent damage. 
Table 8. Correlation Coefficients--0UTERS Damage Versus Storage Parameters.

\begin{tabular}{|c|c|c|c|c|c|c|c|}
\hline \multirow{2}{*}{ Variable 1} & \multirow{2}{*}{ Variable 2} & \multicolumn{3}{|c|}{ Sample Correlation } & \multicolumn{3}{|c|}{ Rank Correlation } \\
\hline & & $\mathrm{N}$ & Coefficient & p-value & N & Coefficient & $p$-value \\
\hline ouTERS-\%Intact & Canister Type & 40 & -0.1156 & 0.478 & 40 & -0.1958 & 0.221 \\
\hline OUTERS-\%Intact & Fuel Type & 40 & 0.0324 & 0.843 & 40 & 0.0729 & 0.649 \\
\hline OUTERS-\%I ntact & Key Date & 40 & 0.1767 & 0.275 & 40 & 0.2322 & 0.147 \\
\hline OUTERS-\%Intact & Years Encapsulated & 34 & 0.1193 & 0.502 & 34 & 0.1271 & 0.465 \\
\hline OUTERS-\%Intact & ${ }^{240} \mathrm{Pu}$ Concentration & 40 & 0.0096 & 0.953 & 40 & 0.0329 & 0.837 \\
\hline OUTERS-\%Breached & Canister Type & 40 & 0.2171 & 0.178 & 40 & 0.2224 & 0.165 \\
\hline OUTERS-\%Breached & Fuel Type & 40 & -0.1992 & 0.218 & 40 & -0.1967 & 0.219 \\
\hline OUTERS-\%Breached & Key Date & 40 & -0.0777 & 0.634 & 40 & -0.1215 & 0.448 \\
\hline OUTERS-\%Breached & Years Encapsulated & 34 & -0.1355 & 0.445 & 34 & -0.0204 & 0.907 \\
\hline OUTERS-\%Breached & ${ }^{240} \mathrm{Pu}$ Concentration & 40 & 0.0755 & 0.635 & 40 & 0.0519 & 0.746 \\
\hline OUTERS-\%Bad & Canister Type & 40 & -0.0673 & 0.680 & 40 & -0.0464 & 0.772 \\
\hline OUTERS-\%Bad & Fuel Type & 40 & 0.1542 & 0.342 & 40 & 0.1366 & 0.394 \\
\hline OUTERS-\%Bad & Key Date & 40 & -0.1454 & 0.371 & 40 & -0.2516 & 0.116 \\
\hline OUTERS-\%Bad & Years Encapsulated & 34 & -0.0153 & 0.932 & 34 & -0.1893 & 0.277 \\
\hline OUTERS-\%Bad & ${ }^{240} \mathrm{Pu}$ Concentration & 40 & -0.0879 & 0.590 & 40 & -0.1442 & 0.368 \\
\hline
\end{tabular}

Table 9. Correlation Coefficients--INNERS Versus OUTERS.

\begin{tabular}{|c|c|c|c|c|c|c|c|}
\hline \multirow{2}{*}{ Variable 1} & \multirow{2}{*}{ Variable 2} & \multicolumn{3}{|c|}{ Sample Correlation } & \multicolumn{3}{|c|}{ Rank Correlation } \\
\hline & & N & Coefficient & p-value & $N$ & Coefficient & $p$-value \\
\hline I NNERS-\%Intact & OUTERS- $\%$ Intact & 39 & 0.1096 & 0.506 & 39 & 0.1317 & 0.417 \\
\hline INNERS-\%Intact & OUTERS-\%Breached & 39 & -0.2164 & 0.186 & 39 & -0.2300 & 0.156 \\
\hline INNERS-\%Intact & OUTERS-\%Bad & 39 & 0.1049 & 0.525 & 39 & -0.0400 & 0.805 \\
\hline INNERS - \%Breached & OUTERS-\%Intact & 39 & 0.0697 & 0.673 & 39 & -0.0763 & 0.638 \\
\hline INNERS -\%Breached & OUTERS-\%Breached & 39 & 0.1658 & 0.313 & 39 & 0.1703 & 0.294 \\
\hline INNERS-\%Breached & OUTERS-\%Bad & 39 & -0.1042 & 0.528 & 39 & 0.0280 & 0.863 \\
\hline INNERS - $\%$ Bad & OUTERS-\%Intact & 39 & -0.1392 & 0.398 & 39 & -0.1464 & 0.367 \\
\hline INNERS-\%Bad & OUTERS-\%Breached & 39 & 0.2009 & 0.220 & 39 & 0.1743 & 0.283 \\
\hline I NNERS-\%B ad & OUTERS-\%Bad & 39 & -0.0350 & 0.833 & 39 & 0.0944 & 0.561 \\
\hline
\end{tabular}


HNF-2314, Rev. 0

Table 10. Correlation Coefficients--INNERS Damage Versus Measured Parameters.

\begin{tabular}{|c|c|c|c|c|c|c|c|}
\hline \multirow{2}{*}{ Variable 1} & \multirow{2}{*}{ Variable 2} & \multicolumn{2}{|c|}{ Sample Correlation } & \multirow[b]{2}{*}{$p$-value } & \multicolumn{3}{|c|}{ Spearman Rank Correlation } \\
\hline & & $\mathrm{N}$ & Coefficient & & $\mathbf{N}$ & Coefficient & p-value \\
\hline INNERS-\%Intact & Gas Trap & 18 & 0.1867 & 0.458 & 18 & 0.0324 & 0.894 \\
\hline INNERS-\%Intact & ${ }^{137} \mathrm{Cs}$ & 38 & 0.0391 & 0.816 & 40 & -0.0858 & 0.597 \\
\hline INNERS - \% Intact & $K$ & 29 & -0.1391 & 0.472 & 30 & -0.0669 & 0.723 \\
\hline INNERS-\%Intact & Coating Code & 39 & -0.2407 & 0.140 & 39 & -0.2070 & 0.202 \\
\hline INNERS-\%Intact & Sludge Code & 39 & -0.2753 & 0.090 & 39 & -0.1640 & 0.312 \\
\hline INWERS-\%Breached & Gas Trap & 18 & -0.2549 & 0.307 & 18 & -0.1494 & 0.538 \\
\hline INNERS -\%Breached & ${ }^{137} \mathrm{Cs}$ & 38 & 0.0013 & 0.994 & 40 & 0.1255 & 0.439 \\
\hline INNERS-\%Breached & $k$ & 29 & 0.1128 & 0.560 & 30 & 0.0815 & 0.666 \\
\hline INNERS-\%Breached & Coating Code & 39 & 0.2156 & 0.188 & 39 & 0.2590 & 0.110 \\
\hline INMERS-\%Breached & sludge code & 39 & 0.3171 & 48 & 39 & 0.2429 & 0.134 \\
\hline I NNERS-\%Bad & Gas Trap & 18 & 0.2362 & 0.345 & 18 & 0.3071 & 0.205 \\
\hline INNERS-\%Bad & ${ }^{137} \mathrm{cs}$ & 39 & -0.0544 & 0.742 & 40 & -0.0396 & 0.807 \\
\hline INNERS-\%Bad & $\mathrm{K}$ & 29 & 0.1098 & 0.571 & 30 & 0.1498 & 0.428 \\
\hline INNERS-\%Bad & Coating Code & 39 & 0.1426 & 0.386 & 39 & 0.1214 & 0.454 \\
\hline I NNERS-\%Bad & sludge Code & 39 & -0.0210 & 0.899 & 39 & -0.0211 & 0.896 \\
\hline
\end{tabular}

Table 11. Correlation Coefficients--OUTERS Damage Versus Measured Parameters.

\begin{tabular}{|c|c|c|c|c|c|c|c|}
\hline \multirow{2}{*}{ Variable 1} & \multirow{2}{*}{ Variable 2} & \multicolumn{2}{|c|}{ Sample Correlation } & \multirow[b]{2}{*}{$p$-value } & \multicolumn{3}{|c|}{ Spearman Rank Correlation } \\
\hline & & $\mathrm{N}$ & Coefficient & & $N$ & Coefficient & $p$-value \\
\hline OUTERS -\%Int act & Gas Trap & 18 & 0.3146 & 0.204 & 18 & 0.0689 & 0.776 \\
\hline OUTERS-\%Intact & ${ }^{137} \mathrm{Cs}$ & 40 & -0.3999 & $8 x$ & 40 & -0.4349 & 28 \\
\hline OUTERS-\%Intact & $k$ & 30 & 0.2534 & 0.177 & 30 & 0.2459 & 0.186 \\
\hline OUTERS-\%Intact & Coating Code & 39 & 0.0589 & 0.722 & 40 & 0.0786 & 0.628 \\
\hline OUTERS-\%Intact & Sludge Code & 40 & -0.2766 & 0.084 & 40 & -0.2391 & 0.136 \\
\hline OUTERS-\%Breached & Gas Trap & 18 & -0.1522 & 0.547 & 18 & 0.2535 & 0.296 \\
\hline OUTERS-\%Breached & ${ }^{137} \mathrm{cs}$ & 40 & -0.0943 & 0.563 & 40 & 0.0988 & 0.537 \\
\hline OUTERS-\%Breached & K & 30 & -0.1973 & 0.296 & 30 & -0.2202 & 0.236 \\
\hline OUTERS-\%Breached & Coating Code & 39 & -0.0377 & 0.820 & 40 & -0.0434 & 0.789 \\
\hline OUTERS-\%Breached & Sludge Code & 40 & -0.0298 & 0.855 & 40 & -0.0594 & 0.711 \\
\hline OUTERS-\%Bad & Gas Trap & 18 & -0.2900 & 0.243 & 18 & -0.3699 & 0.127 \\
\hline OUTERS-\%Bad & ${ }^{137} \mathrm{cs}$ & 40 & 0.5927 & 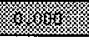 & 40 & 0.4782 & 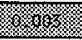 \\
\hline OUTERS-\%Bad & $k$ & 30 & -0.1134 & 0.551 & 30 & 0.0118 & 0.950 \\
\hline OUTERS-\%Bad & Coating Code & 39 & -0.0481 & 0.771 & 40 & 0.0293 & 0.857 \\
\hline OUTERS-\%Bad & sludige code & 40 & 0.3758 & 86 & 40 & 0.3948 & \\
\hline
\end{tabular}


HNF-2314, Rev. 0

Table 12. Correlation Coefficients--Known Versus Measured Parameters.

\begin{tabular}{|c|c|c|c|c|c|c|c|}
\hline \multirow{2}{*}{ Variable 1} & \multirow{2}{*}{ Variable 2} & \multicolumn{3}{|c|}{ Sample Correlation } & \multicolumn{3}{|c|}{ Spearman Rank Correlation } \\
\hline & & Coefficient & $N$ & p-value & Coefficient & $\mathrm{N}$ & $p$-value \\
\hline Can Type & Fuel Type & -0.2530 & 40 & 0.115 & -0.2614 & 40 & 0.103 \\
\hline Can Type & Key Date & -0.1904 & 40 & 0.239 & -0.2379 & 40 & 0.137 \\
\hline Can Type & Years & -0.8175 & 34 & 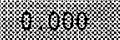 & -0.8147 & 40 & $8,8.800$ \\
\hline Can Type & ${ }^{240} \mathrm{Pu}$ & 0.2192 & 40 & 0.174 & 0.1323 & 40 & 0.409 \\
\hline Can Type & Gàs Trap & 1.0000 & 18 & 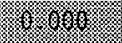 & 1.0000 & 40 & 0.860. \\
\hline Can Type & {$\left[{ }^{137} \mathrm{Cs}\right]$} & -0.0134 & 39 & 0.936 & -0.0446 & 40 & 0.783 \\
\hline Can Type & {$[\mathrm{K}]$} & -0.6609 & 30 & 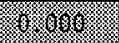 & -0.5439 & 40 & 0.608 \\
\hline Can Type & Coating Code & -0.6788 & 39 & 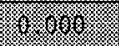 & -0.5852 & 40 & 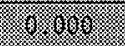 \\
\hline Can Type & STudge Code & 0.0308 & 40 & 0.850 & 0.0288 & 40 & 0.858 \\
\hline Fuel Type & Can Type & -0.2530 & 40 & 0.115 & -0.2614 & 40 & 0.103 \\
\hline Fuel Type & Key Date & -0.2761 & 40 & 0.085 & -0.2611 & 40 & 0.103 \\
\hline Fuel Type & Years & -0.0067 & 34 & 0.970 & 0.0177 & 40 & 0.919 \\
\hline Fuel Type & ${ }^{240} \mathrm{Pu}$ & -0.3916 & 40 & 6.92 & -0.1820 & 40 & 0.256 \\
\hline Fuel Type & Gastrap & -0.2302 & 18 & 0.358 & -0.1079 & 40 & 0.656 \\
\hline Fue1 Type & {$\left[{ }^{137} \mathrm{Cs}\right]$} & 0.3011 & 39 & 0.063 & 0.4760 & 40 & (3.608. \\
\hline Fuel Type & {$[\mathrm{K}]$} & 0.1632 & 30 & 0.389 & 0.0213 & 40 & 0.909 \\
\hline Fue1 Type & Coating Code & -0.1403 & 39 & 0.394 & -0.2080 & 40 & 0.200 \\
\hline Fuel Type & Sludge Code & 0.1189 & 40 & 0.465 & 0.1262 & 40 & 0.431 \\
\hline Key Date & Can Type & -0.1904 & 40 & 0.239 & -0.2379 & 40 & 0.137 \\
\hline Key Date & Fuel Type & -0.2761 & 40 & 0.085 & -0.2611 & 40 & 0.103 \\
\hline Key Date & Years & 0.3449 & 34 & 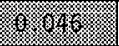 & 0.0782 & 40 & 0.653 \\
\hline Key Date & ${ }^{240} \mathrm{Pu}$ & -0.1977 & 40 & 0.222 & -0.3398 & 40 & 8.8083 \\
\hline Key Date & Gastrap & -0.1072 & 18 & 0.672 & 0.0063 & 40 & 0.979 \\
\hline Key Date & {$\left[{ }^{137} \mathrm{Cs}\right]$} & -0.0405 & 39 & 0.807 & -0.1072 & 40 & 0.509 \\
\hline Key Date & {$[K]$} & 0.0385 & 30 & 0.840 & -0.1161 & 40 & 0.532 \\
\hline Key Date & Coating Code & 0.3110 & 39 & 0.054 & 0.3193 & 40 & 80.043 \\
\hline Key Date & Sludge Code & 0.2008 & 40 & 0.214 & 0.2229 & 40 & 0.164 \\
\hline
\end{tabular}


HNF-2314, Rev. 0

Table 12. Correlation Coefficients--Known Versus Measured Parameters. (Continued)

\begin{tabular}{|c|c|c|c|c|c|c|c|}
\hline \multirow{2}{*}{ Variable 1} & \multirow{2}{*}{ Variable 2} & \multicolumn{3}{|c|}{ Sample Correlation } & \multicolumn{3}{|c|}{ Spearman Rank Correlation } \\
\hline & & Coefficient & $\mathrm{N}$ & p-value & Coefficient & $\mathrm{N}$ & $p$-value \\
\hline Years & Can Type & -0.8175 & 34 & 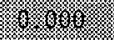 & -0.8147 & 40 & 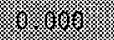 \\
\hline Years & FueT Type & -0.0067 & 34 & 0.970 & 0.0177 & 40 & 0.919 \\
\hline Years & Key Date & 0.3449 & 34 & 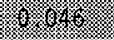 & 0.0782 & 40 & 0.653 \\
\hline Years & ${ }^{240} \mathrm{Pu}$ & 0.3959 & 34 & 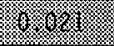 & 0.3702 & 34 & 80.896 \\
\hline Years & Gastrap & -0.2120 & 12 & 0.508 & 0.0146 & 34 & 0.961 \\
\hline Years & {$\left[{ }^{137} \mathrm{Cs}\right]$} & -0.1249 & 33 & 0.489 & -0.2490 & 34 & 0.159 \\
\hline Years & {$[\mathrm{K}]$} & 0.5126 & 26 & $20.04 \%$ & 0.5013 & 34 & 0.3 .93 \\
\hline Years & Coating Code & 0.4344 & 33 & 3.326 & 0.3787 & 34 & 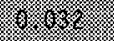 \\
\hline Years & Sludge Code & -0.2396 & 34 & 0.172 & -0.3293 & 34 & 0.059 \\
\hline${ }^{240} \mathrm{Pu}$ & Can Type & 0.2192 & 40 & 0.174 & 0.1323 & 40 & 0.409 \\
\hline${ }^{240} \mathrm{Pu}$ & Fuel Type & -0.3916 & 40 & (1) & -0.1820 & 40 & 0.256 \\
\hline${ }^{240} \mathrm{Pu}$ & Key Date & -0.1977 & 40 & 0.222 & -0.3398 & 40 & 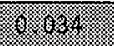 \\
\hline${ }^{240} \mathrm{Pu}$ & Years & 0.3959 & 34 & (1) & 0.3702 & 34 & 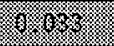 \\
\hline${ }^{240} \mathrm{Pu}$ & Gastrap & 0.5422 & 18 & 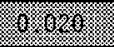 & 0.3644 & 40 & 0.133 \\
\hline${ }^{240} \mathrm{Pu}$ & {$\left[{ }^{137} \mathrm{Cs}\right]$} & -0.1355 & 39 & 0.411 & -0.2197 & 40 & 0.176 \\
\hline${ }^{240} \mathrm{Pu}$ & {$[\mathrm{K}]$} & -0.0836 & 30 & 0.661 & -0.0434 & 40 & 0.815 \\
\hline${ }^{240} \mathrm{Pu}$ & Coating Code & -0.2576 & 39 & 0.113 & -0.4303 & 40 & (3) \\
\hline${ }^{240} \mathrm{Pu}$ & Sludge Code & -0.3607 & 40 & 8.0 .02 & -0.3401 & 40 & 0.634 \\
\hline Gas Trap & Can Type & 1.0000 & 18 & 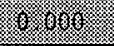 & 1.0000 & 40 & 1.0 .903 \\
\hline Gas Trap & Fue\} Type & -0.2302 & 18 & 0.358 & -0.1079 & 40 & 0.656 \\
\hline Gas Trap & Key Date & -0.1072 & 18 & 0.672 & 0.0063 & 40 & 0.979 \\
\hline Gas Trap & Years & -0.2120 & 12 & 0.508 & 0.0146 & 34 & 0.961 \\
\hline Gas Trap & ${ }^{240} \mathrm{Pu}$ & 0.5422 & 18 & (3.628. & 0.3644 & 40 & 0.133 \\
\hline Gas Trap & {$\left[{ }^{137} \mathrm{Cs}\right]$} & -0.3942 & 17 & 0.117 & -0.4408 & 18 & 0.078 \\
\hline Gas Trap & {$[\mathrm{K}]$} & 0.7093 & 12 & 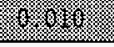 & 0.4628 & 18 & 0.125 \\
\hline Gas Trap & Coating Code & 0.0266 & 18 & 0.917 & 0.0516 & 18 & 0.832 \\
\hline Gas Trap & Sludge Code & -0.4113 & 18 & 0.090 & -0.3076 & 18 & 0.205 \\
\hline
\end{tabular}


HNF-2314, Rev. 0

Table 12. Correlation Coefficients--Known Versus Measured Parameters. (Continued)

\begin{tabular}{|c|c|c|c|c|c|c|c|}
\hline \multirow{2}{*}{ Variable 1} & \multirow{2}{*}{ Variable 2} & \multicolumn{3}{|c|}{ Sample Correlation } & \multicolumn{3}{|c|}{ Spearman Rank Correlation } \\
\hline & & Coefficient & $N$ & p-value & Coefficient & $\mathrm{N}$ & $p$-value \\
\hline$\left[{ }^{137} \mathrm{Cs}\right]$ & Can Type & -0.0134 & 39 & 0.936 & -0.0446 & 40 & 0.783 \\
\hline$\left[{ }^{137} \mathrm{Cs}\right]$ & Fuel Type & 0.3011 & 39 & 0.063 & 0.4760 & 40 & 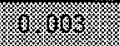 \\
\hline$\left[{ }^{137} \mathrm{Cs}\right]$ & Key Date & -0.0405 & 39 & 0.807 & -0.1072 & 40 & 0.509 \\
\hline$\left[{ }^{137} \mathrm{Cs}\right]$ & Years & -0.1249 & 33 & 0.489 & -0.2490 & 34 & 0.159 \\
\hline$\left[{ }^{137} \mathrm{Cs}\right]$ & ${ }^{240} \mathrm{Pu}$ & -0.1355 & 39 & 0.411 & -0.2197 & 40 & 0.176 \\
\hline$\left[{ }^{137} \mathrm{Cs}\right]$ & Gastrap & -0.3942 & 17 & 0.117 & -0.4408 & 18 & 0.078 \\
\hline$\left[{ }^{137} \mathrm{Cs}\right]$ & {$[\mathrm{K}]$} & -0.2238 & 30 & 0.234 & -0.1880 & 39 & 0.311 \\
\hline$\left[{ }^{137} \mathrm{Cs}\right]$ & Coating Code & -0.2088 & 38 & 0.208 & -0.1161 & 39 & 0.480 \\
\hline$\left[{ }^{137} \mathrm{Cs}\right]$ & STudge Code & 0.4979 & 39 & (2.3. & 0.5657 & 39 & 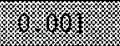 \\
\hline$[\mathrm{K}]$ & Can Type & -0.6609 & 30 & (6) & -0.5439 & 40 & 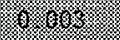 \\
\hline [K] & Fue] Type & 0.1632 & 30 & 0.389 & 0.0213 & 40 & 0.909 \\
\hline [K] & Key Date & 0.0385 & 30 & 0.840 & -0.1161 & 40 & 0.532 \\
\hline [K] & Years & 0.5126 & 26 & 8.6928 & 0.5013 & 34 & 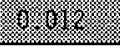 \\
\hline$[\mathrm{K}]$ & ${ }^{240} \mathrm{Pu}$ & -0.0836 & 30 & 0.661 & -0.0434 & 40 & 0.815 \\
\hline$[\mathrm{K}]$ & Gastrap & 0.7093 & 12 & 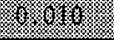 & 0.4628 & 18 & 0.125 \\
\hline [K] & {$\left[{ }^{137} \mathrm{Cs}\right]$} & -0.2238 & 30 & 0.234 & -0.1880 & 39 & 0.311 \\
\hline [K] & Coating Code & 0.6661 & 29 & (x) & 0.6291 & 30 & 3.006 \\
\hline$[\mathrm{K}]$ & Sludge Code & -0.1945 & 30 & 0.303 & -0.2696 & 30 & 0.147 \\
\hline Coating Code & Can Type & -0.6788 & 39 & 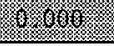 & -0.5852 & 40 & 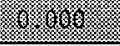 \\
\hline Coating Code & Fuel Type & -0.1403 & 39 & 0.394 & -0.2080 & 40 & 0.200 \\
\hline Coating Code & Key Date & 0.3110 & 39 & 0.054 & 0.3193 & 40 & 80.80 .89 \\
\hline Coating Code & Years & 0.4344 & 33 & 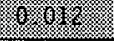 & 0.3787 & 34 & 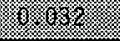 \\
\hline Coating Code & ${ }^{240} \mathrm{Pu}$ & -0.2576 & 39 & 0.113 & -0.4303 & 40 & 0.63. \\
\hline Coating Code & Gastrap & 0.0266 & 18 & 0.917 & 0.0516 & 18 & 0.832 \\
\hline Coating Code & {$\left[{ }^{137} \mathrm{Cs}\right]$} & -0.2088 & 38 & 0.208 & -0.1161 & 39 & 0.480 \\
\hline Coating Code & {$[\mathrm{K}]$} & 0.6661 & 29 & 8. & 0.6291 & 30 & 30 \\
\hline Coating Code & Sludge Code & -0.0133 & 39 & 0.936 & 0.0070 & 39 & 0.966 \\
\hline
\end{tabular}


Table 12. Correlation Coefficients--Known Versus Measured Parameters. (Continued)

\begin{tabular}{|c|c|c|c|c|c|c|c|}
\hline \multirow{2}{*}{ Variable I } & \multirow{2}{*}{ Variable 2} & \multicolumn{3}{|c|}{ Sample Correlation } & \multicolumn{3}{|c|}{ Spearman Rank Correlation } \\
\hline & & Coefficient & $\mathrm{N}$ & $p$-value & Coefficient & $N$ & $p$-value \\
\hline Sludge Code & Can Type & 0.0308 & 40 & 0.850 & 0.0288 & 40 & 0.858 \\
\hline Sludge Code & Fuel Type & 0.1189 & 40 & 0.465 & 0.1262 & 40 & 0.431 \\
\hline Sludge Code & Key Date & 0.2008 & 40 & 0.214 & 0.2229 & 40 & 0.164 \\
\hline Sludge Code & Years & -0.2396 & 34 & 0.172 & -0.3293 & 34 & 0.059 \\
\hline Sludge Code & ${ }^{240} \mathrm{Pu}$ & -0.3607 & 40 & 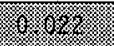 & -0.3401 & 40 & 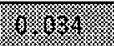 \\
\hline STudge Code & Gastrap & -0.4113 & 18 & 0.090 & -0.3076 & 18 & 0.205 \\
\hline Sludge Code & {$\left[{ }^{137} \mathrm{Cs}\right]$} & 0.4979 & 39 & 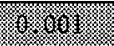 & 0.5657 & 39 & 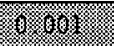 \\
\hline Sludge Code & [K] & -0.1945 & 30 & 0.303 & -0.2696 & $\overline{30}$ & 0.147 \\
\hline Sludge Code & Coating Code & -0.0133 & 39 & 0.936 & 0.0070 & 39 & 0.966 \\
\hline
\end{tabular}


HNF-2314, Rev. 0

This page intentionally left blank. 
HNF-2314, Rev. 0

Figure 1. Histogram: INNERS--Percent Intact.

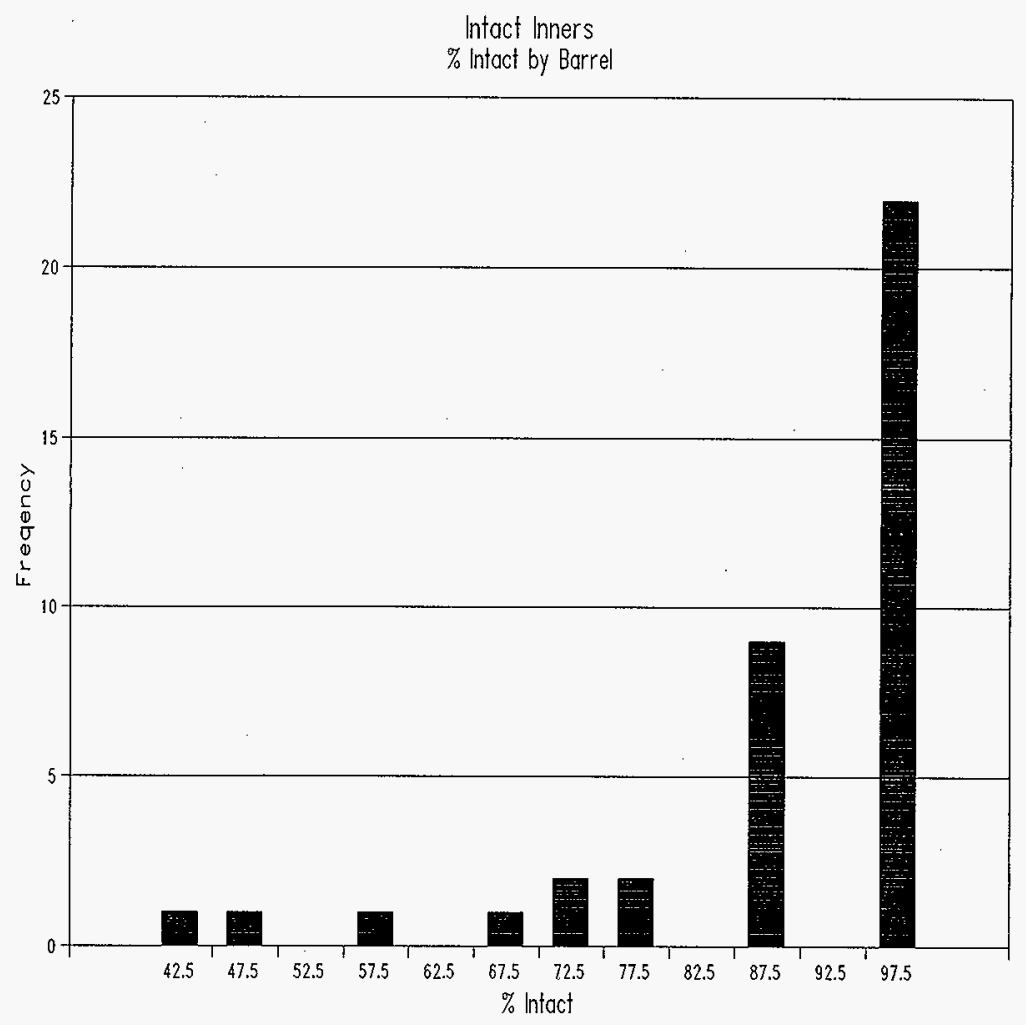


HNF-23I4, Rev. 0

Figure 2. Histogram: INNERS--Percent Breached.

Breached Inners

$\%$ Breached by Barrel

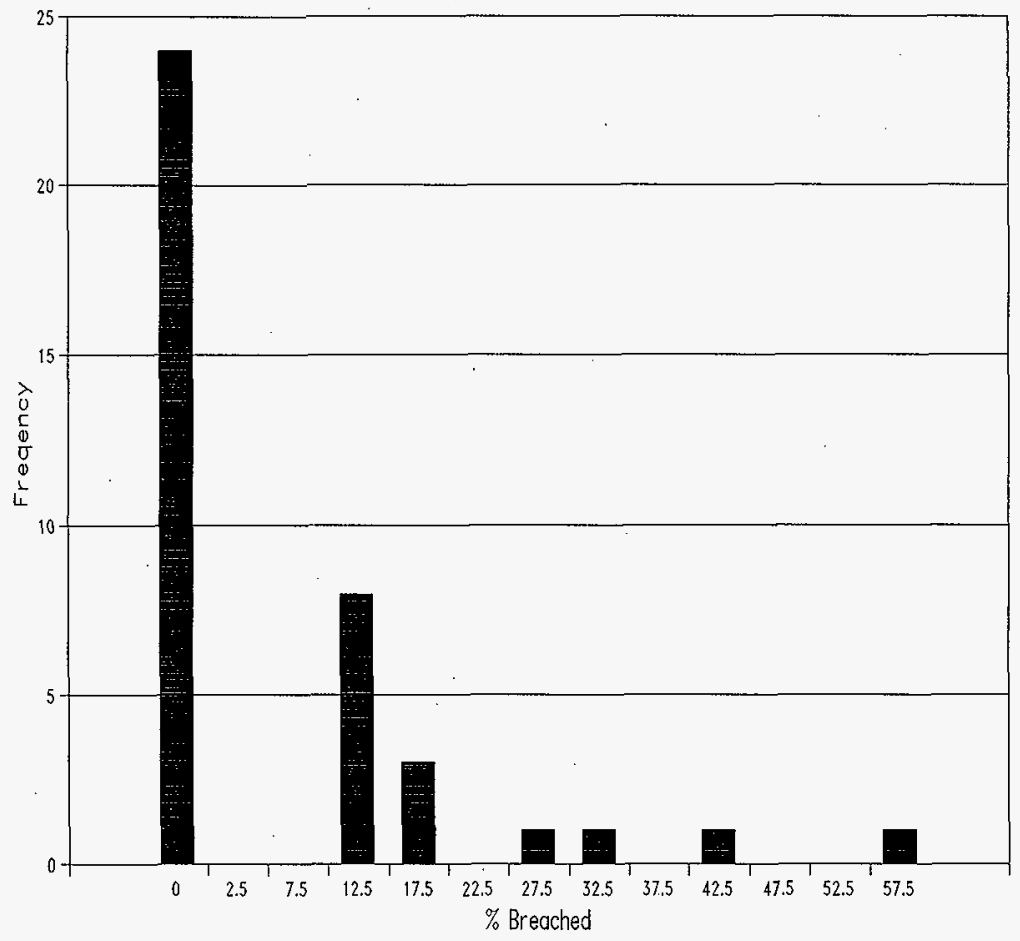


HNF-2314, Rev. 0

Figure 3. Histogram: INNERS--Percent Bad.

Bad Inners

$\%$ Bad by Barrel

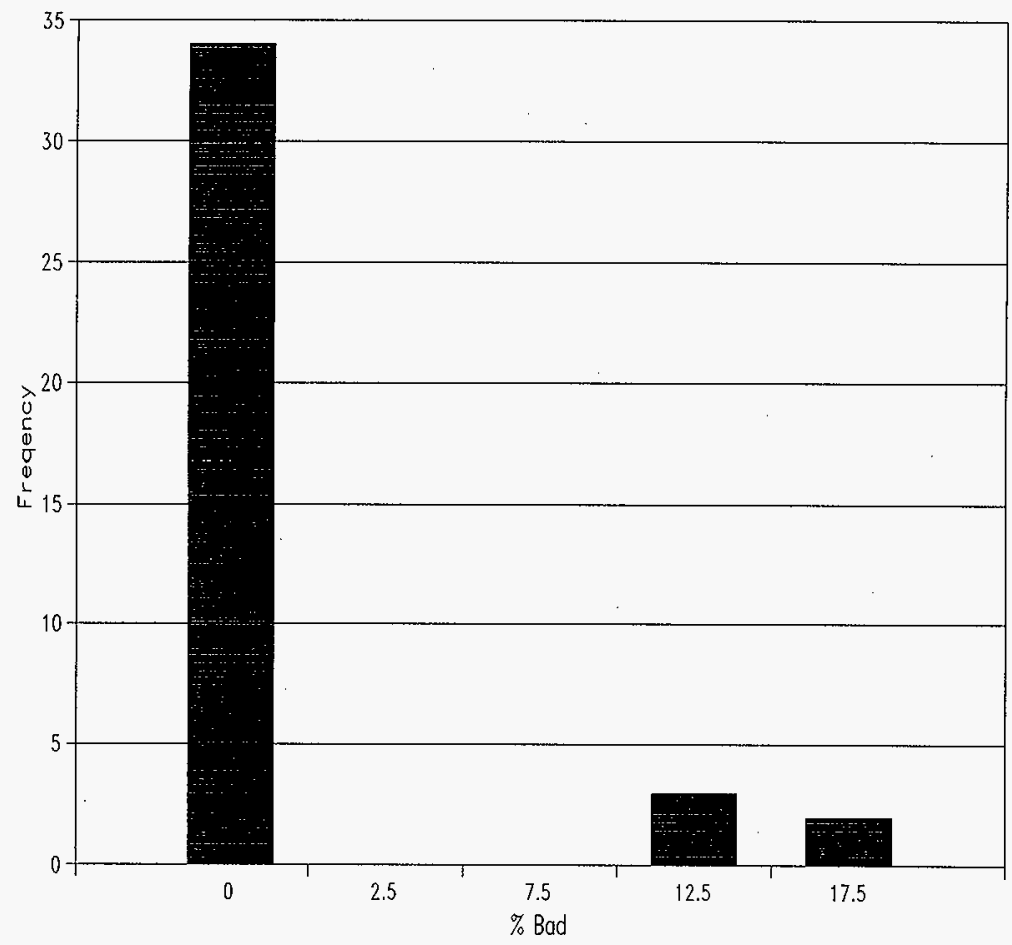


HNF-2314, Rev. 0

Figure 4. Histogram: OUTERS--Percent Intact.

Intact Outers

\% Intact by Barrel

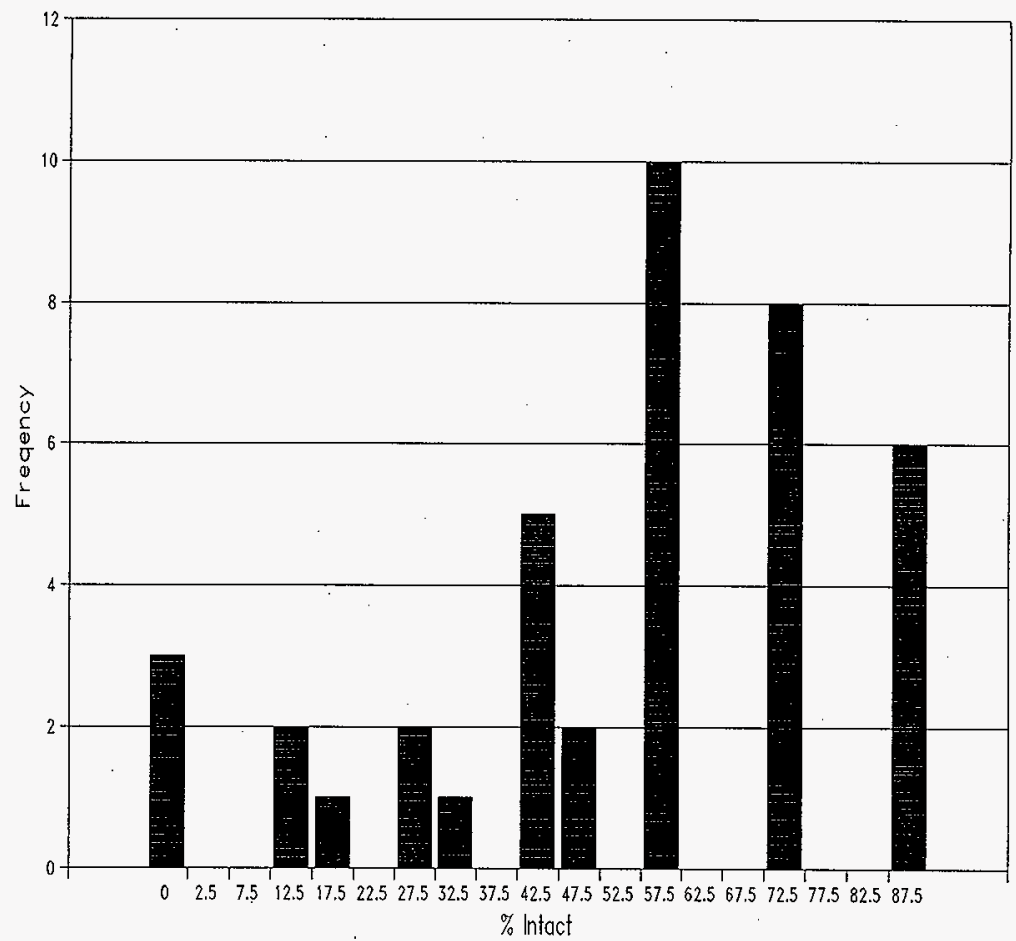


HNF-2314, Rev. 0

Figure 5. Histogram: OUTERS--Percent Breached.

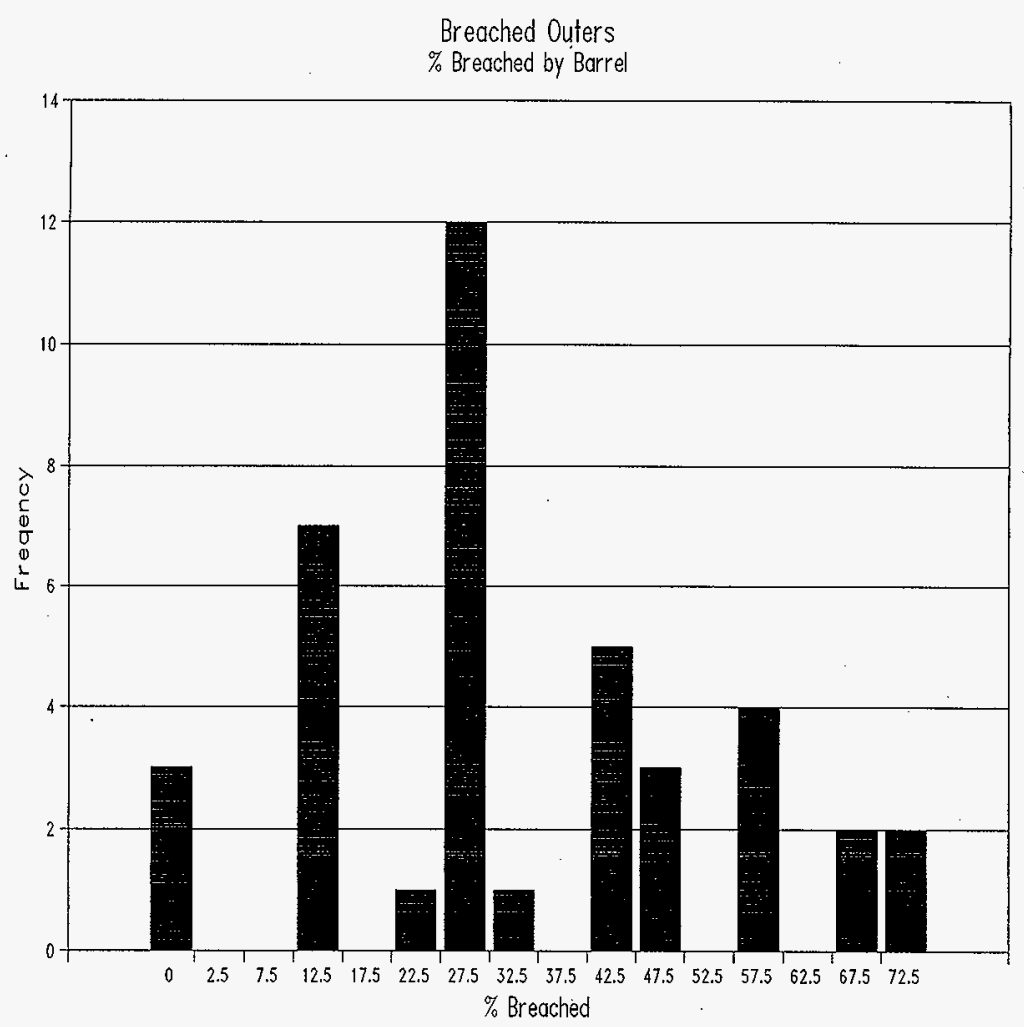


HNF-2314, Rev. 0

Figure 6. Histogram: OUTERS--Percent Bad.

Bad Outers

$\%$ Bad by Barrel

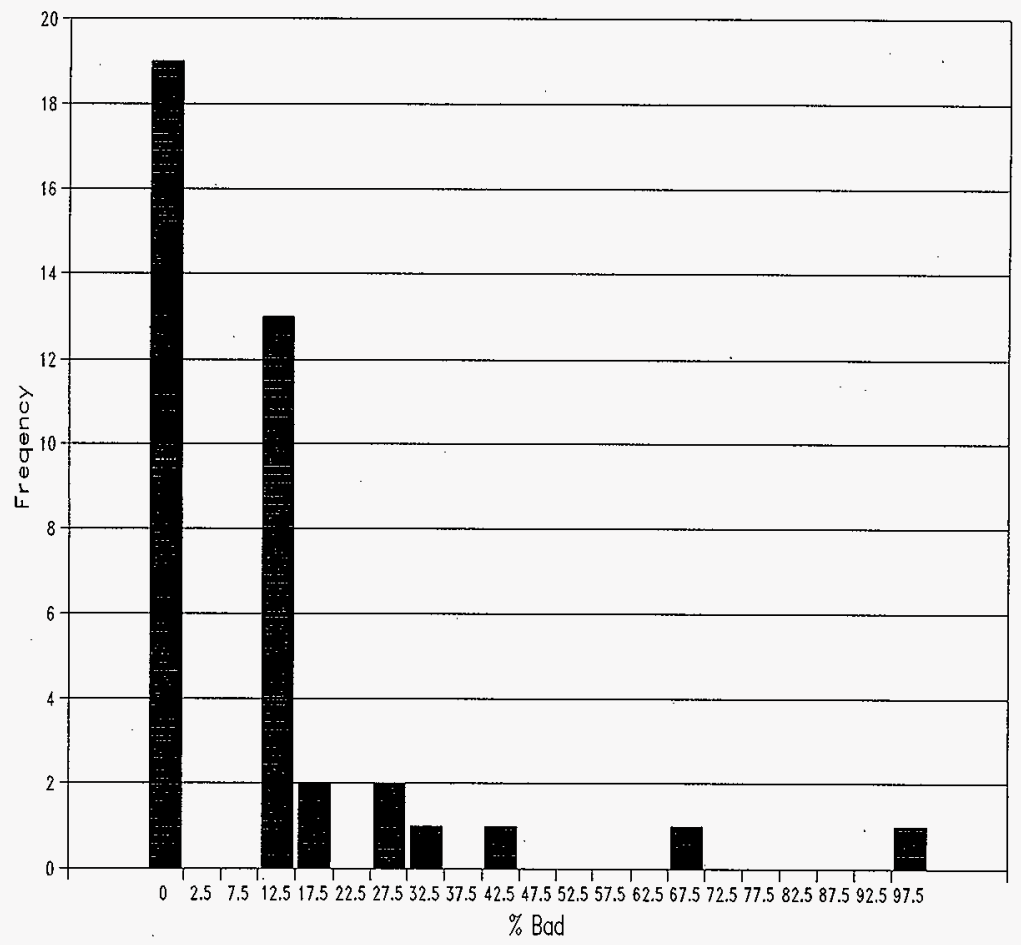


HNF-2314, Rev. 0

Figure 7. Damage Versus Canister Type--INNERS.

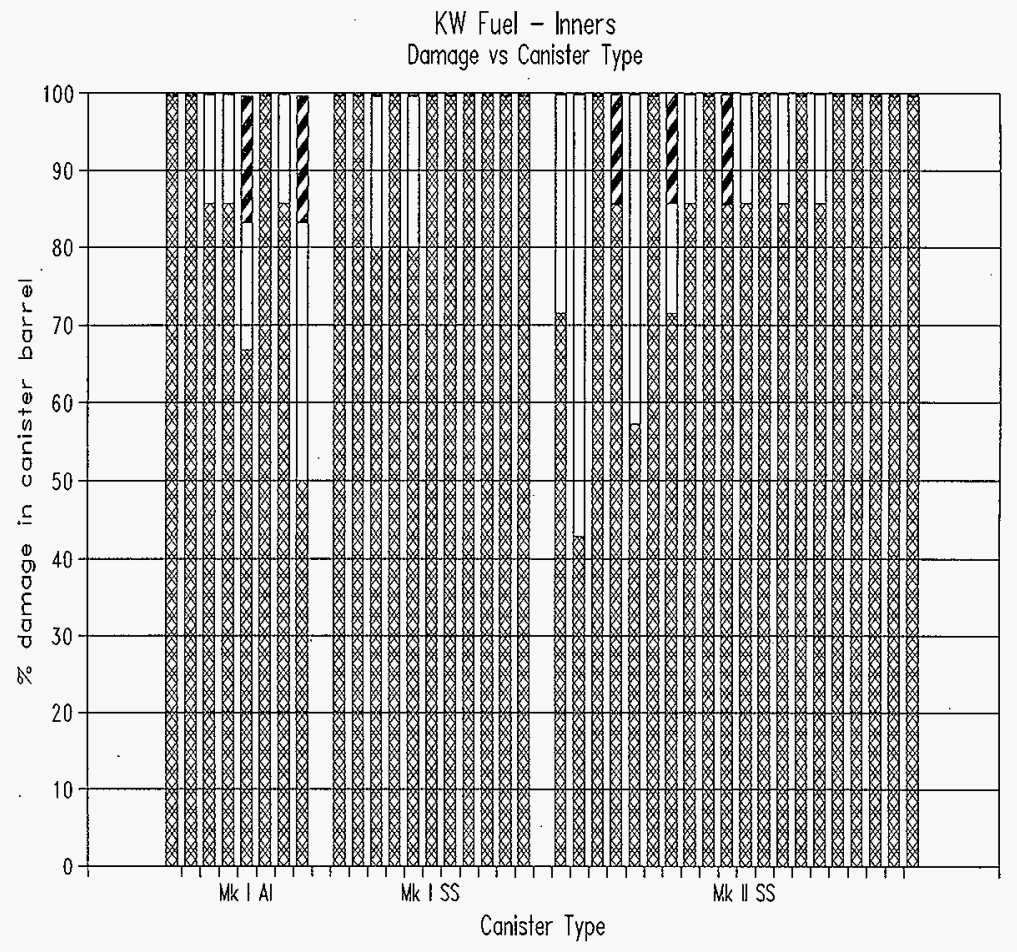

$\square$ Breoched $\mathbf{Z}$ Bad 
HNF-2314, Rev. 0

Figure 8. Damage Versus Fuel Type--INNERS.

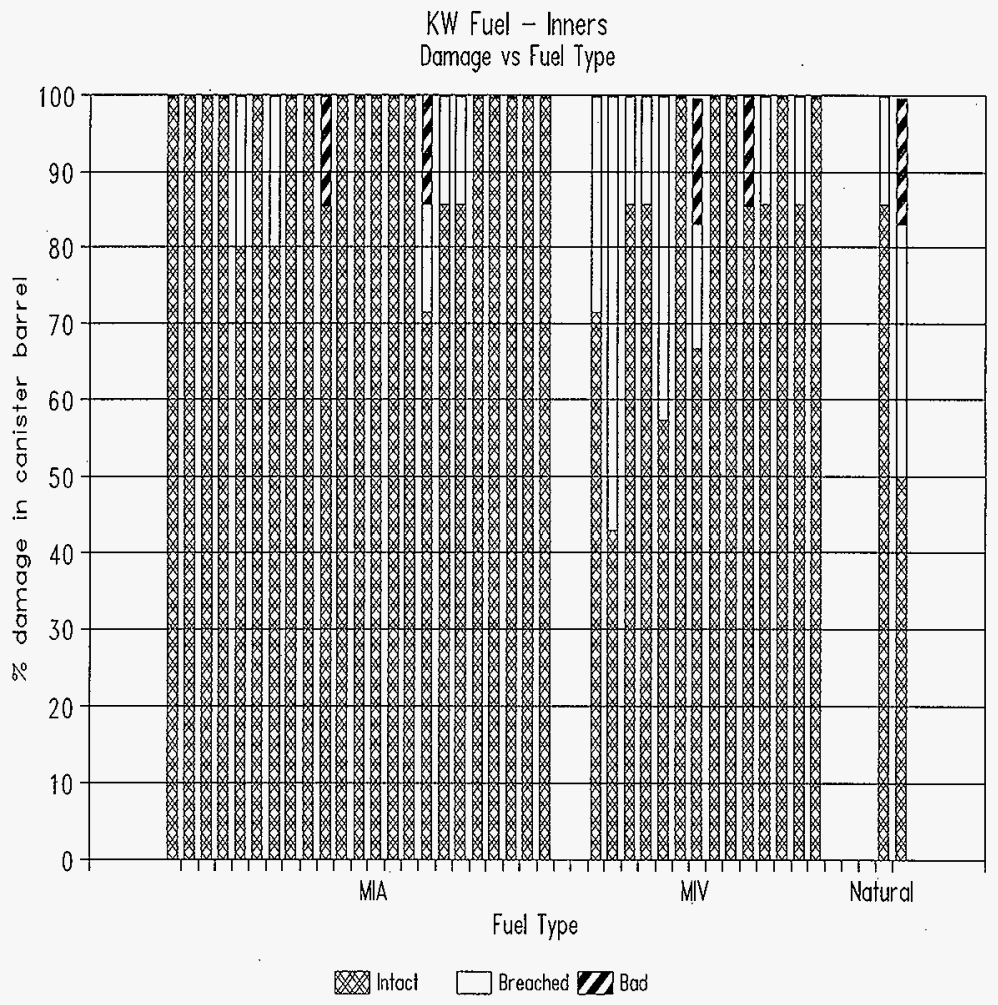


HNF-2314, Rev. 0

Figure 9. Damage Versus Key Date--INNERS.

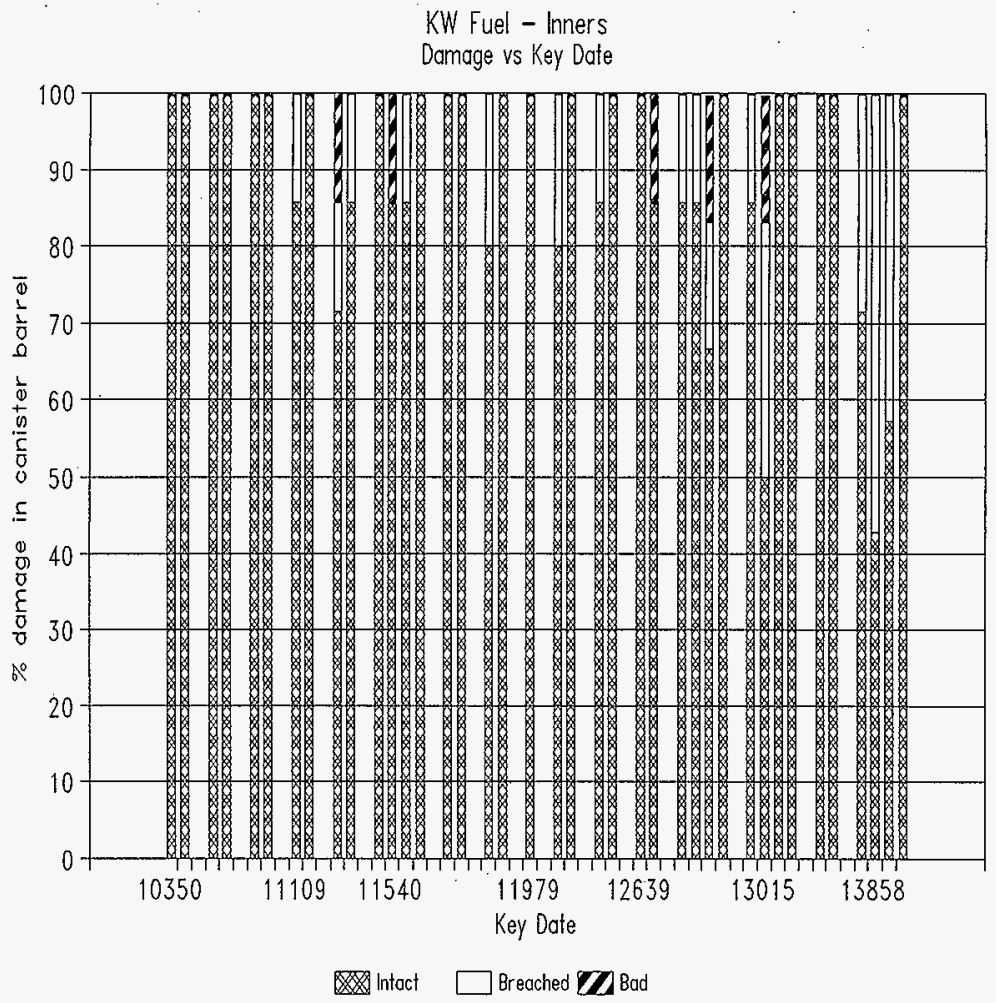


\% damage in canister barrel

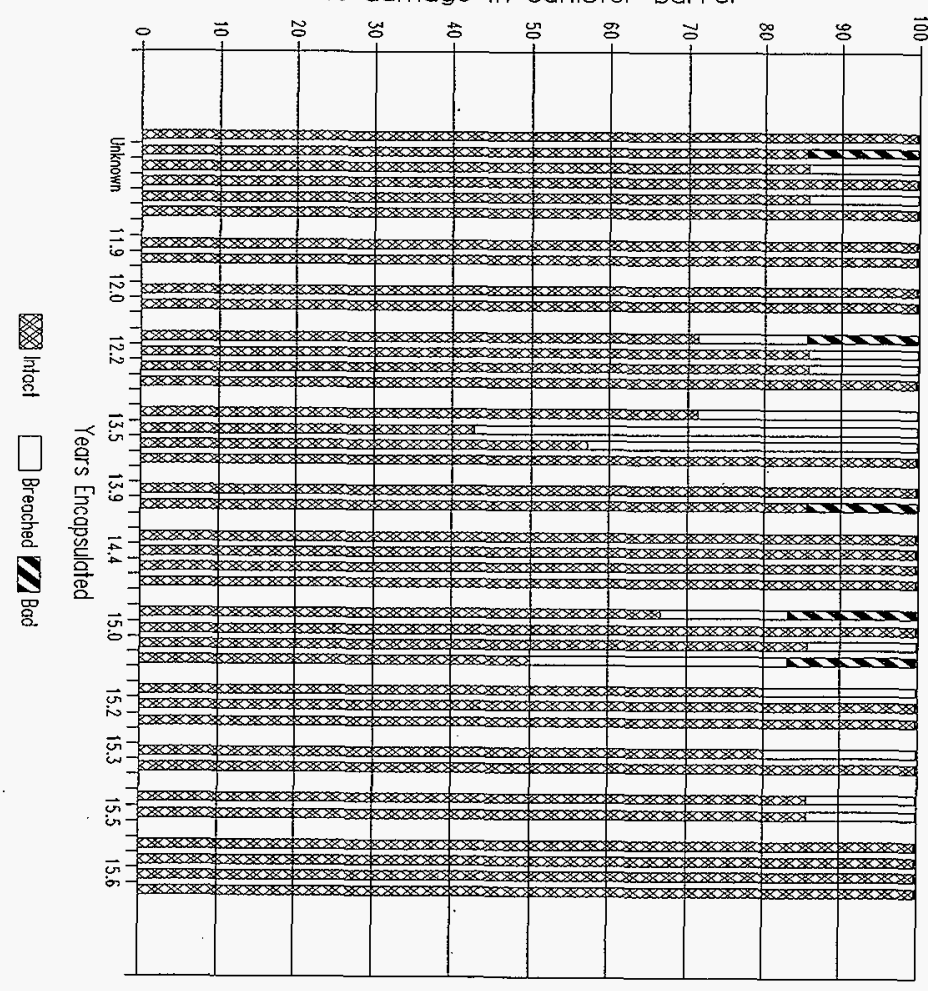


HNF-2314, Rev, 0

Figure 11. Damage Versus Plutonium-240--INNERS.

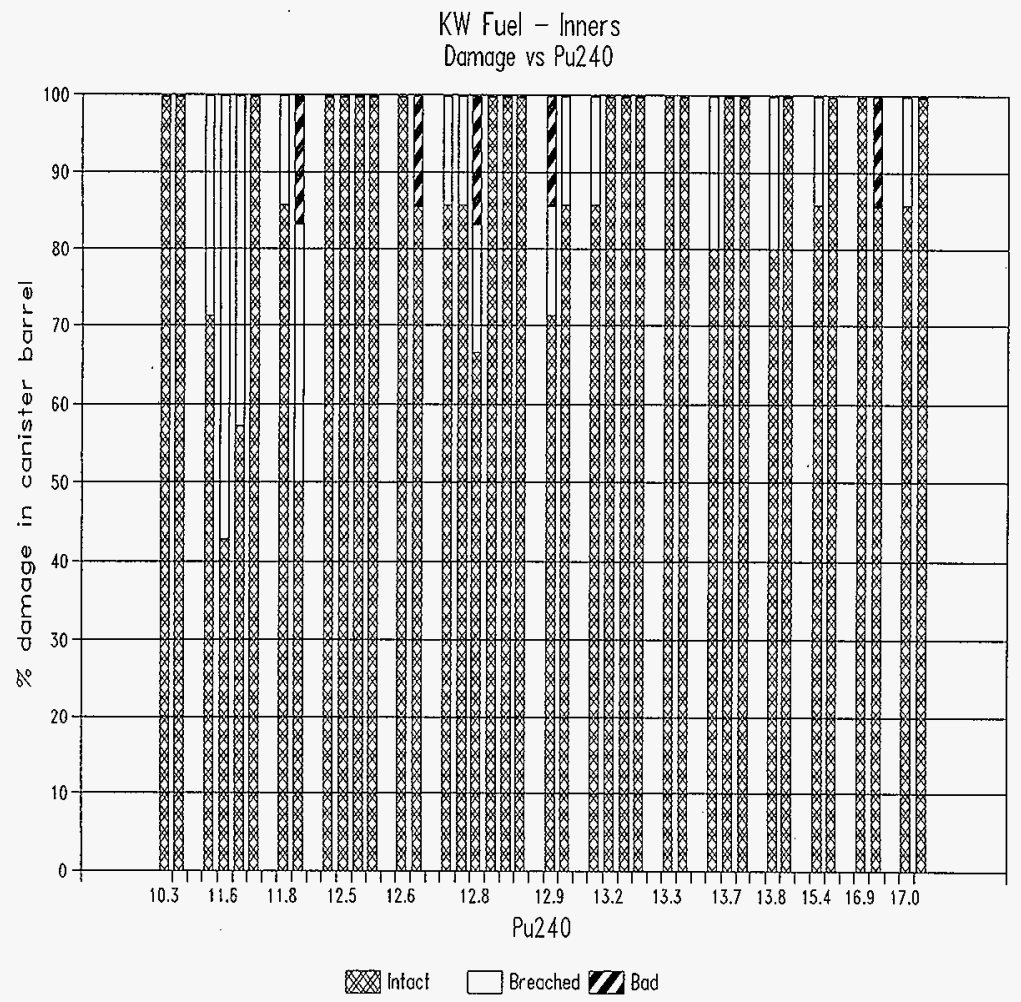


HNF-2314, Rev. 0

Figure 12. INNERS Versus Canister Type.

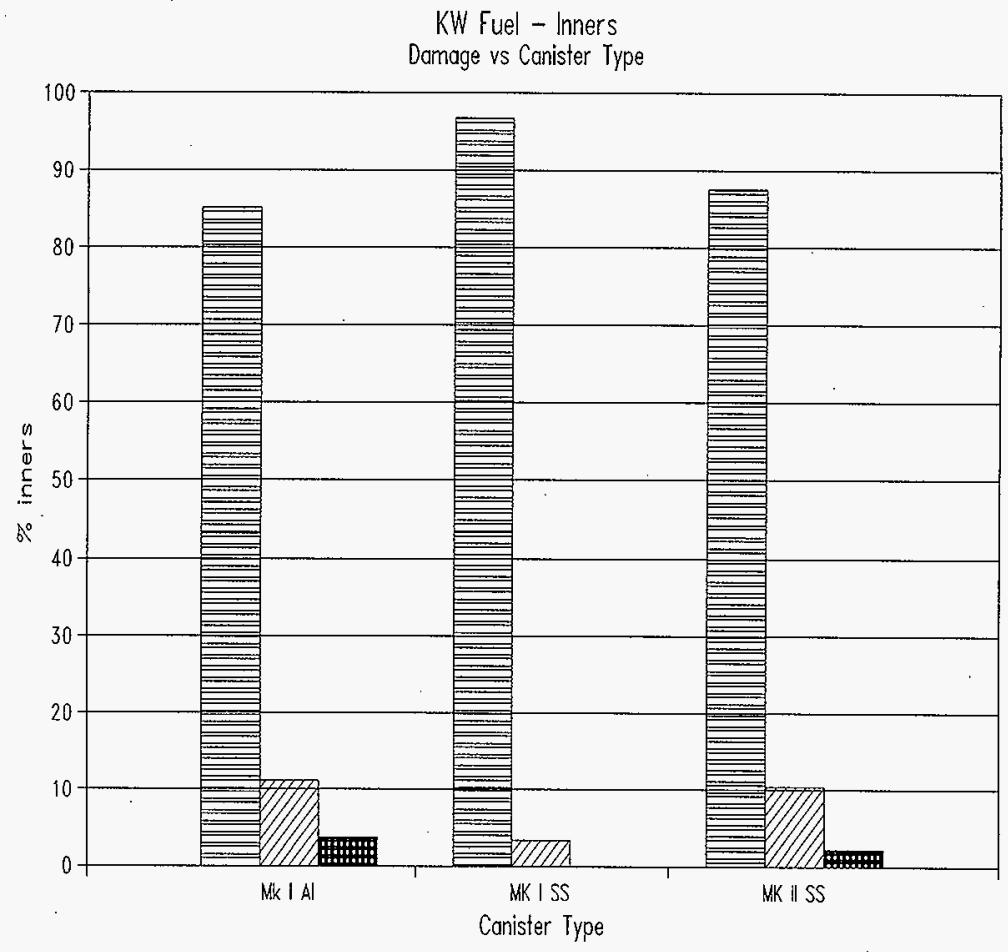

EIntoci $\mathbb{Z}$ Breached Bad 
HNF-2314, Rev. 0

Figure 13. INNERS Versus Fuel Type.

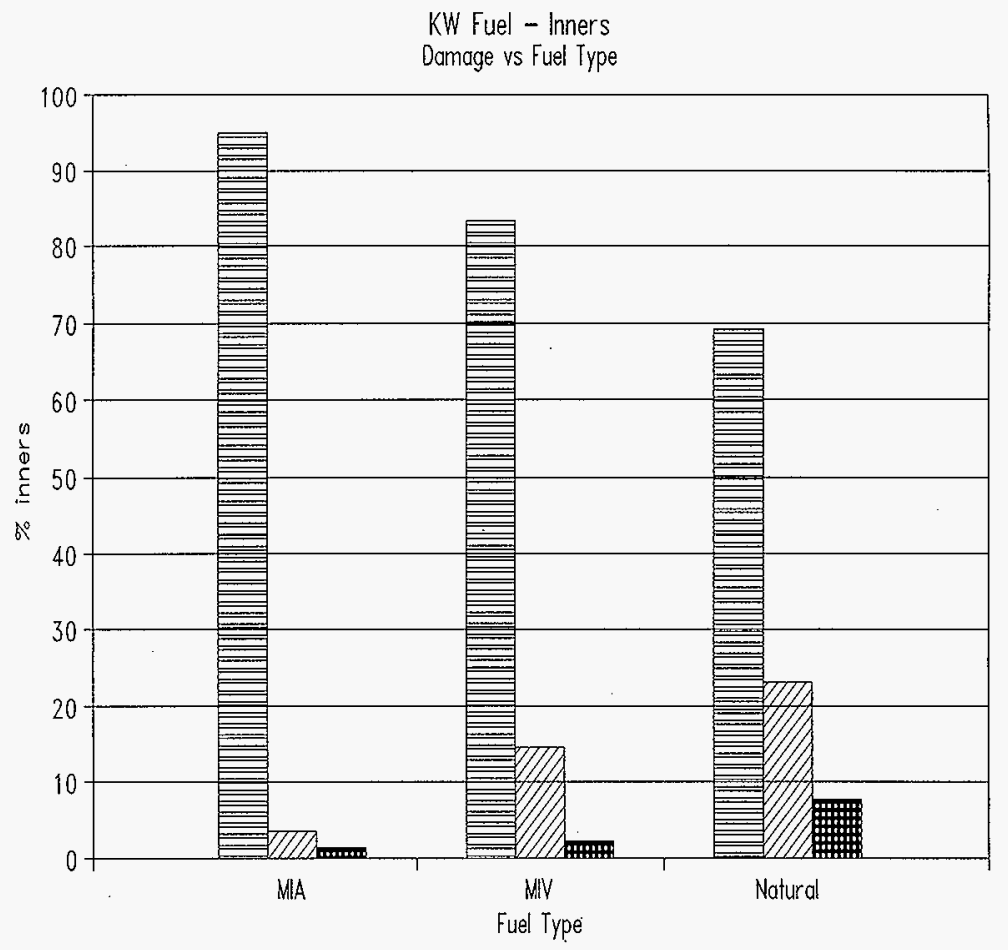

$\exists$ intoct $\overline{Z B D}$ Breched 
HNF-2314, Rev. 0

Figure 14. INNERS Versus Key Date.

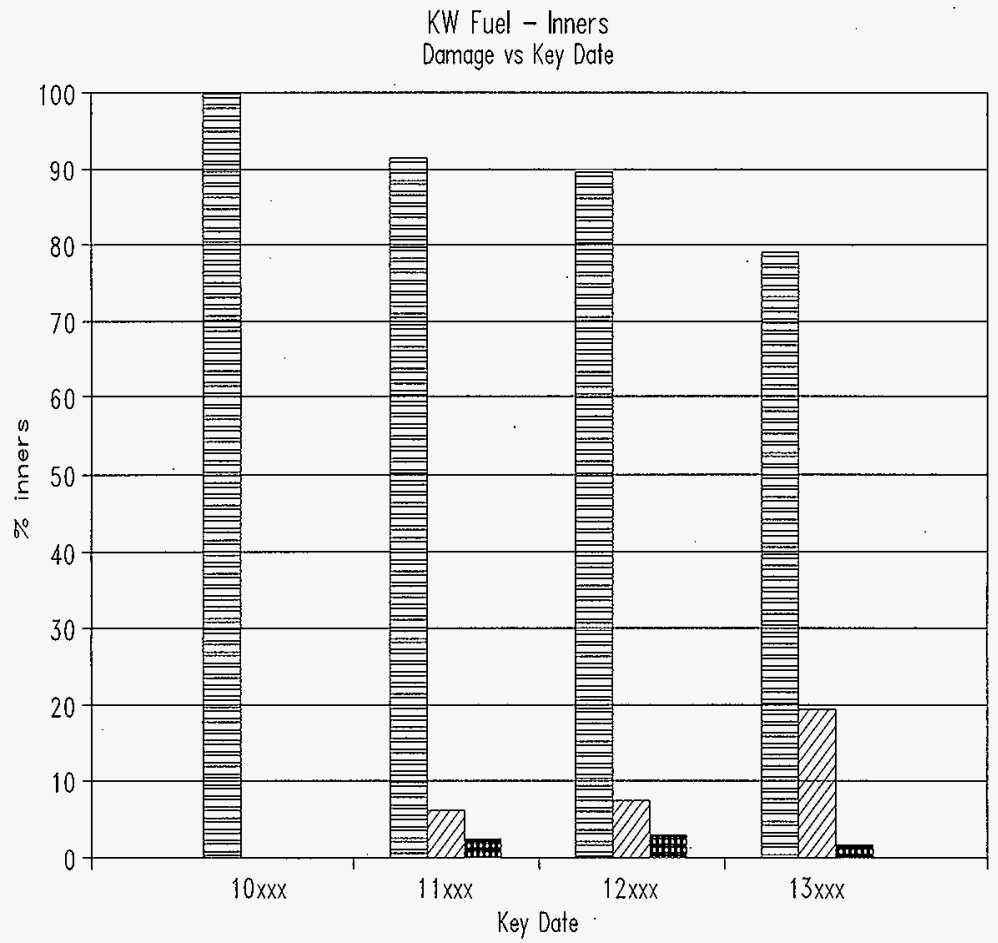

EIntact QZAB Breached Bad 
HNF-2314, Rev. 0

Figure 15. INNERS Versus Years Encapsulated.

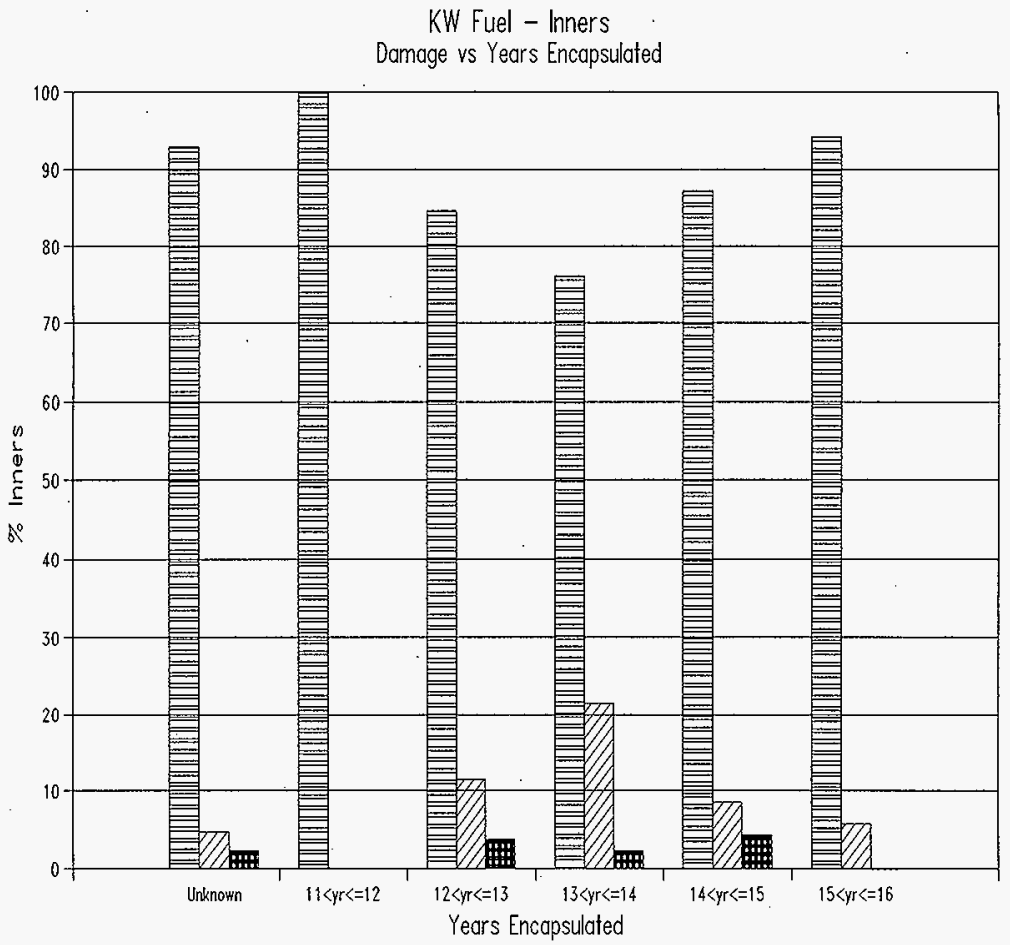

DIntoct 
HNF-2314, Rev. 0

Figure 16. INNERS Versus Plutonium-240.

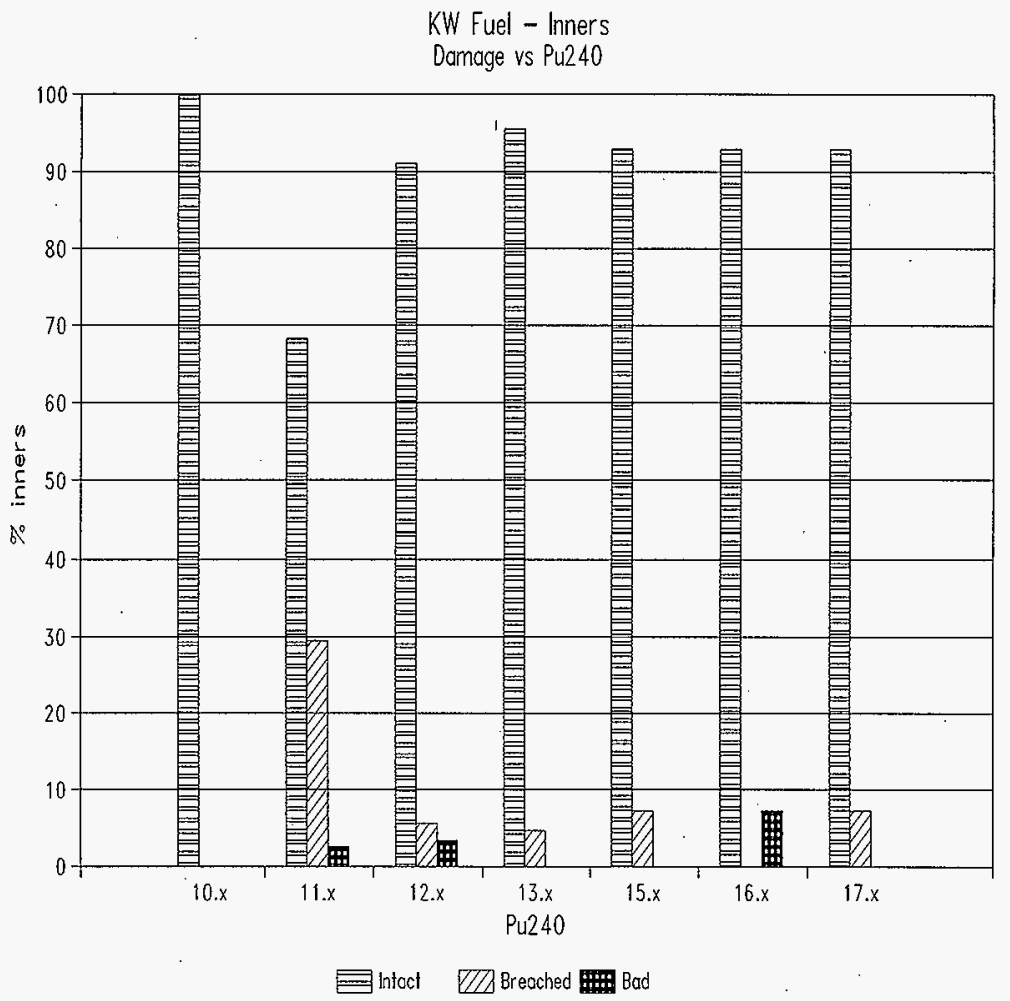


\% damage in canister barrel

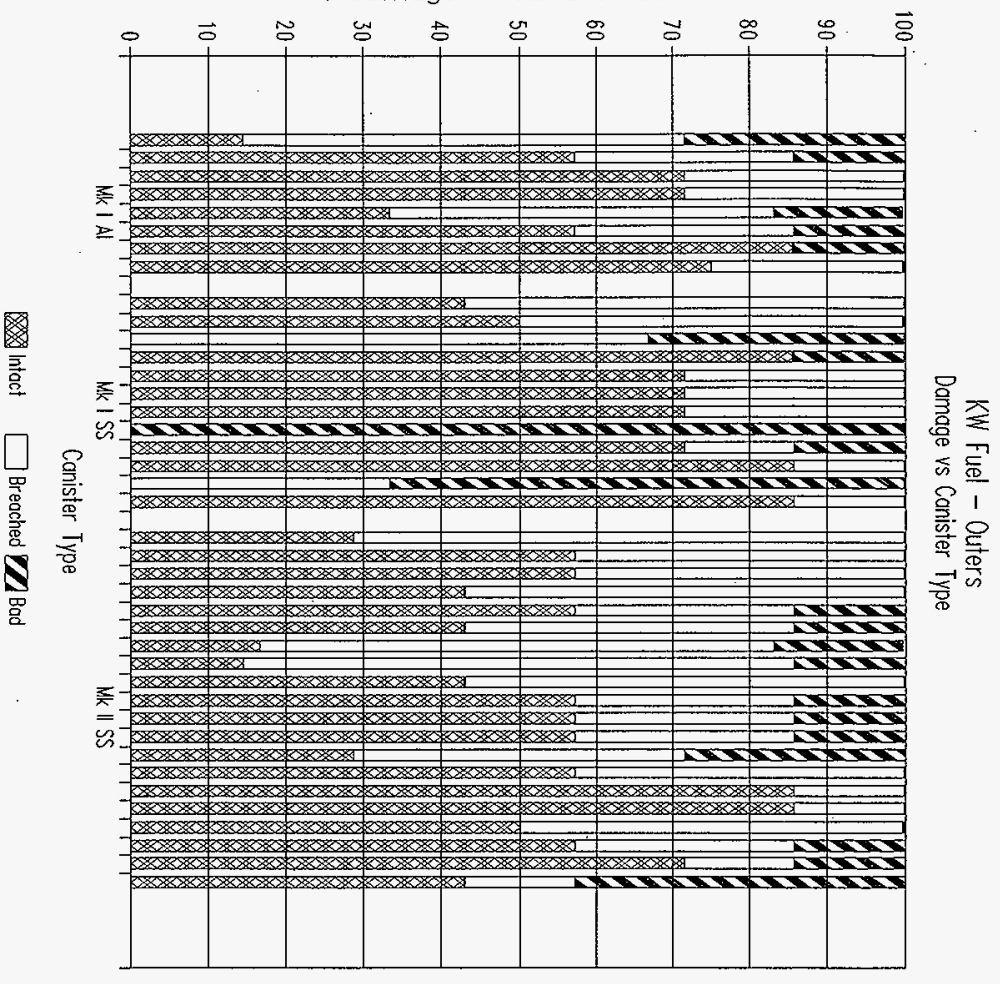


HNF-2314, Rev. 0

Figure 18. Damage Versus Fuet Type--OUTERS.

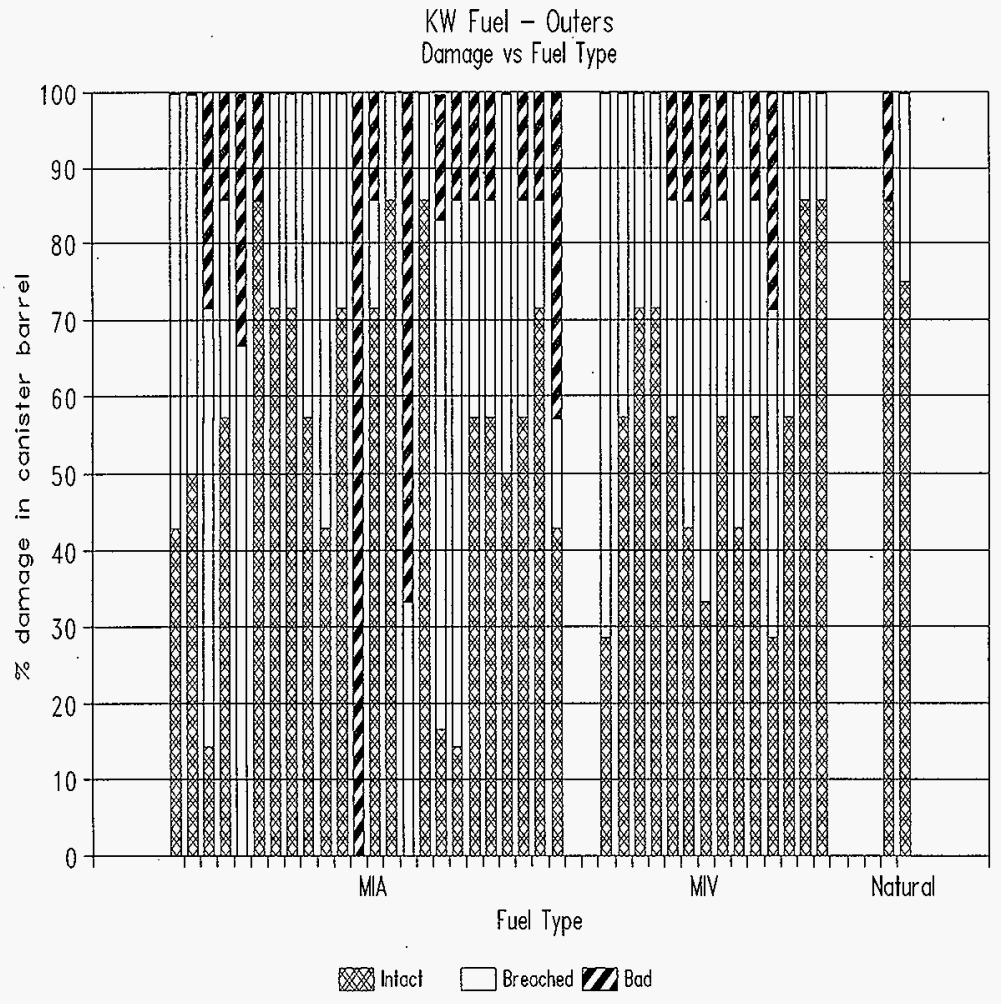


HNF-2314, Rev. 0

Figure 19. Damage Versus Key Date--OUTERS.

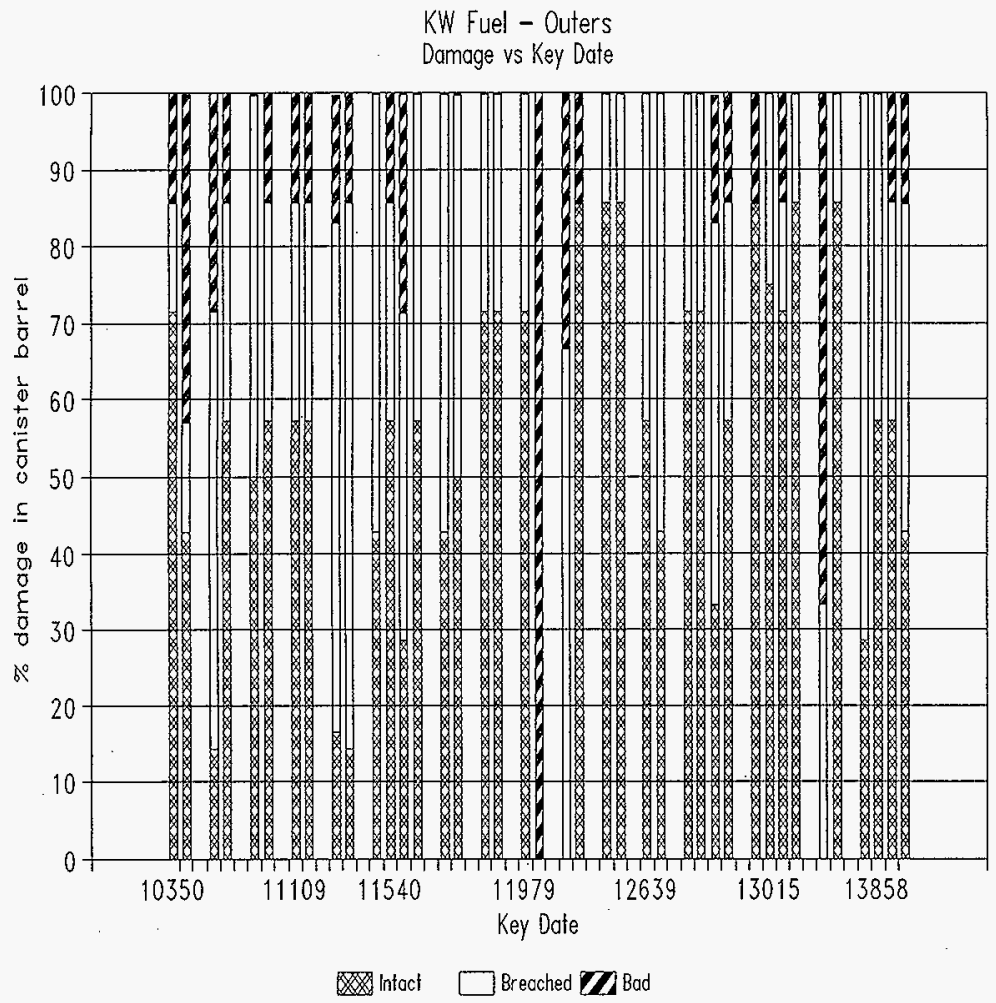


HNF-2314, Rev. 0

Figure 20. Damage Versus Years Encapsulated--OUTERS.

KW Fuel - Outers

Damage vs Years Encapsulated

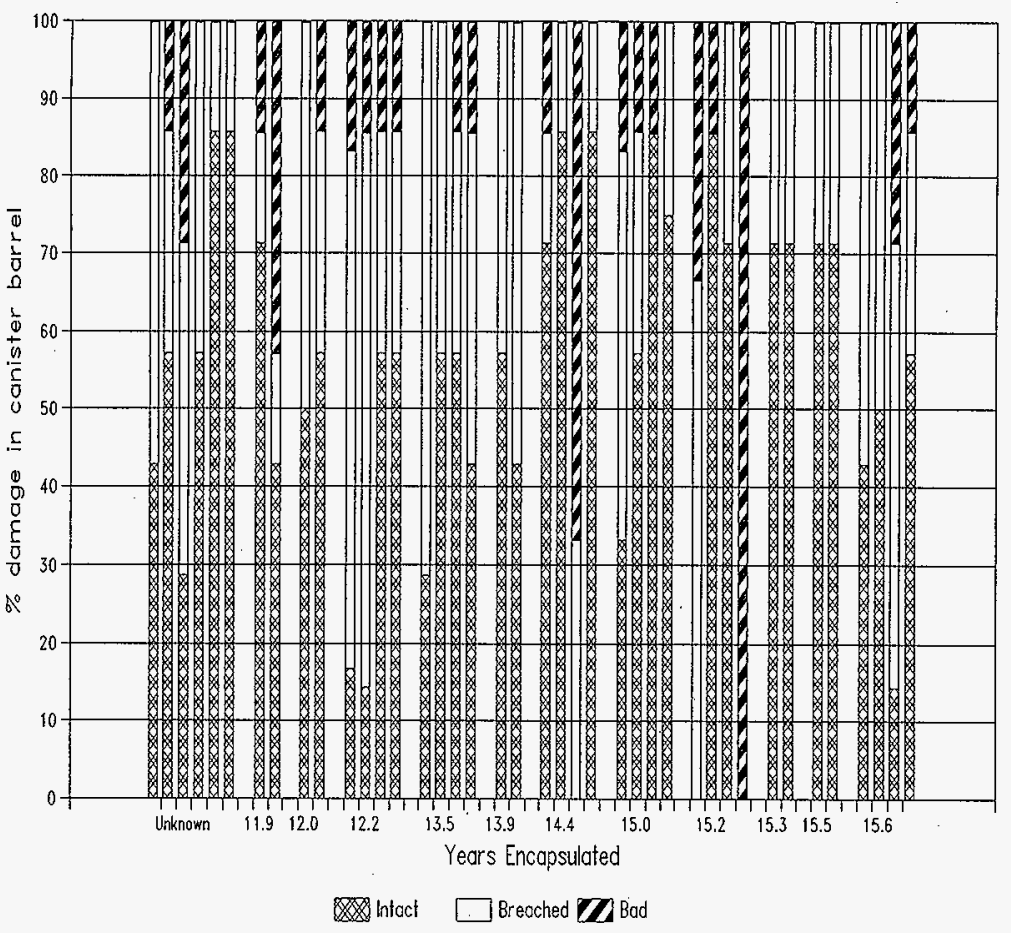


HNF-2314, Rev. 0

Figure 21. Damage Versus Plutonium-240--0UTERS.

KW Fuel - Outers

Damage vs Pu240

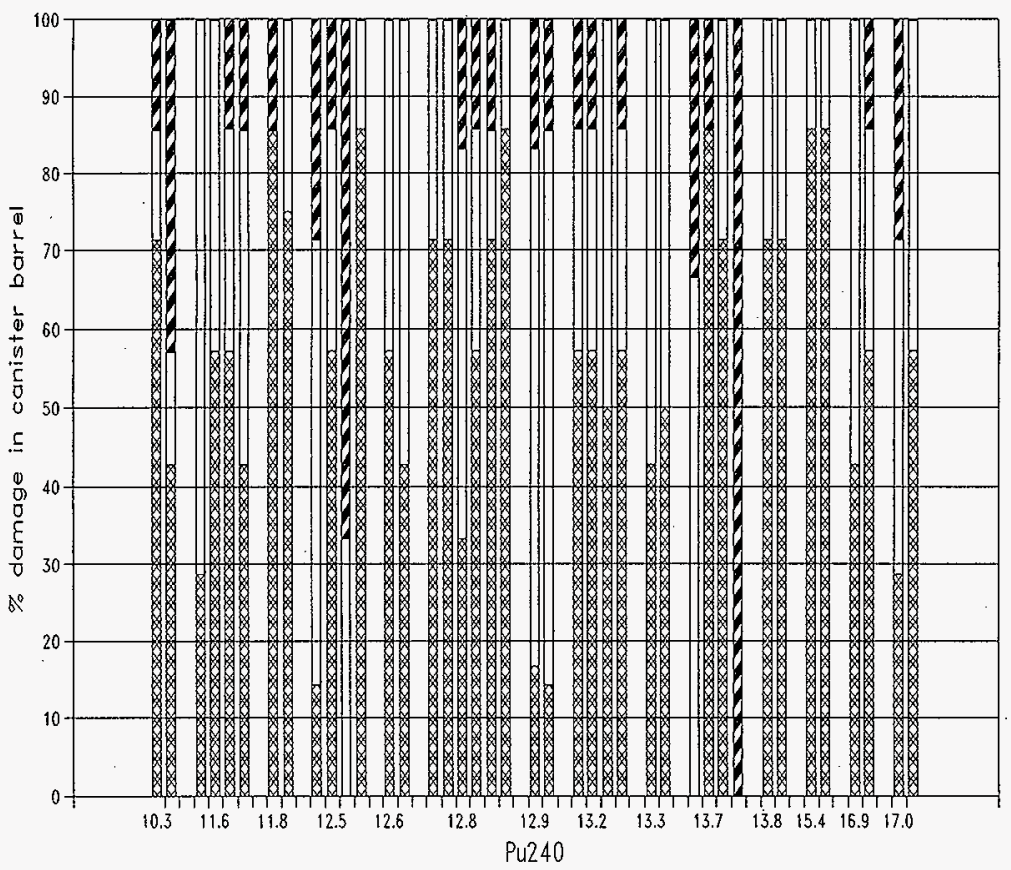

Intact $\square$ Brecched $\boldsymbol{Z}$ Bad 
HNF-2314, Rev. 0

Figure 22. OUTERS Versus Canister Type.

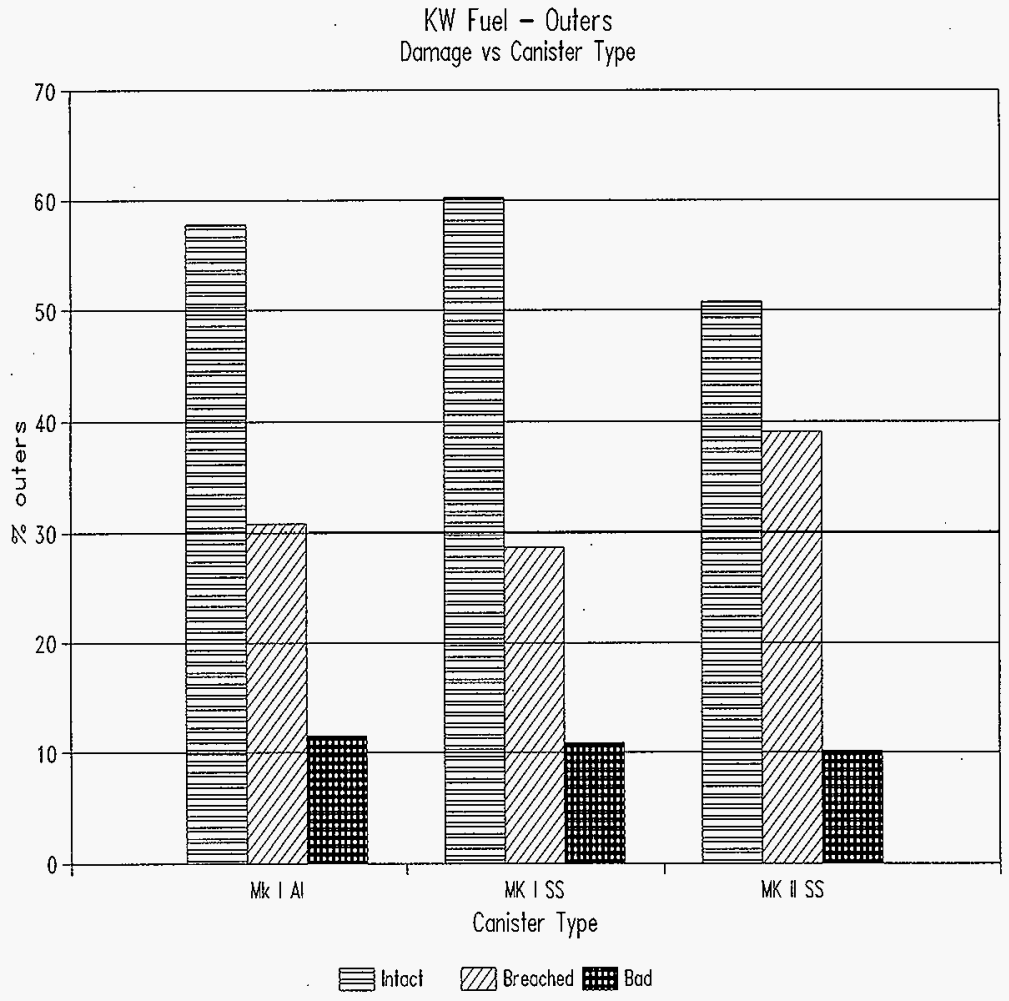


HNF-2314, Rev. 0

Figure 23. OUTERS Versus Fue] Type.

KW Fuel - Outers

Damage vs Fuel Type

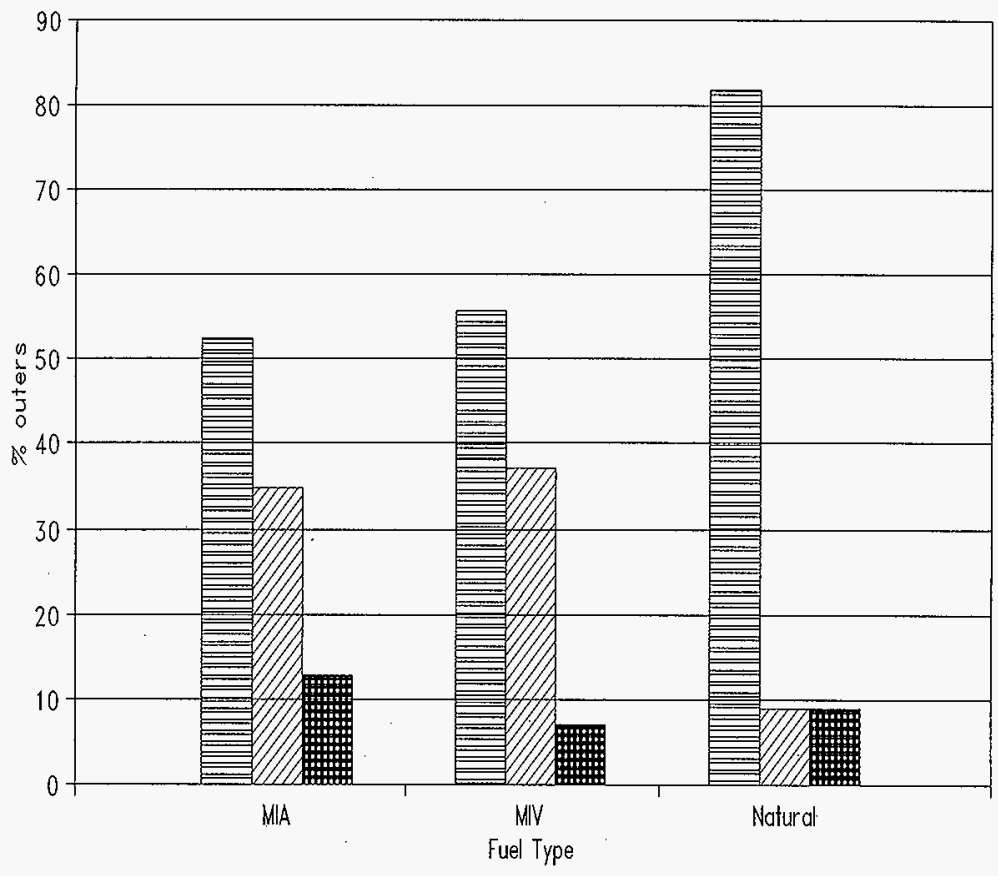

Intact Bas Breached 8ad 
HNF-2314, Rev. 0

Figure 24. OUTERS Versus Key Date.

KW Fuel - Outers

Damage vs Key Date

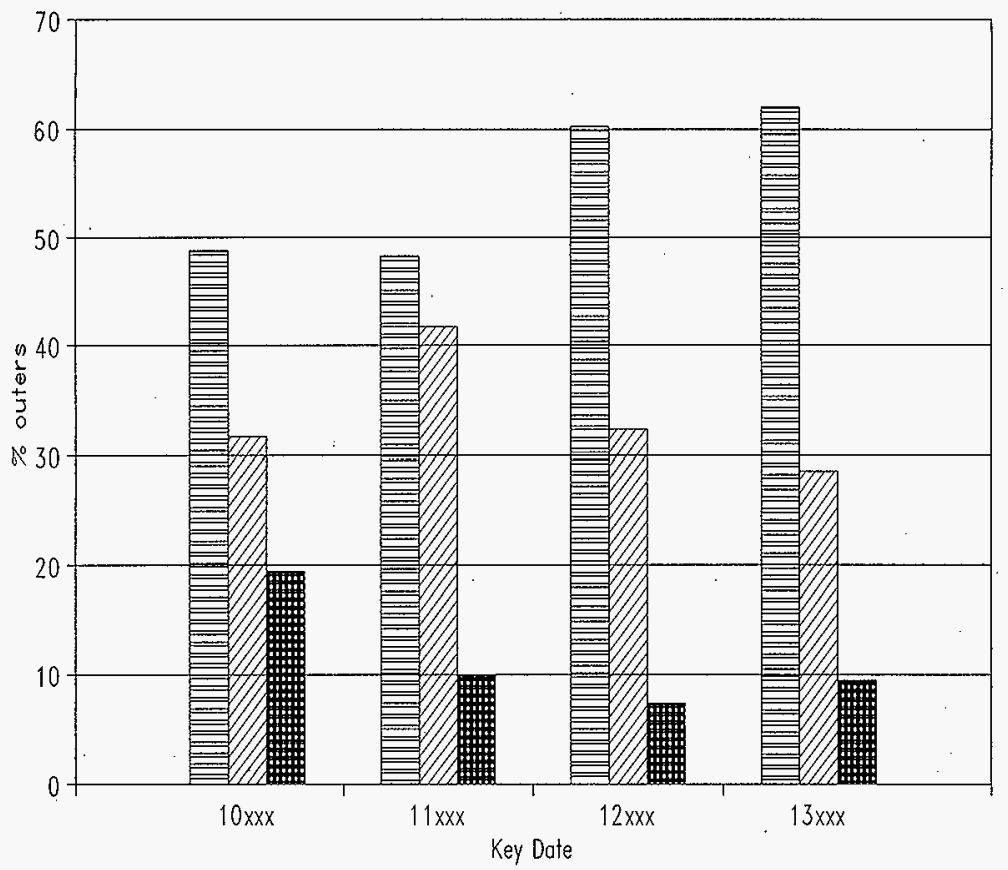

EIntact $\square$ Bas Breached Bad 
HNF-2314, Rev. 0

Figure 25. OUTERS Versus Years Encapsulated.

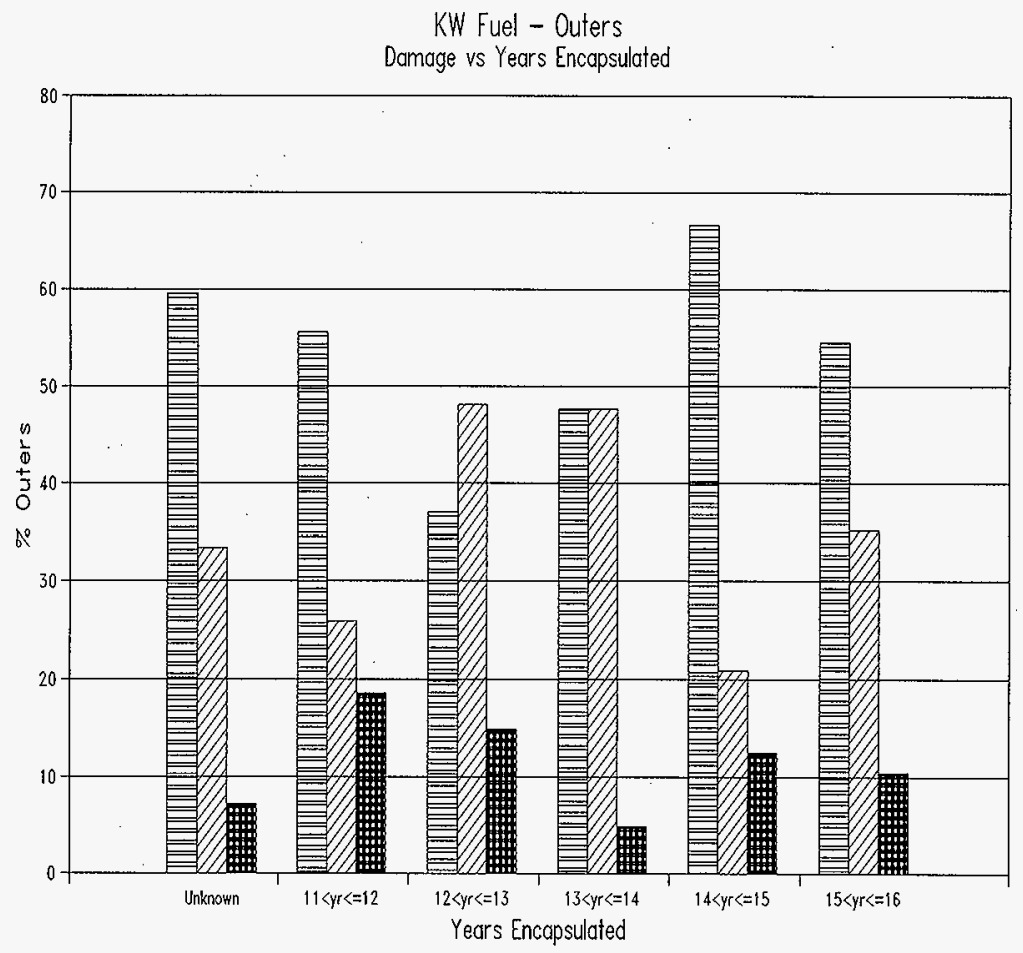

Intact एZI Breached Bad 
HNF-2314, Rev. 0

Figure 26. OUTERS Versus PIutonium-240.

KW Fuel - Outers

Damage vs Pu240

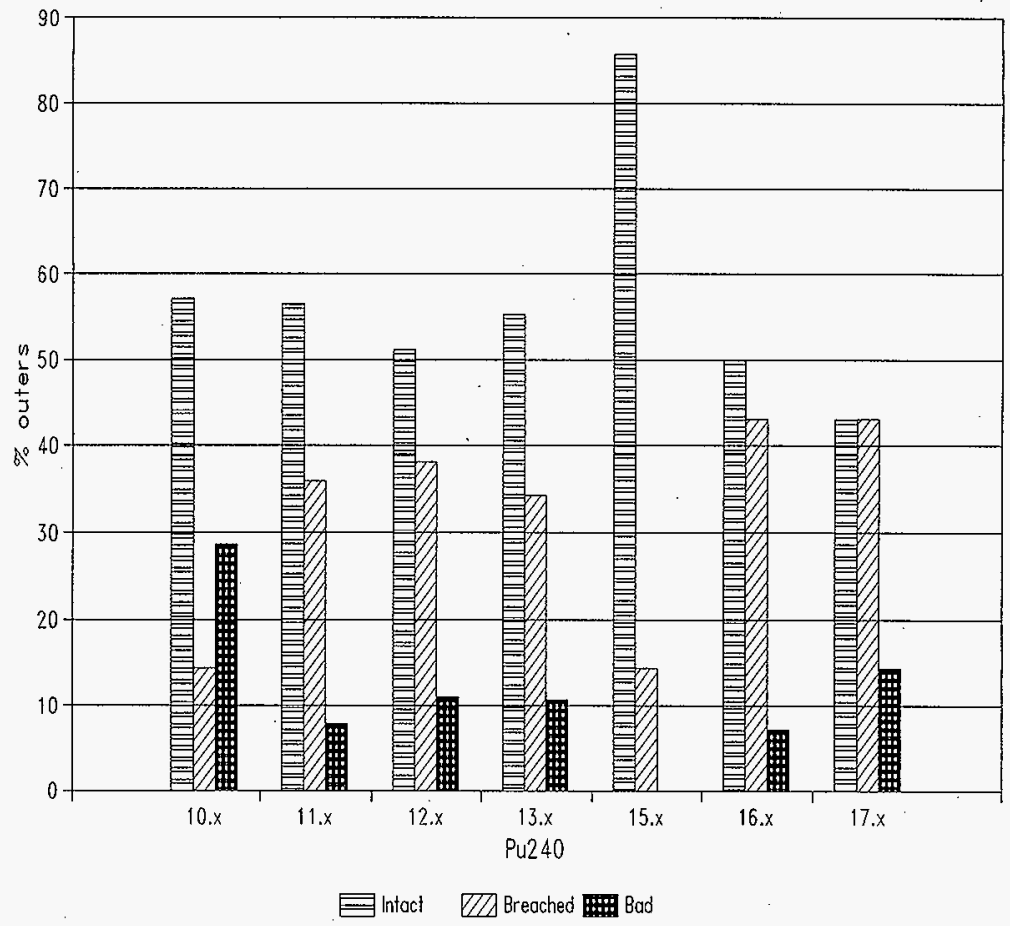


HNF-2314, Rev. 0

Figure 27. INNERS-Intact Versus OUTERS-Intact. $\mathrm{KW}$ fuel

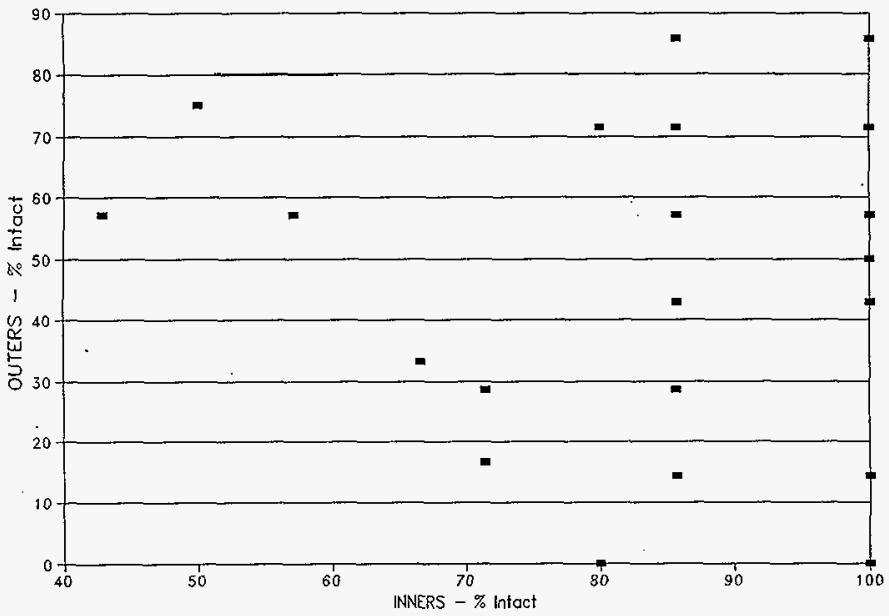

Figure 28. INNERS-Intact Versus OUTERS-Breached.

$\mathrm{KW}$ fuel

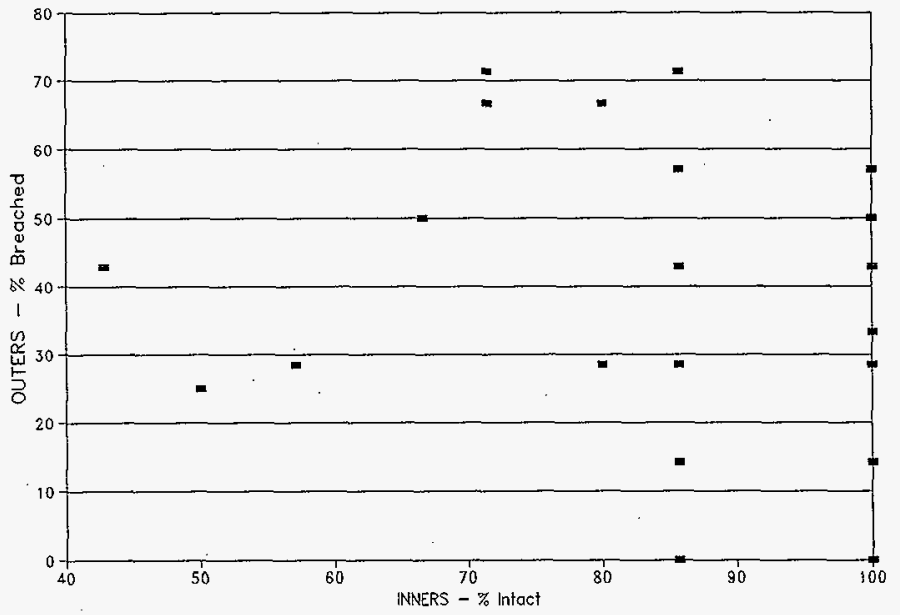


HNF-2314, Rev. 0

Figure 29. INNERS-Intact Versus OUTERS-Bad.

$\mathrm{KW}$ fuel

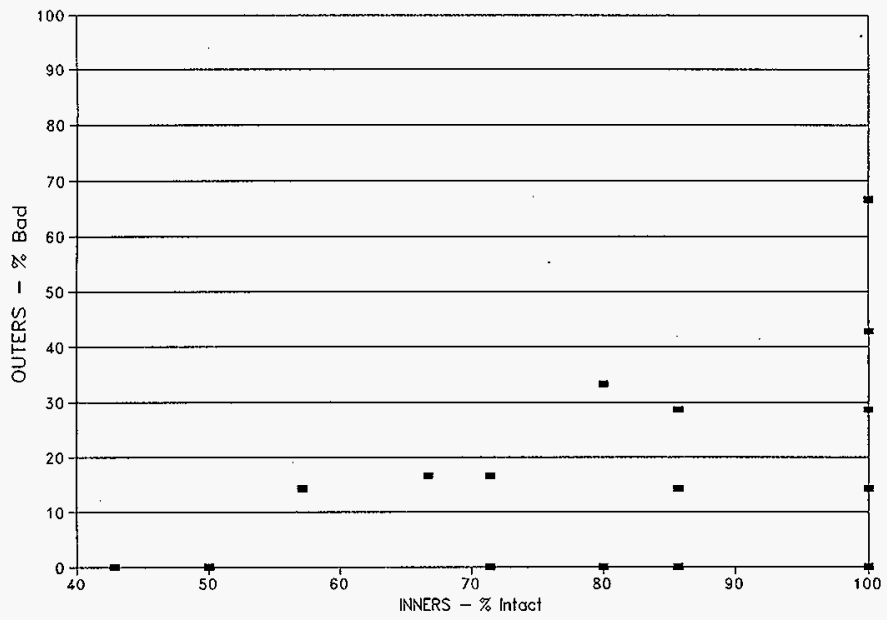

Figure 30. INNERS-Breached Versus OUTERS-Intact.

KW fuel

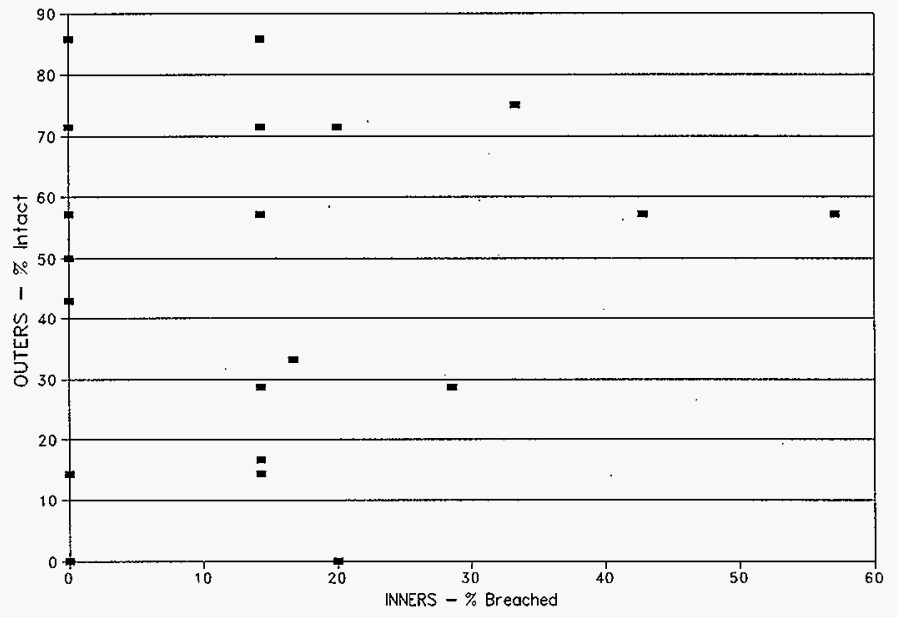


HNF-2314, Rev. 0

Figure 31. INNERS-Breached Versus OUTERS-Breached. KW fuel

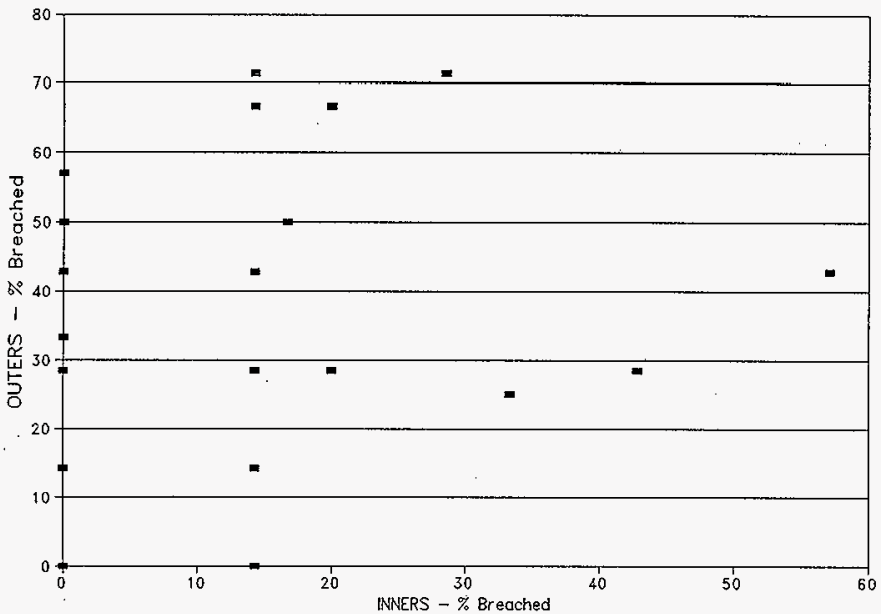

Figure 32. INNERS-Breached Versus OUTERS-Bad.

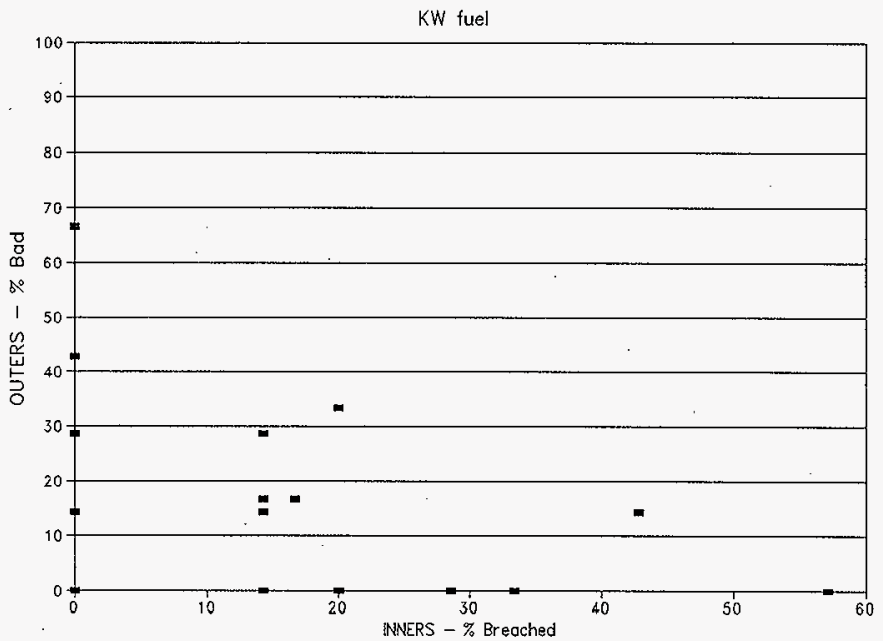


HNF-2314, Rev. 0

Figure 33. INNERS-Bad Versus OUTERS-Intact. KW fuel

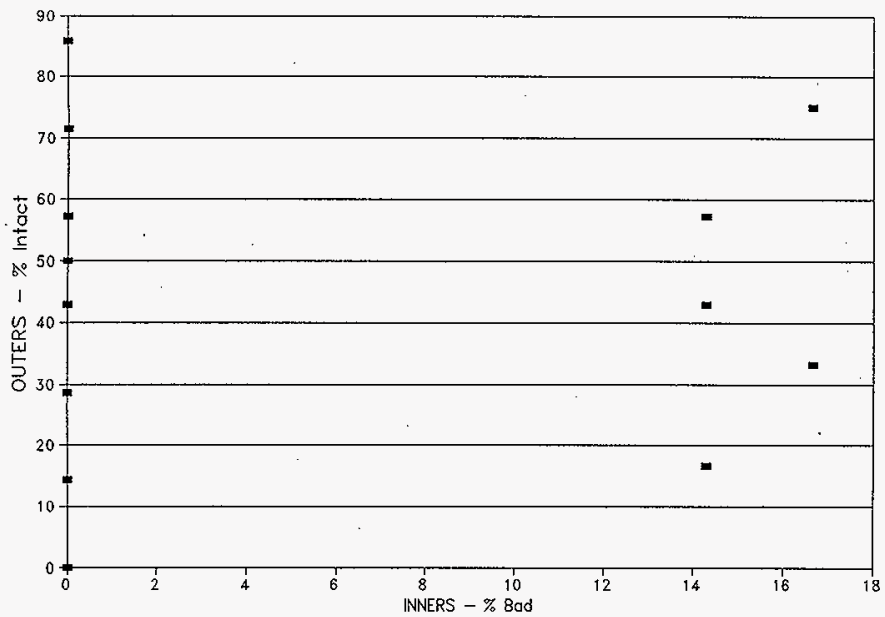

Figure 34. INNERS-Bad Versus OUTERS-Breached.

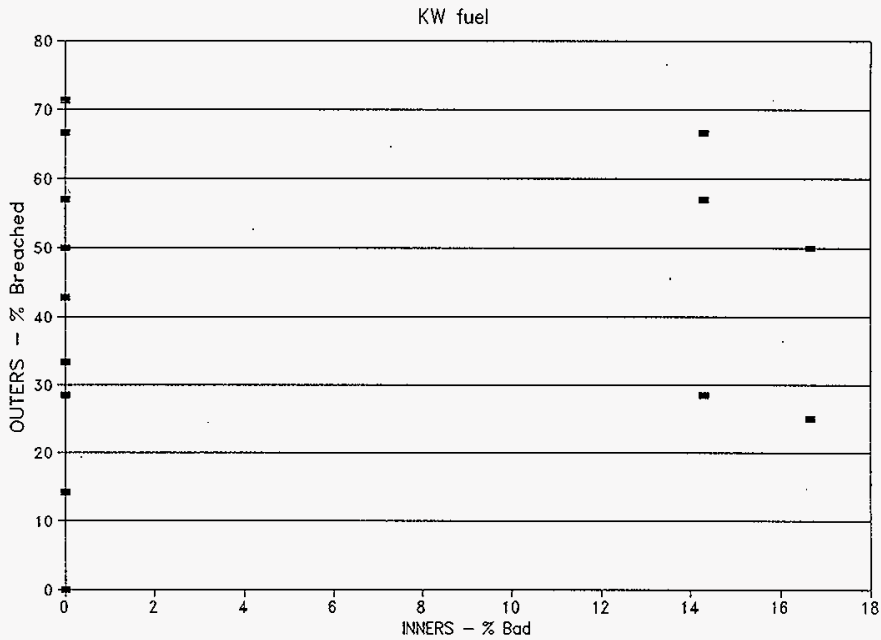


HNF-2314, Rev. 0

Figure 35. INNERS-Bad Versus OUTERS-Bad.

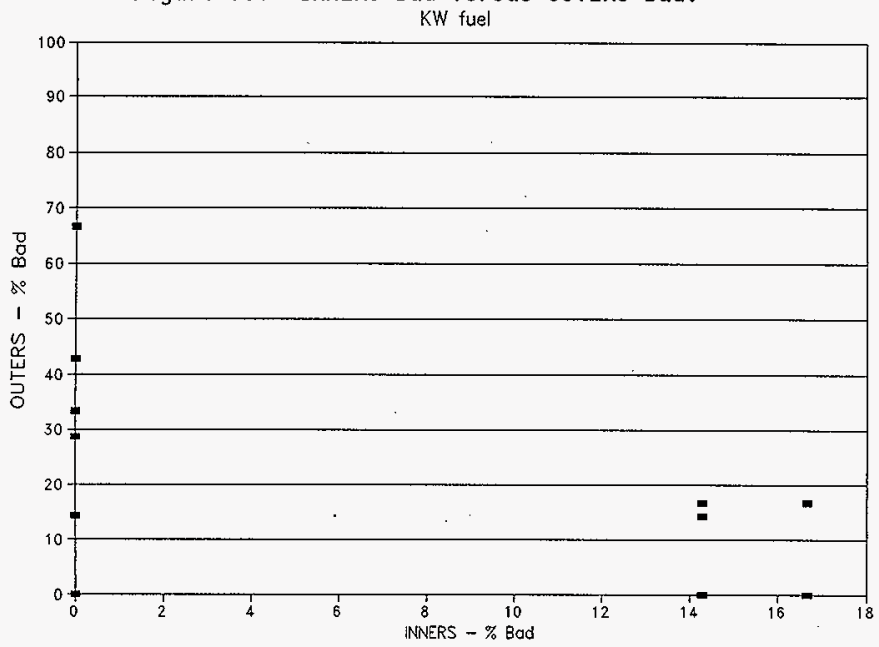


HNF-2314, Rev. 0

Figure 36. Sludge Code Versus INNERS-Percent Damage.

KW Fuel

Damage vs Sludge Quantity

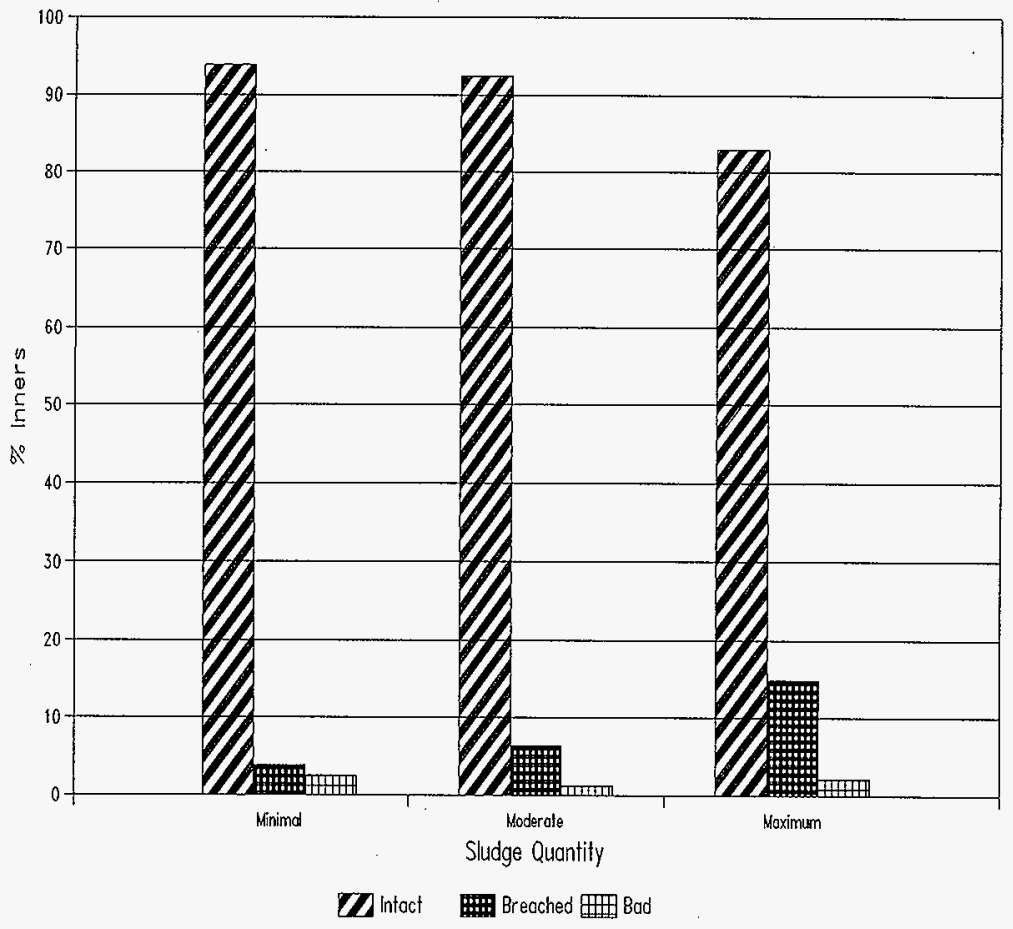


HNF-2314, Rev. 0

Figure 37. Cesium-137 Versus OUTERS-Percent Damage.

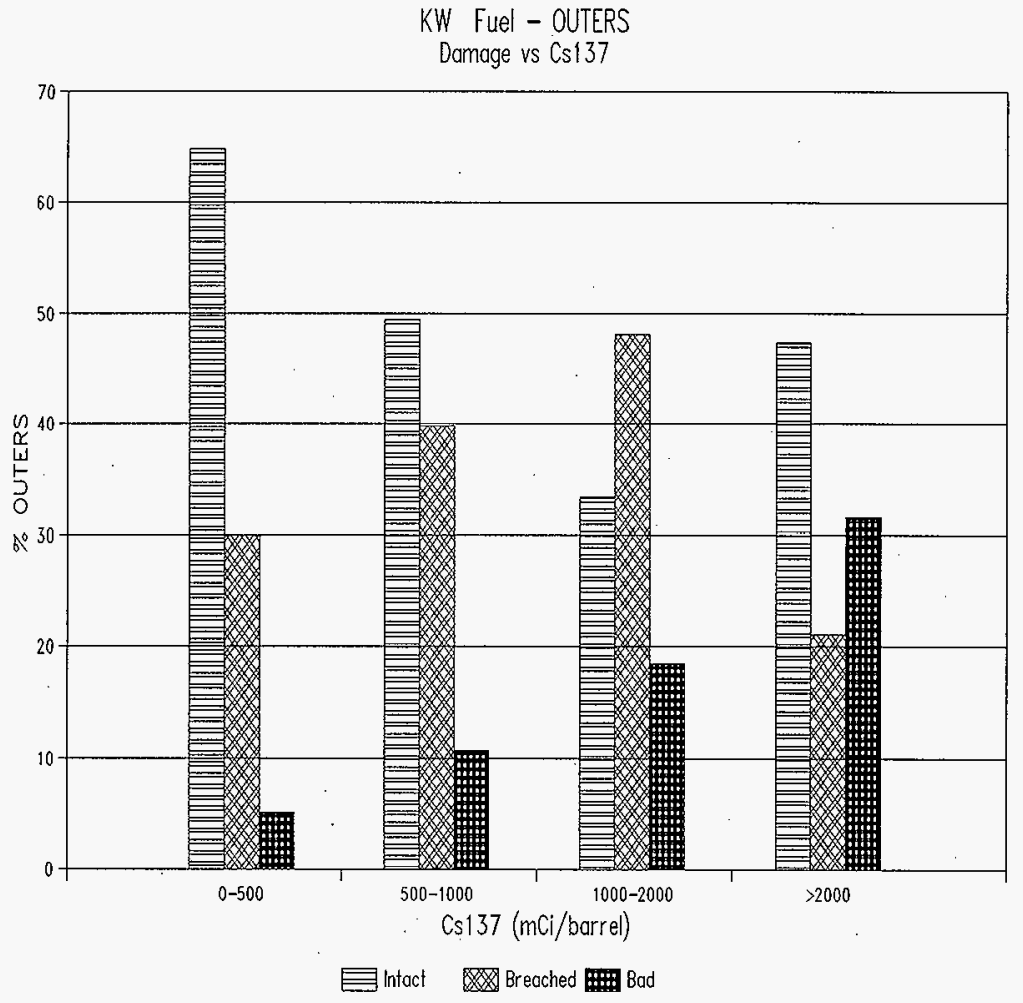


HNF-2314, Rev. 0

Figure 38. Sludge Code Versus OUTERS-Percent Damage.

KW Fuel

Damage vs Sludge Quantity

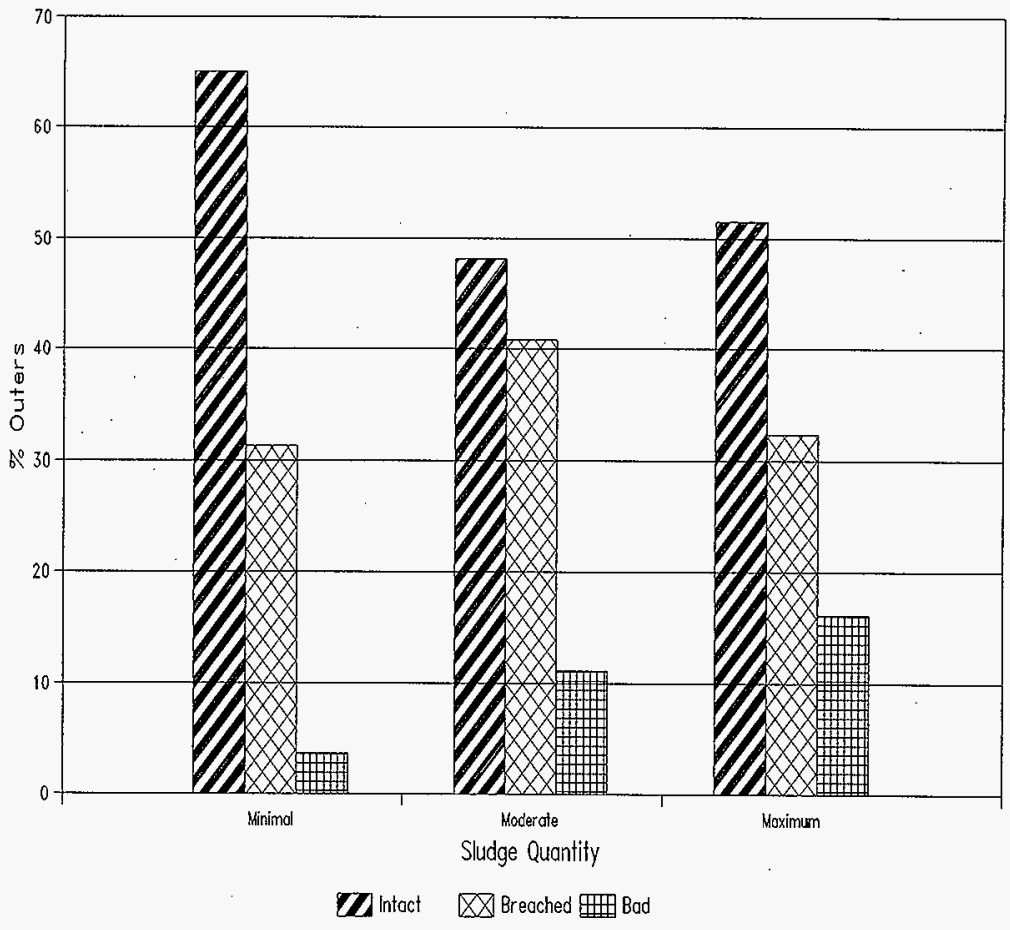


HNF-2314, Rev. 0

Figure 39. Canister Type Versus Years Since Encapsulated.

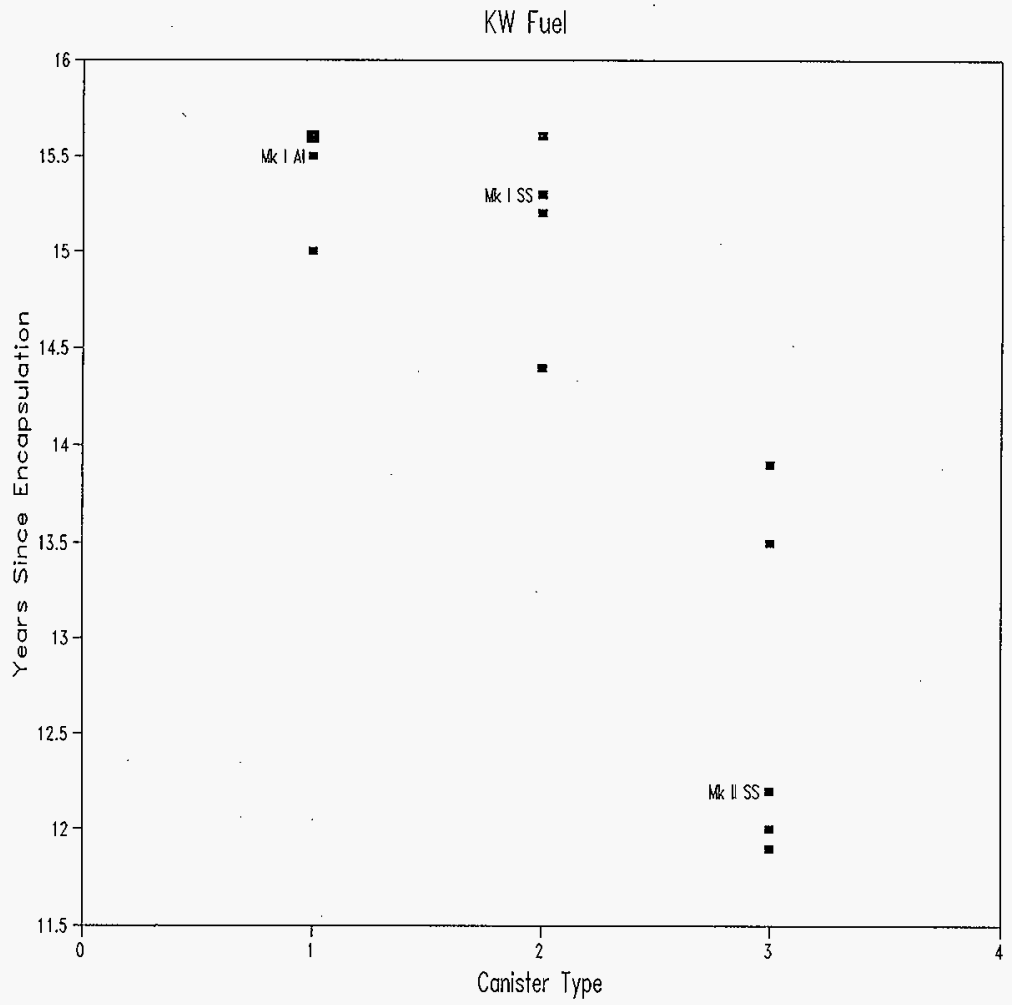


HNF-2314, Rev. 0

Figure 40. Canister Type Versus Potassium.

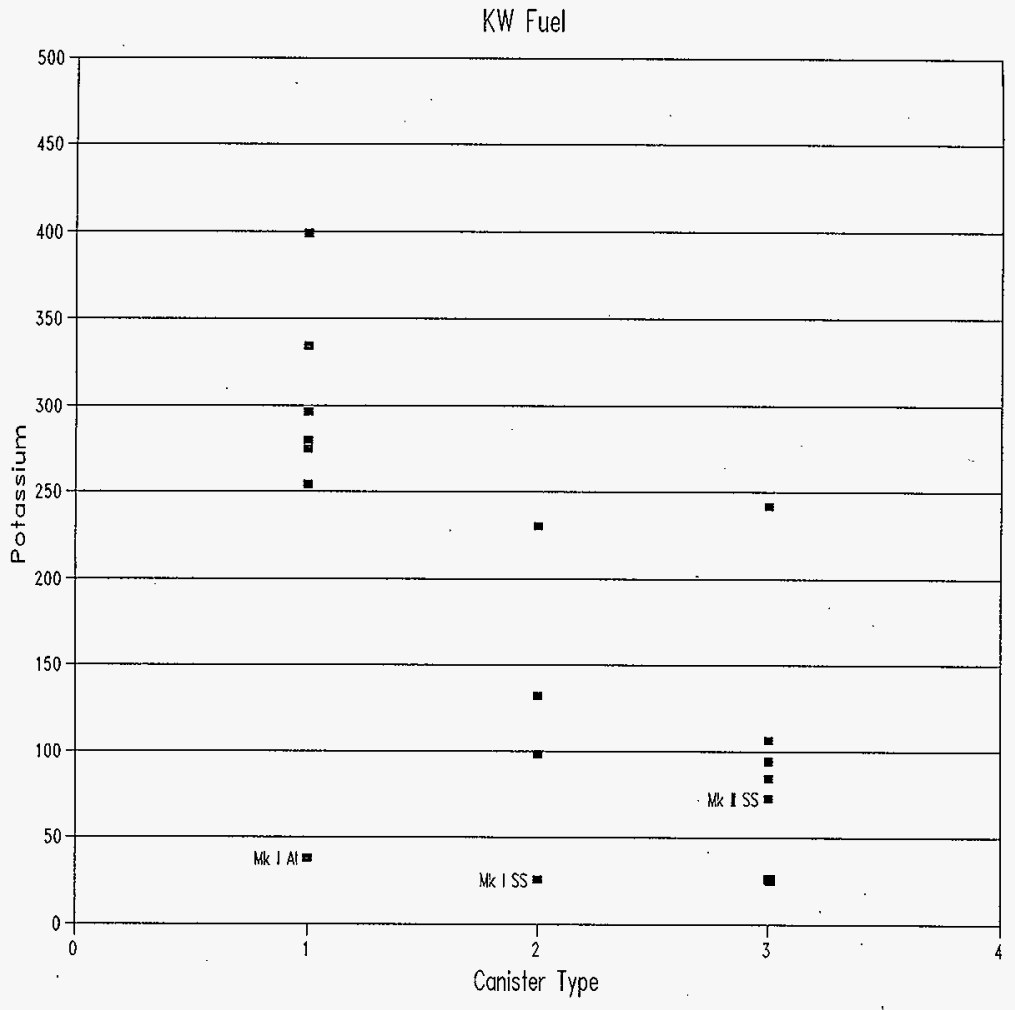


HNF-2314, Rev. 0

Figure 41. Canister Type Versus Coating Code.

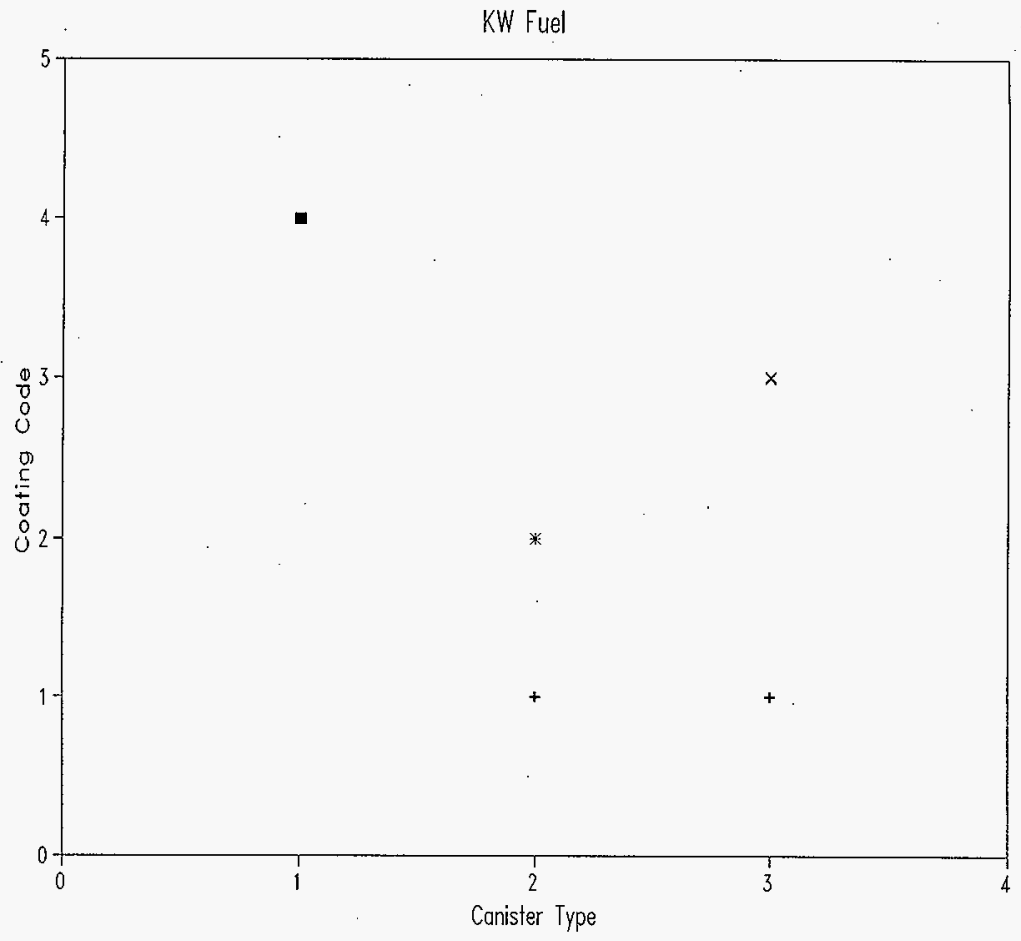

+ Med-Gray:1 * Ned-0ronge:2 X Light-Green:3 $\mathbf{0}$ Heovy-While:4 
HNF-2314, Rev. 0

Figure 42. Fuel Type Versus Plutonium-240.

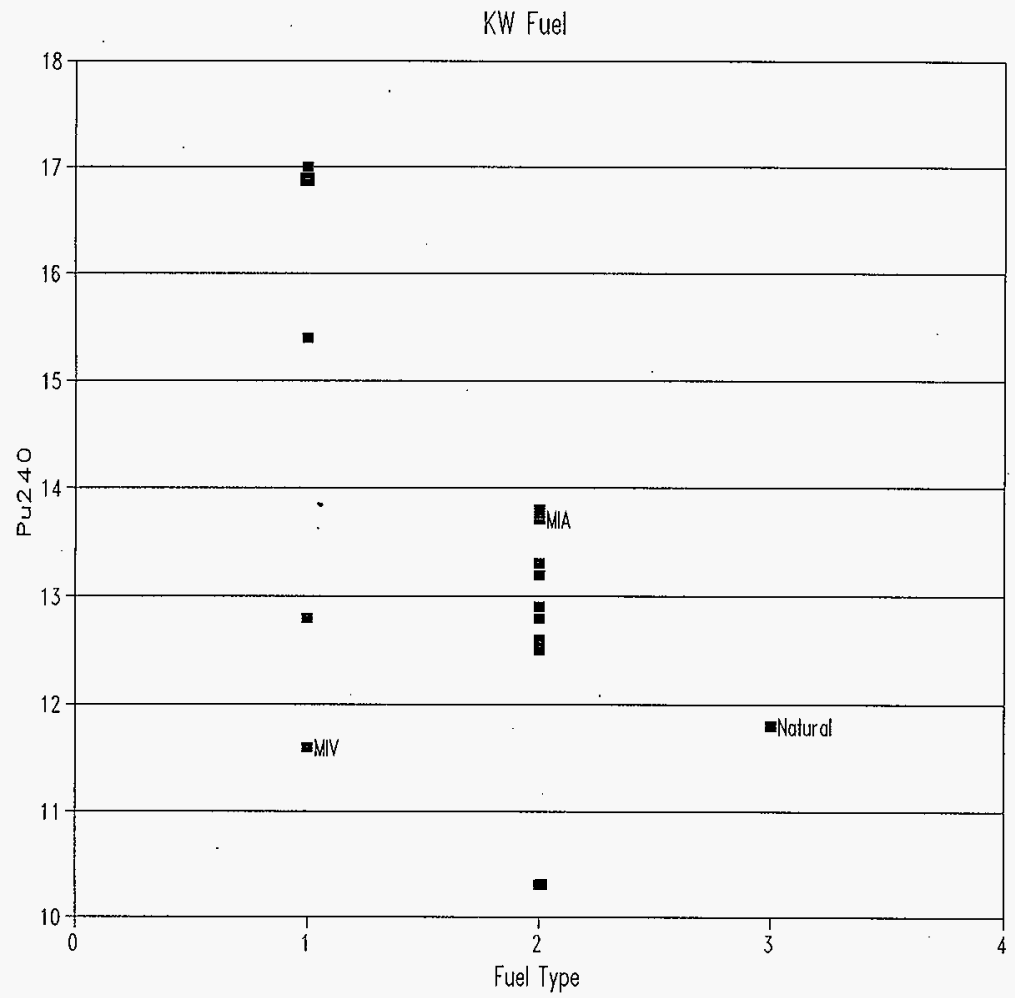


HNF-23I4, Rev. 0

Figure 43. Fuei Type Versus Cesium-137.

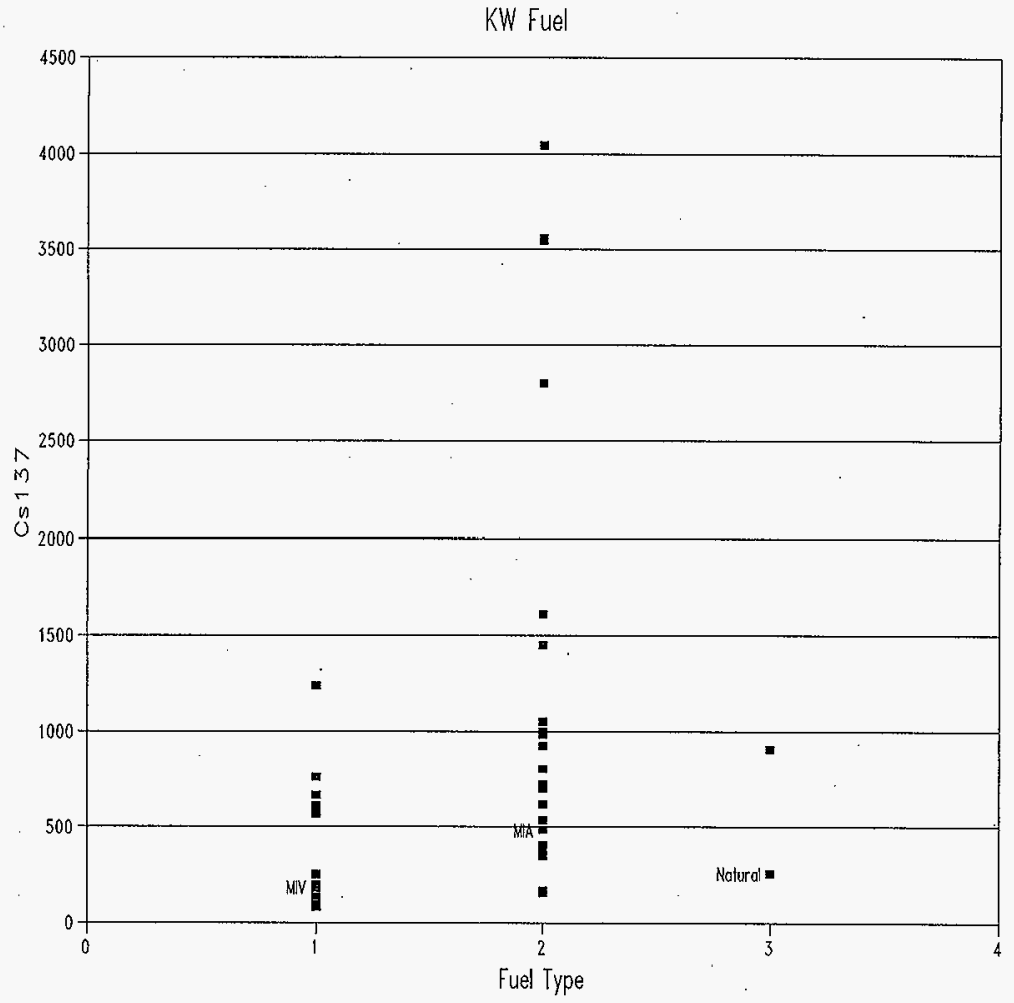


HNF-2314, Rev. 0

Figure 44. Key Date Versus Years Since Encapsulation.

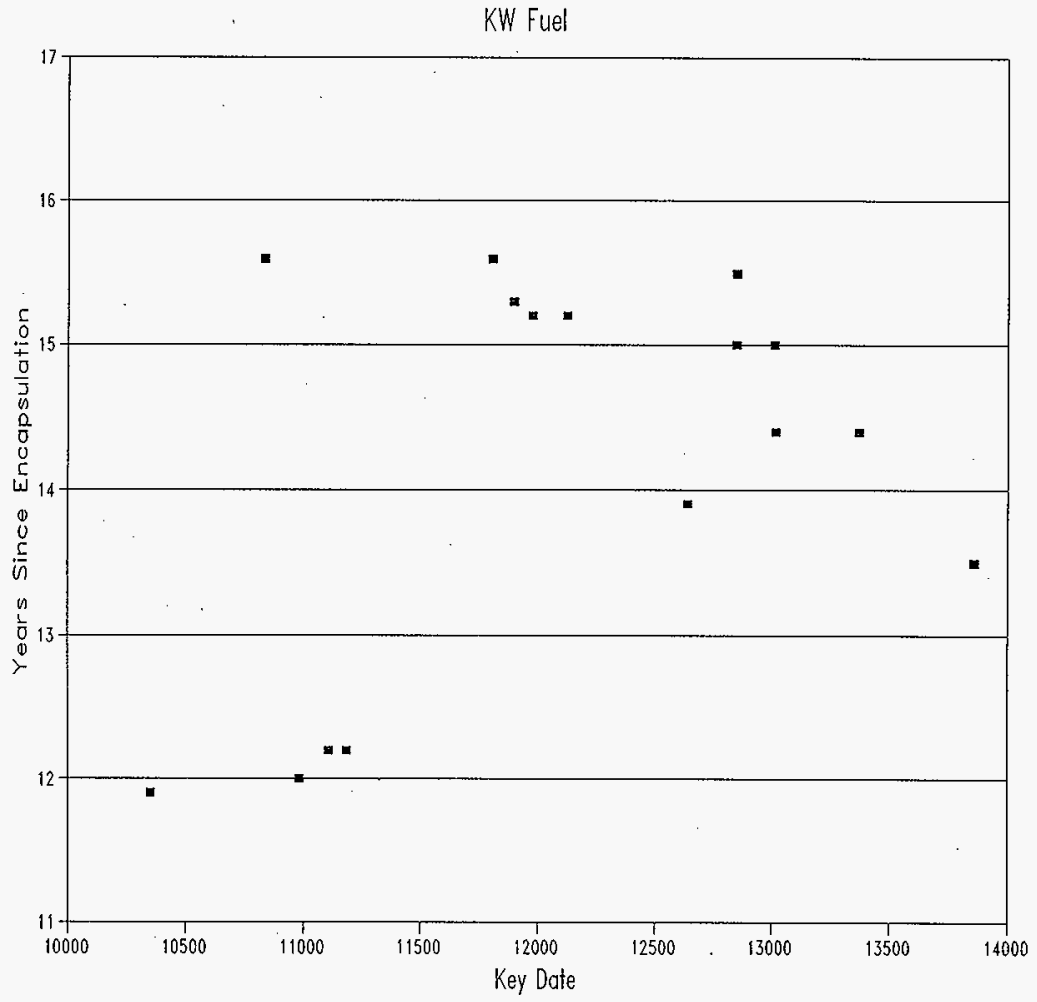


HNF-2314, Rev. 0

Figure 45. Key Date Versus Coating Code.

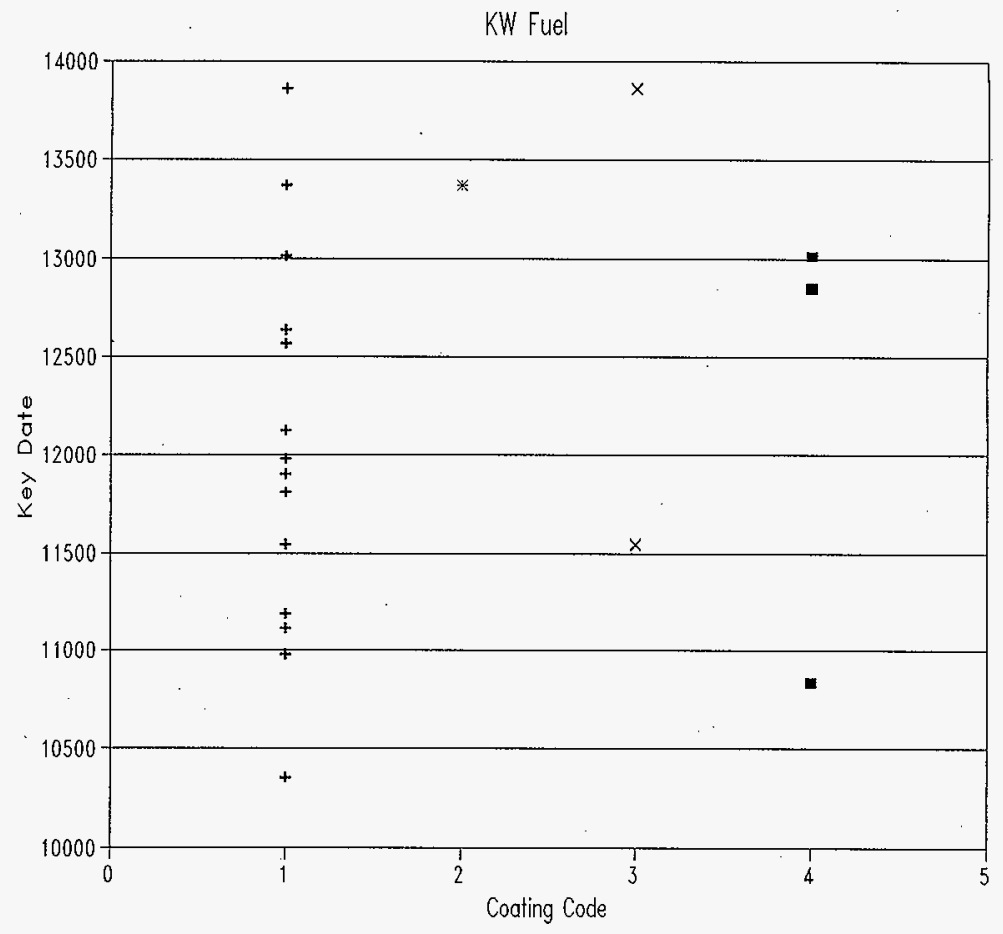

+ Med-Gray:1 $*$ Med-Orange:2 $\times$ Light-Green:3 
HNF-2314, Rev. 0

Figure 46. Key Date Versus Plutonium-240.

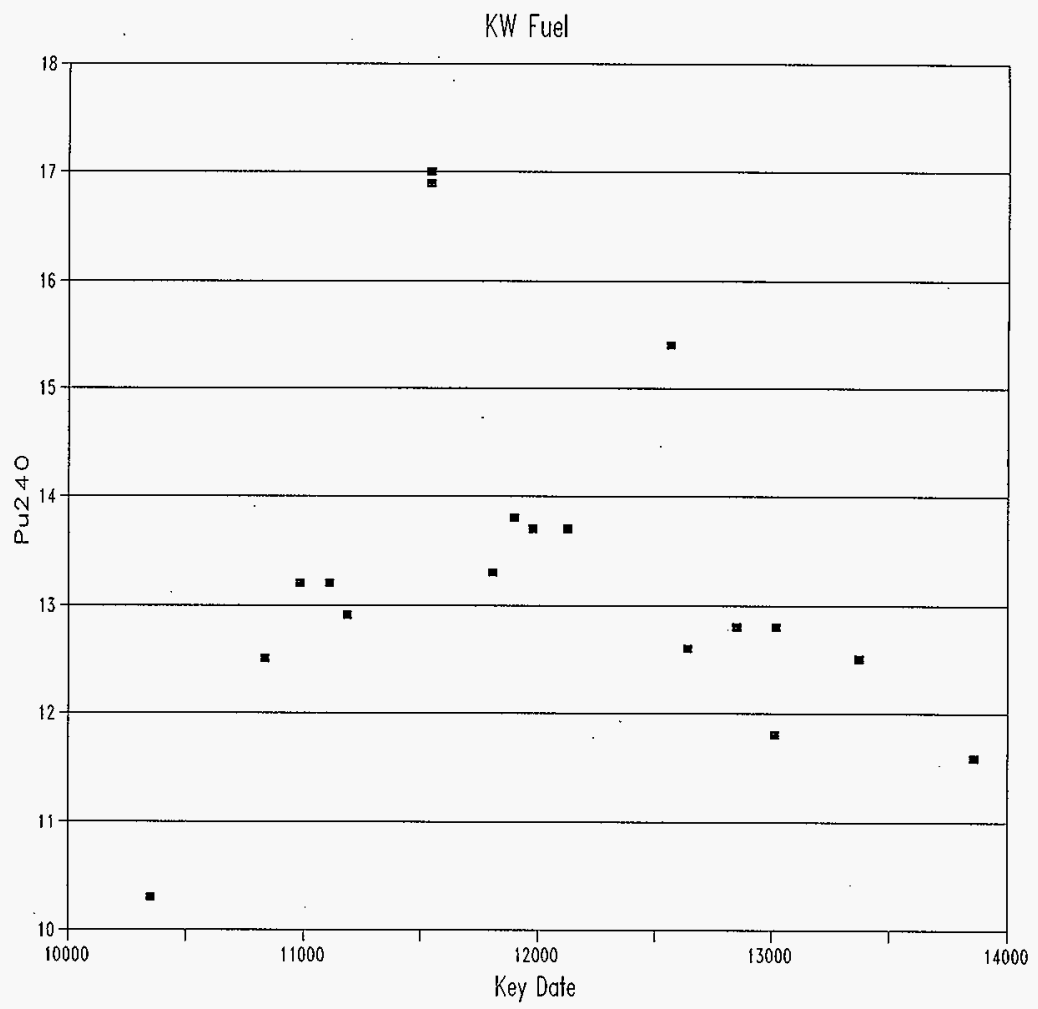


HNF-2314, Rev. 0

Figure 47. Years Since Encapsulation Versus P7utonium-240.

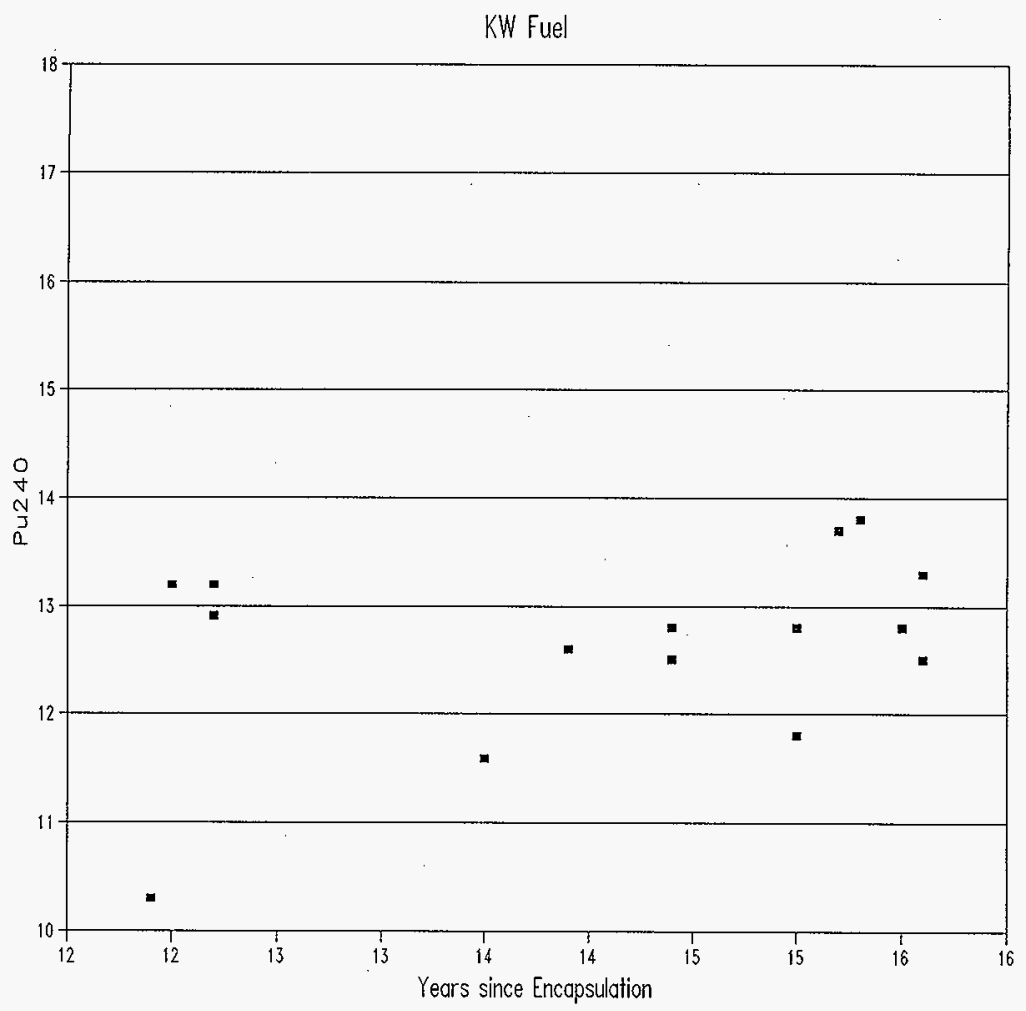


HNF-2314, Rev. 0

Figure 48. Years Since Encapsulation Versus Coating Code.

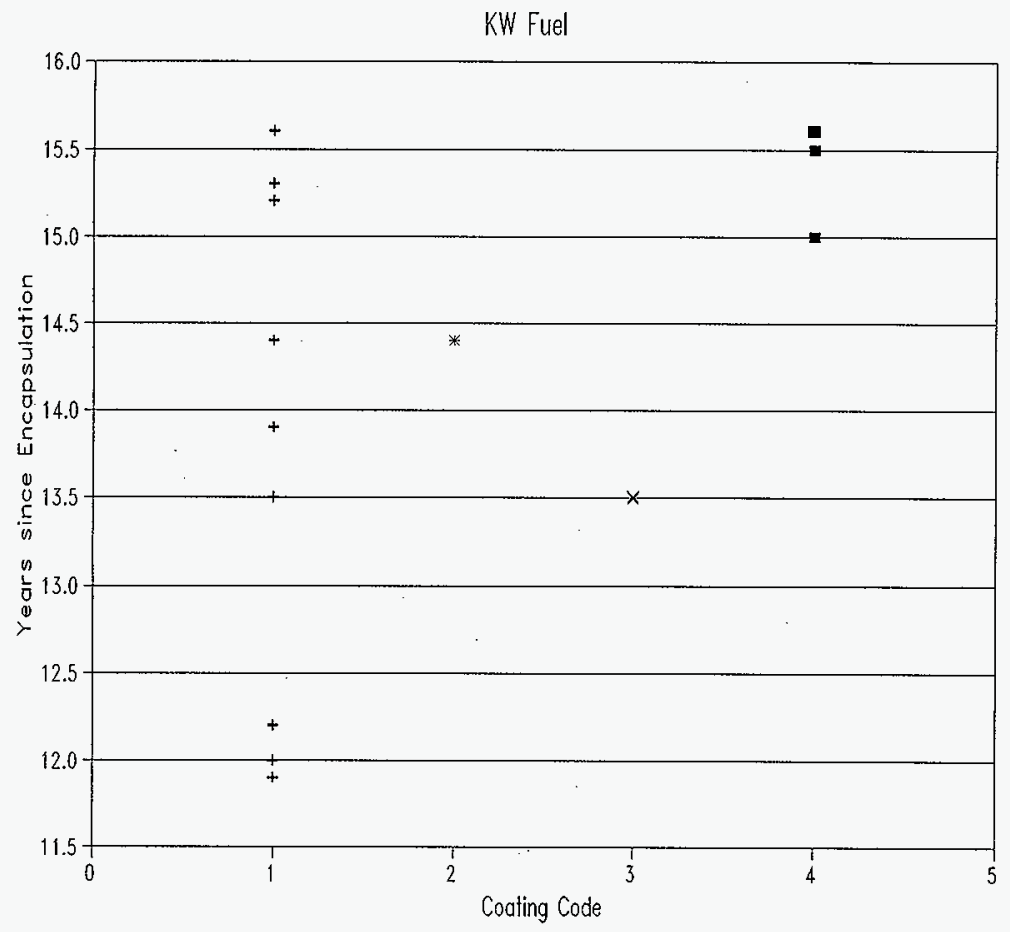

+ Med-Gray:1 * Med-Orange:2 $\times$ Light-Green:3 $\mathbf{E}$ Hvy-White:4 
HNF-2314, Rev. 0

Figure 49. Years Since Encapsulation Versus Potassium.

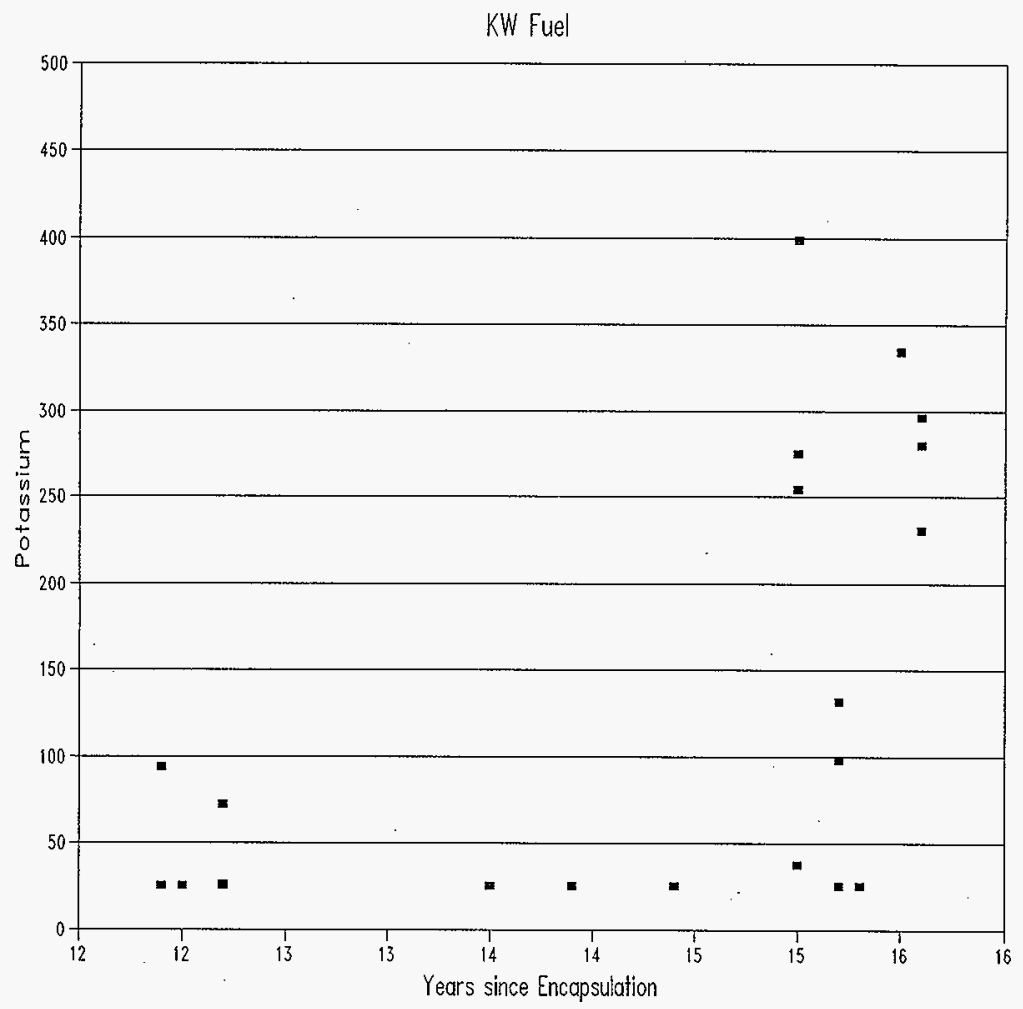


HNF-2314, Rev. 0

Figure 50. Plutonium-240 Versus Gas Trap.

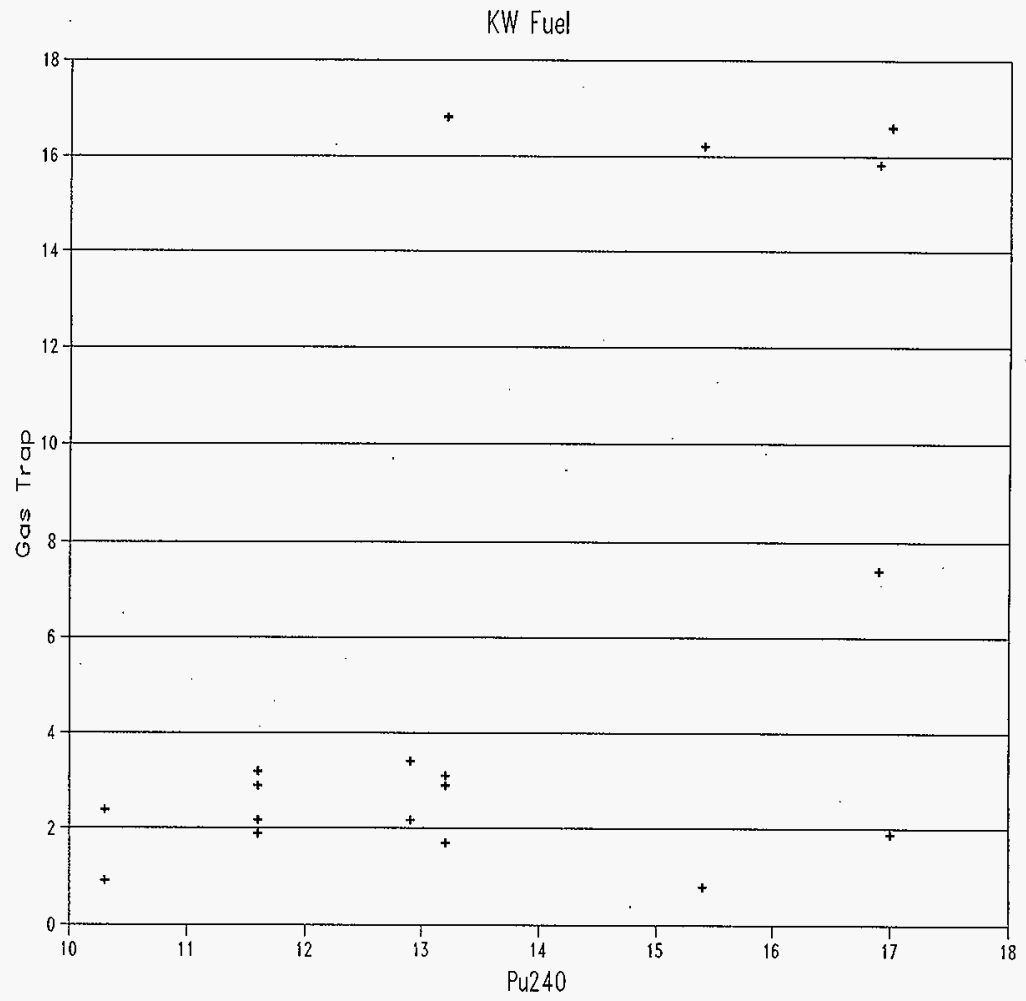


HNF-2314, Rev. 0

Figure 51. Plutonium-240 Versus Coating Code.

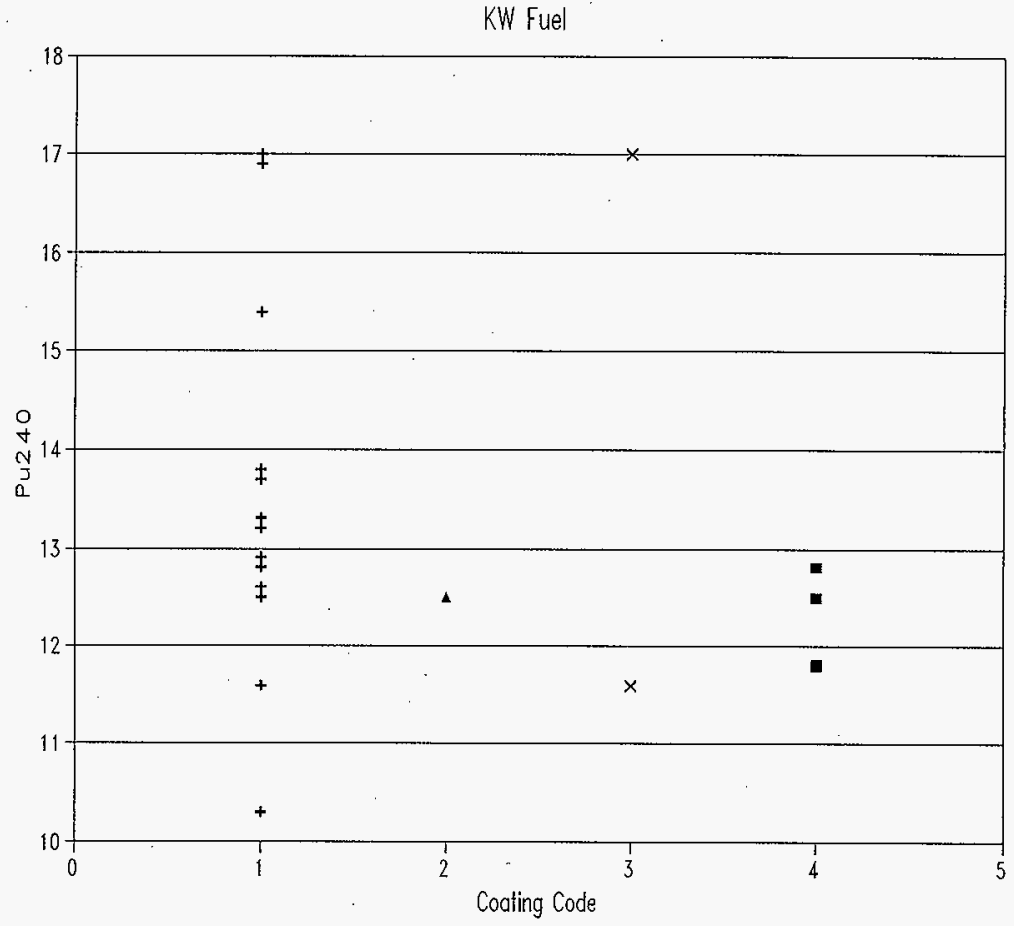

+ Med-Gray/White:1 $\Delta$ Med-Oronge:2 $\times$ Light-Green:3 a Hvy-White:4 
HNF-2314, Rev. 0

Figure 52. PTutonium-240 Versus Sludge Code.

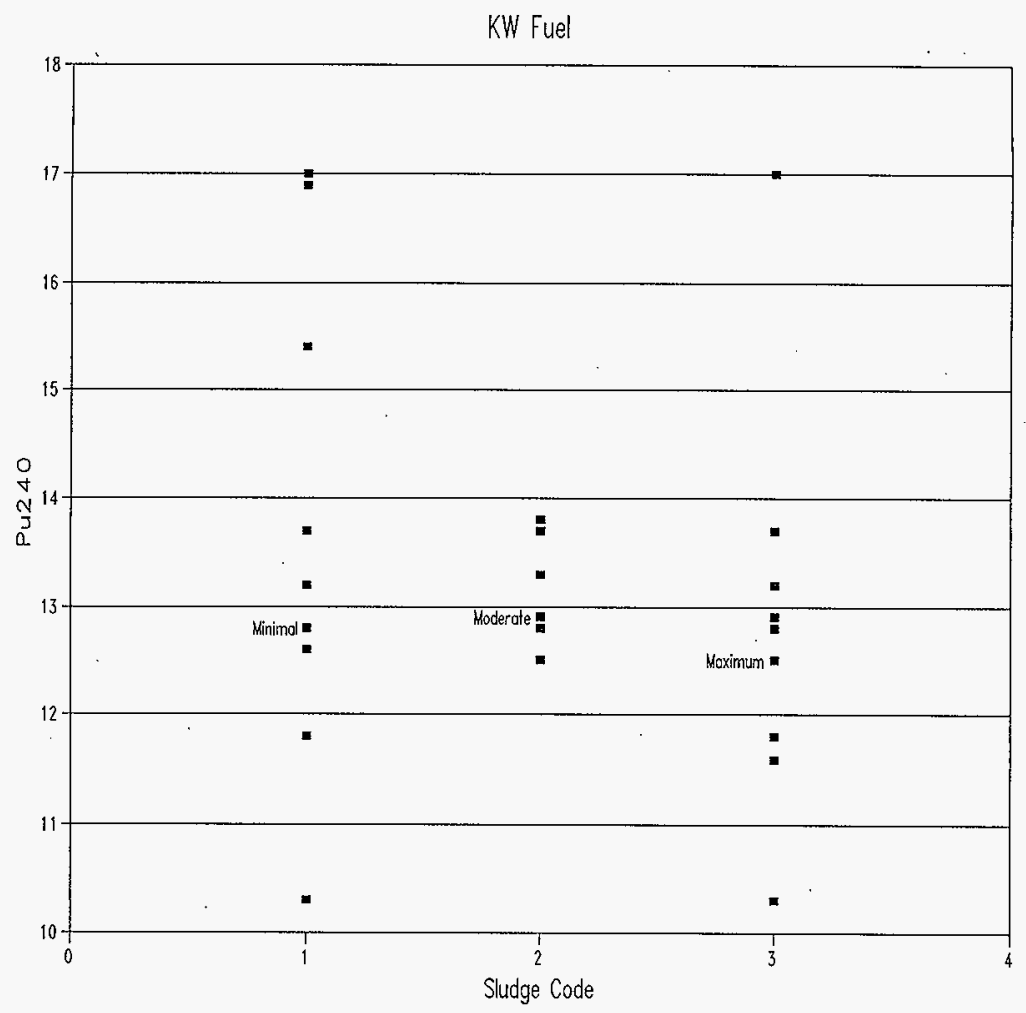


HNF-2314, Rev. 0

Figure 53. Gas Trap Versus Potassium.

KW Fuel

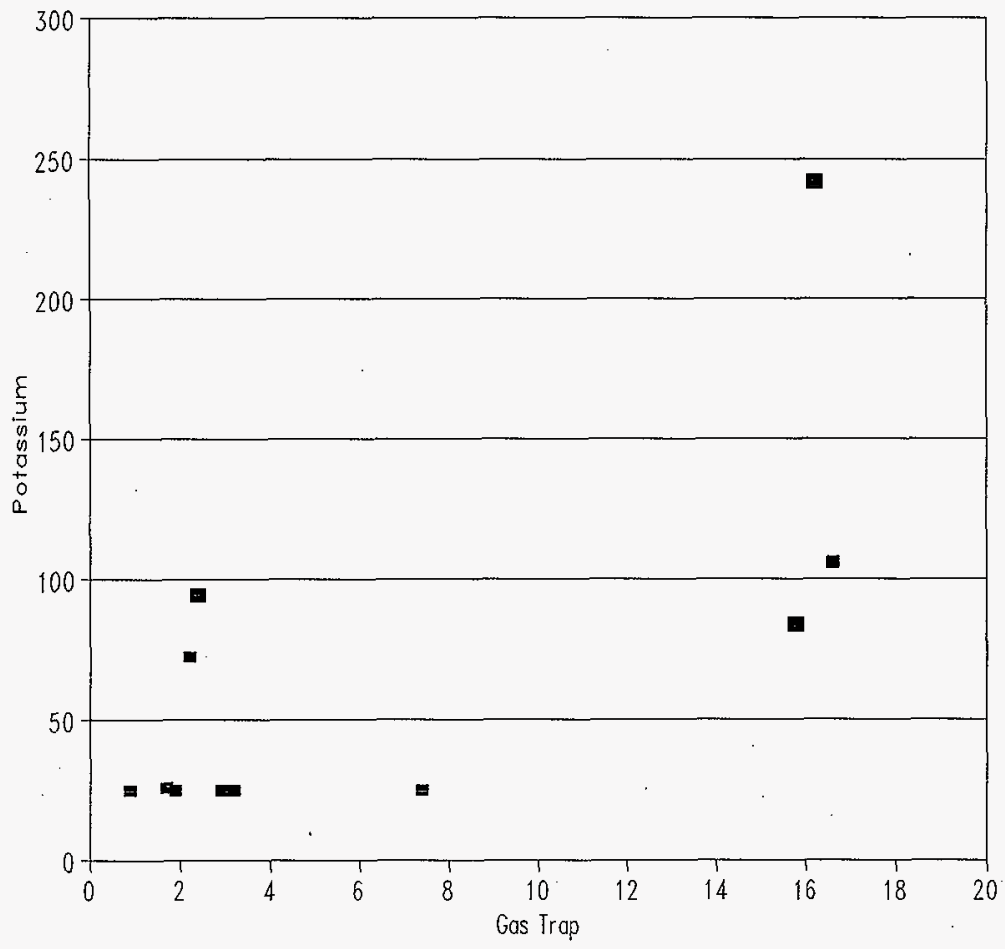


HNF-2314, Rev. 0

Figure 54. Cesium-137 Versus Sludge Code.

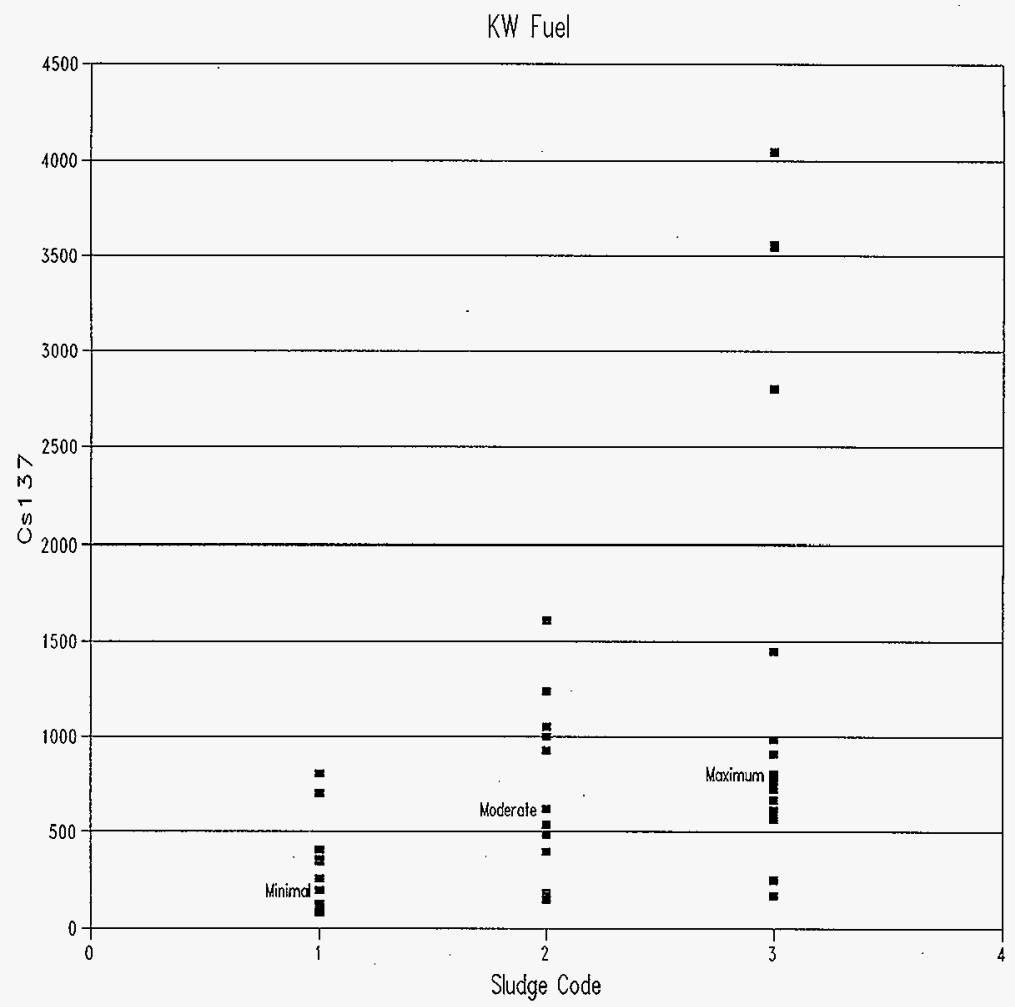


HNF-2314, Rev. 0

Figure 55. Potassium Versus Coating Code.

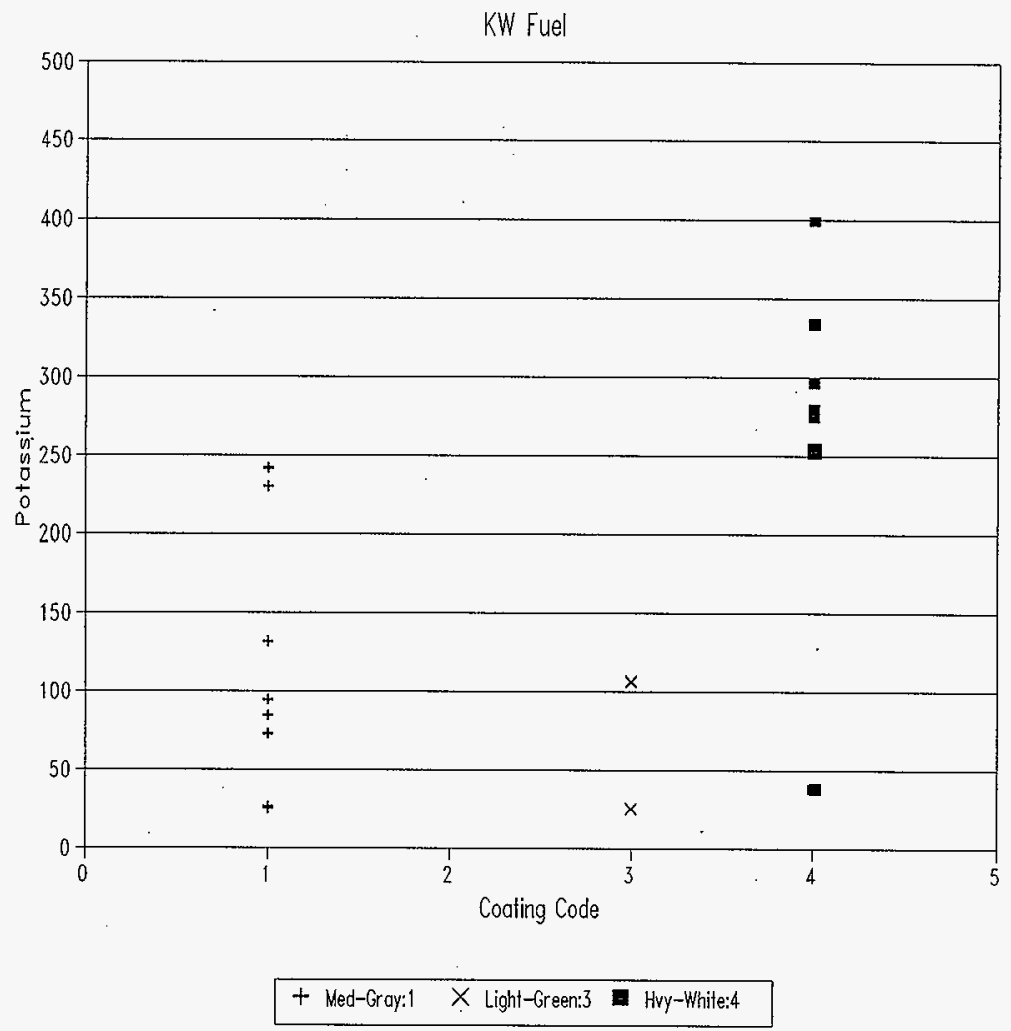




\begin{tabular}{|c|c|c|c|c|c|c|}
\hline \multicolumn{7}{|c|}{ DISTRIBUTION SHEET } \\
\hline \multirow{2}{*}{$\begin{array}{l}\text { To } \\
\text { Distribution }\end{array}$} & \multirow{2}{*}{\multicolumn{4}{|c|}{$\begin{array}{l}\text { From } \\
\text { SNF Characterization Project }\end{array}$}} & \multicolumn{2}{|c|}{ Page 1 of 2} \\
\hline & & & & & \multicolumn{2}{|c|}{ Date $02 / 27 / 98$} \\
\hline \multirow{2}{*}{\multicolumn{5}{|c|}{$\begin{array}{l}\text { Project Title/Work Order } \\
\text { Spent Nuclear Fuel Project }\end{array}$}} & \multirow{2}{*}{\multicolumn{2}{|c|}{$\begin{array}{l}\text { EDT No. } 620801 \\
\text { ECN No. }\end{array}$}} \\
\hline & & & & & & \\
\hline Name & & MSIN & $\begin{array}{l}\text { Text } \\
\text { With All } \\
\text { Attach. }\end{array}$ & Text Only & $\begin{array}{l}\text { Attach./ } \\
\text { Appendix } \\
\text { Only }\end{array}$ & $\begin{array}{l}\text { EDT/ECN } \\
\text { Only }\end{array}$ \\
\hline $\begin{array}{l}\text { Fluor Daniel Hanford, Inc. } \\
\text { E. W. Gerber } \\
\text { N. H. Williams }\end{array}$ & & $\begin{array}{l}\mathrm{R} 3-11 \\
\mathrm{R} 3-11\end{array}$ & $\begin{array}{l}X \\
X\end{array}$ & & & \\
\hline $\begin{array}{l}\text { Eluor Daniel Northwest } \\
\text { R. D. Crowe } \\
\text { L. J. Garvin }\end{array}$ & & $\begin{array}{l}\mathrm{R} 3-26 \\
\mathrm{R} 3-26\end{array}$ & $\hat{x}$ & & & \\
\hline $\begin{array}{l}\text { B \& W Protec. Inc. } \\
\text { D. D. Scott } \\
\text { T. L. Welsh (5) }\end{array}$ & & $\begin{array}{l}T 4-40 \\
T 4-40\end{array}$ & $\hat{x}$ & & & \\
\hline $\begin{array}{l}\text { ICF Kaiser Hanford Company } \\
\text { G. Baston } \\
\text { R. P. Denise }\end{array}$ & & $\begin{array}{l}\mathrm{R} 3-82 \\
\mathrm{R} 3-82\end{array}$ & $\begin{array}{l}X \\
X\end{array}$ & & & \\
\hline $\begin{array}{l}\text { Numatec Hanford Corporation } \\
\text { T. A. Flament } \\
\text { J. J. Irwin } \\
\text { C. R. Miska } \\
\text { J. P. Sloughter }\end{array}$ & & $\begin{array}{l}\text { R3-86 } \\
\text { R3-86 } \\
\text { R3-86 } \\
\text { H5-49 }\end{array}$ & $\begin{array}{l}x \\
X \\
x \\
X\end{array}$ & & & \\
\hline $\begin{array}{l}\text { Pacific Northwest National L } \\
\text { J. Abrefah } \\
\text { A. B. Johnson } \\
\text { S. C. Marschman }\end{array}$ & tory & $\begin{array}{l}\mathrm{P} 7-27 \\
\mathrm{~K} 8-34 \\
\mathrm{P} 7-27\end{array}$ & $\begin{array}{l}X \\
X \\
X\end{array}$ & & & \\
\hline$\frac{\text { SGN Eurisys Services Corp. }}{\text { A. L. Pajunen }}$ & & $\mathrm{R} 3-86$ & $X$ & & & \\
\hline$\frac{\text { XWest }}{\text { R. P. Dipiazza }}$ & & R3-15 & $X$ & & & \\
\hline $\begin{array}{l}\text { Duke Engineering \& Services } \\
\text { Hanford, Inc. } \\
\text { C. J. Alderman } \\
\text { R. B. Baker } \\
\text { D. W. Bergmann } \\
\text { K. H. Bergsman } \\
\text { L. D. Bruggeman } \\
\text { A. E. Bridges } \\
\text { S. A. Brisbin } \\
\text { S. A. Chastain }\end{array}$ & & $\begin{array}{l}X 3-85 \\
H 0-40 \\
X 3-79 \\
X 3-85 \\
H 0-40 \\
H 0-40 \\
\text { R3-86 } \\
H O-40\end{array}$ & $\begin{array}{l}x \\
X \\
X \\
X \\
X \\
X \\
X \\
X\end{array}$ & & & \\
\hline
\end{tabular}


DISTRIBUTION SHEET

\begin{tabular}{|c|c|c|c|c|c|}
\hline \multirow{2}{*}{$\begin{array}{l}\text { To } \\
\text { Distribution }\end{array}$} & \multirow{2}{*}{\multicolumn{3}{|c|}{$\begin{array}{l}\text { From } \\
\text { SNF Characterization Project }\end{array}$}} & \multicolumn{2}{|l|}{ Page 2 of 2} \\
\hline & & & & \multicolumn{2}{|c|}{ Date $02 / 27 / 98$} \\
\hline \multirow{2}{*}{\multicolumn{4}{|c|}{$\begin{array}{l}\text { Project Title } \text { Work Order } \\
\text { Spent Nuclear Fuel Project }\end{array}$}} & \multicolumn{2}{|c|}{ EDT No. 620801} \\
\hline & & & & \multicolumn{2}{|l|}{ ECN No. } \\
\hline Name & MSIN & $\begin{array}{l}\text { Text } \\
\text { With All } \\
\text { Attach. }\end{array}$ & Text Only & $\begin{array}{l}\text { Attach./ } \\
\text { Appendix } \\
\text { Only }\end{array}$ & $\begin{array}{l}\text { EDT/ECN } \\
\text { Only }\end{array}$ \\
\hline
\end{tabular}

Duke Engineering \& Services

Hanford. Inc. (Continued)

D. R. Duncan

J. R. Frederickson

W. M. Funderburke

R. G. Gant

L. H. Goldman

J. J. Jernberg

A. T. Kee

L. A. Lawrence

C. D. Lucas

B. J. Makenas

F. W. Moore

R. P. Omberg

M. J. Packer

A. L. Pitner (5)

A. N. Praga

K. L. Pearce

D. R. Precechte1

R. W. Rasmussen

A. M. Segrest

E. J. Shen

J. A. Swenson

J. H. Wicks

D. S. Takasumi

D. J. Trimble

D. J. Watson

R. M. Yanocho

R3-86

R3-86

R3-11

$\times 3-79$

R3-86

$\times 3-72$

R3-86

$40-40$

X3-56

HO- 40

R3-86

HO- 40

$\times 3-85$

$\mathrm{H} 0-40$

R3-86

$\mathrm{R} 3-47$

$\times 3-85$

R3-86

R3-11

$\times 3-75$

R3-11

R3-11

$\times 3-85$

HO- 40

$\times 3-79$

R3-86

R3-11

B] -07

$x$
$x$
$x$
$x$
$x$
$x$
$x$
$x$
$x$
$x$
$x$
$x$
$x$
$x$
$x$
$x$
$x$
$x$
$x$
$x$
$x$
$x$
$x$
$x$
$x$
$x$
$x$
$x$
$x$

Central Files

U.S. Department of Energy,

Richland Operations office

J. M. Escamil]io

S7-41

S7-41

S7-41

S7-41

S7-41

S7-41

S7-41

$x$
$X$
$x$
$X$
$X$
$X$
$X$

